\title{
INFRAESTRUTURA \\ NATURAL PARA \\ ÁGUA NA REGIÃO \\ METROPOLITANA \\ DA GRANDE VITÓRIA
}

GrupoBoticário $\quad$ FNACIÓ

1 Bio Uicn $\begin{array}{ll}\text { natural } \\ \text { capital } \\ \text { PRajECT }\end{array}$ Conservancy

RAFAEL FELTRAN-BARBIERI, SUZANNE OZMENT, MARCELO MATSUMOTO, ERIN GRAY, THIAGO BELOTE SILVA E MARIANA OLIVEIRA 


\section{SOBRE OS AUTORES}

Rafael Feltran-Barbieri é economista

sênior do WRI Brasil.

Contato: rafael.barbieri@wri.org

Suzanne Ozment é pesquisadora sênior em infraestrutura natural do WRI, baseada em Washington. - -

Contato: sozment@wri.org

Marcelo M. Matsumoto é coordenador de GIS do WRI Brasil.

Contato: marcelo.matsumoto@wri.org

Erin Gray é economista do WRI, baseada em Washington, DC.

Contato: egray@wri.org

Thiago Belote Silva é especialista em restauração do WWF Brasil.

Contato: thiagobelote@wwf.org.br

Mariana Oliveira é coordenadora de projetos no programa de florestas do WRI Brasil.

Contato: moliveira@wri.org

\section{AGRADECIMENTOS}

Este relatório é produto da parceria entre o World Resources Institute (WRI), o WRI Brasil, a Fundação FEMSA, The Nature Conservancy, a União Internacional para a Conservação da Natureza, o Instituto BioAtlântica, a Fundação Grupo Boticário para a Proteção da Natureza e o Projeto Natural Capital (que pôde participar através do projeto ClimateWise, doação NSF \#1624329). 0 trabalho foi possível graças ao generoso apoio financeiro e ao compartilhamento de conhecimento dos parceiros do projeto. Contamos também com 0 apoio da Latin American Water Funds Partnership pelo Department for International Development (DFID) e da iniciativa Cities4Forests.

Os revisores deste relatório, ou de parte de seu conteúdo, forneceram críticas e sugestões inestimáveis, fortalecendo substancialmente o estudo. Expressamos nossa sincera gratidão às pessoas que cederam seu tempo e conhecimento na revisão deste estudo: Adam Keough (Catholic Relief Services), Carlos Aurélio Linhalis (Cesan), Fábio Ahnert (AGERH - Agência Estadual de Recursos Hídricos), Jorge Leon (TNC), Marcos Sossai (Programa Reflorestar), Paul Hicks (Catholic Relief Services), Perrine Hamel (Projeto Capital Natural) e Stefano Pagiola (Banco Mundial). Gostaríamos também de agradecer especialmente aos nossos colegas e revisores internos Andrew Wu (WRI), Betsy 0tto (WRI), Chuck Kent, James Anderson (WRI), Juan Carlos Altamirano (WRI), Kevin Moss (WRI), Laura Malaguzzi Valeri (WRI), Maggie Gonzalez (WRI), Maria Franco Chuaire (WRI), Miguel Calmon, Rachel Biderman (Cl), Thiago Guimarães Rodrigues (WRI), Todd Gartner (WRI) e Viviane Romeiro.

Muitos especialistas e profissionais forneceram orientações e contribuições sobre 0 conteúdo deste relatório em seus estágios iniciais (veja o Apêndice A para essa lista). Apreciamos muito sua disposição de compartilhar conhecimentos e experiências.

Também agradecemos a Bruno Calixto, Fernanda Boscaini, Joana Oliveira, Suzanna Lund e Vitor Tornello, do WRI Brasil, bem como a Romain Warnault, do WRI, e aos revisores André Caramori e Anaelena Lima. 


\section{ÍNDICE}

3 Prefácio

5 Sumário executivo

13 Contextualização

25 Avaliação das Infraestruturas Natural e Convencional (Verde e Cinza) para controle de sedimentos

39 Análise de sensibilidade

47 Conclusões

52 Apêndice A. Método de consulta às partes interessadas e desenvolvimento das premissas e portfólios de investimento

54 Apêndice B. Métodos e premissas para modelos biofísicos e componentes do mapeamento

59 Apêndice C. Métodos e premissas da análise financeira

64 Referências 


\section{PREFÁCIO}

Crises hídricas são deflagradas em condições

climáticas atípicas. Mas suas causas são estruturais.

É reconhecido no Brasil que a infraestrutura

de saneamento e abastecimento é incipiente e

falha: $16 \%$ dos brasileiros não são atendidos por serviços de água e $46 \%$ não têm coleta de esgoto. O país investe anualmente menos da metade do planejado e empurra a universalização para além de 2050. A demanda por água nos próximos 25 anos deve crescer entre $18 \%$ e $25 \%$, enquanto o consumo de energia elétrica deve triplicar até 2050, aumentando o desafio do gerenciamento hídrico.

As mudanças climáticas em curso têm transformado condições atípicas em cotidianas, estabelecendo um novo patamar de risco hídrico sistêmico. Não se trata de investir cinco vezes mais em infraestrutura para simplesmente cobrir os déficits passados. É urgente reconhecer que infraestruturas convencionais, como reservatórios e estações de tratamento de água, são relevantes para gerenciamento da água disponibilizada pelos mananciais, mas não alteram a capacidade de produção dos mesmos. Para isso, a conservação e restauração das florestas e ecossistemas nativos, como infraestruturas naturais, prestam serviços essenciais e complementares à estrutura construída pela engenharia civil.

Como soluções baseadas na natureza, a infraestrutura natural reabilita os mananciais a fornecerem água com maior regularidade e melhor qualidade. Quanto mais nascentes protegidas, quanto mais matas ciliares ao longo dos rios, mais encostas e topos de morro cobertos por vegetação de porte florestal e de uso sustentável, quanto mais conservados os fundos de vale e várzeas, mais água haverá para encher reservatórios, irrigar plantações e abastecer indústrias.
O estado do Espírito Santo tem uma vulnerabilidade hídrica naturalmente alta e tem sofrido com escassez de água desde a crise de 2014. No momento de publicação deste relatório, a pauta nacional, e também do Espírito Santo, é a nova crise hídrica que assola o Sudeste em 2021 e se abate sobretudo na produção de energia, tão cara para a recuperação econômica em tempos de epidemia de Covid-19.

Felizmente, através do Programa Reflorestar e outras iniciativas locais, o Espírito Santo vem despontando como liderança nacional no reconhecimento da relevância da infraestrutura natural, inclusive como parte da solução do gerenciamento hídrico. Mas esse é apenas o primeiro passo de uma longa caminhada que precisa ser feita rumo à segurança hídrica. Este relatório pretende ajudar a dar os próximos passos.

\section{Marcos F. Sossai}

Gerente do Programa

Reflorestar/Seama-ES

\section{Suzanna Lund}

Gerente Sênior de

Projetos do Programa de

Florestas do WRI Brasil 


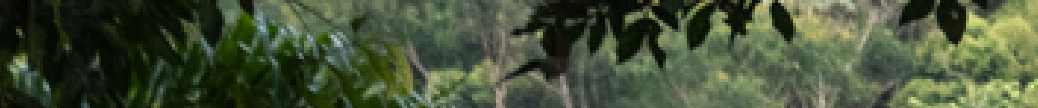

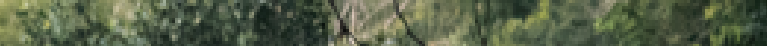

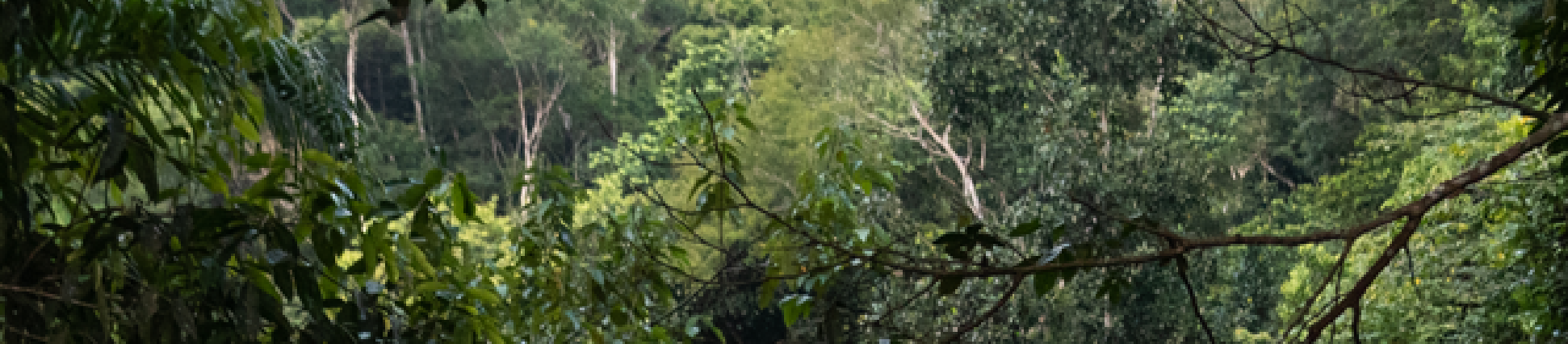

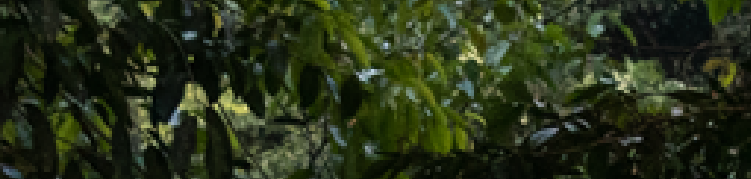

$y=250$ is

$30 \% 1$.

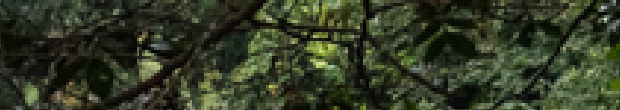

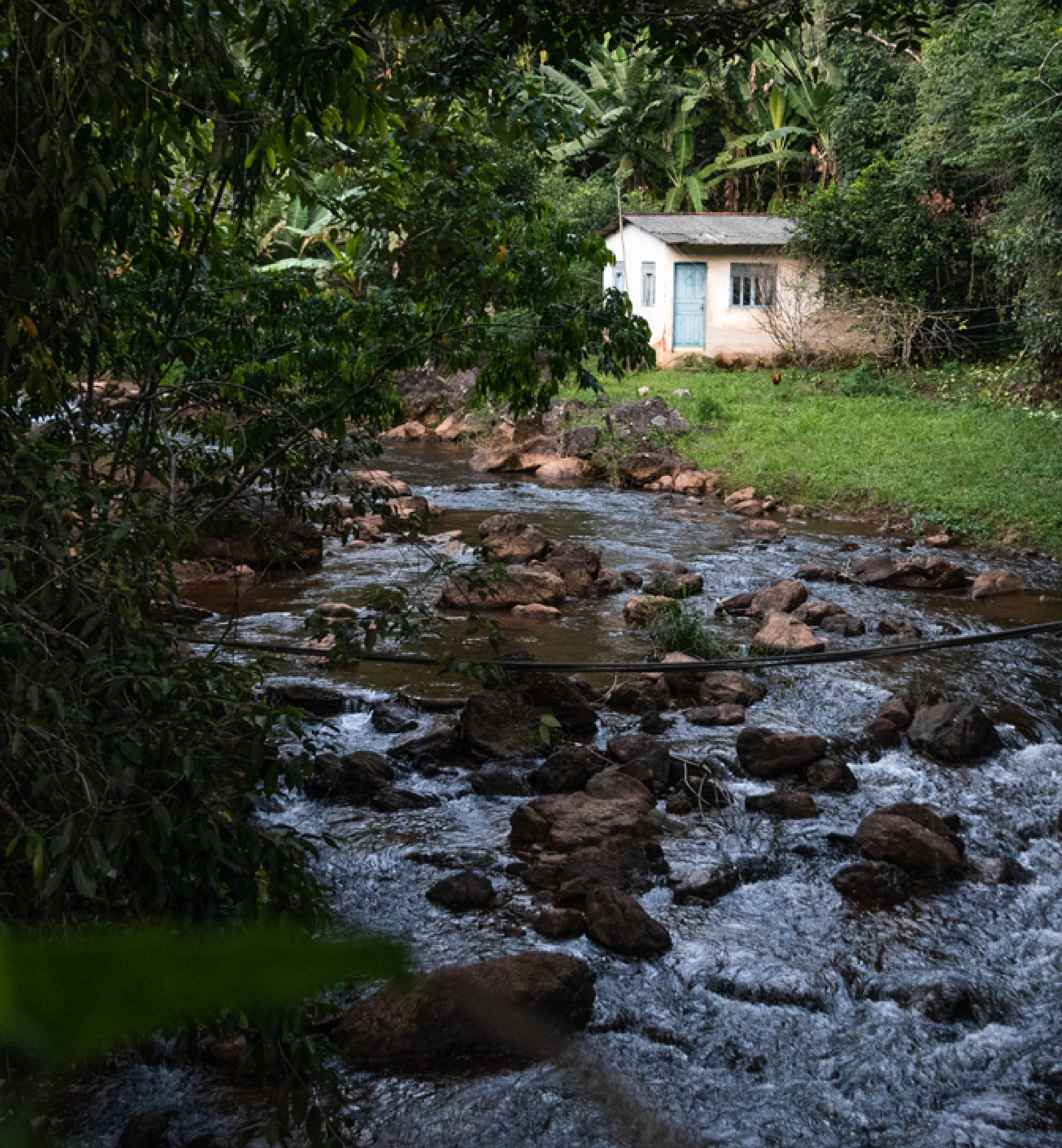




\section{SUMÁRIO EXECUTIVO}

Infraestrutura natural - florestas e outras formas de vegetação

nativa - constitui uma das mais importantes estratégias de soluções baseadas na natureza aplicadas à gestão de recursos hídricos. Este relatório demonstra como a restauração florestal de áreas criticamente degradadas nas Bacias do Jucu e do Santa Maria da Vitória poderia melhorar o desempenho operacional da reservação e tratamento de água que abastece a Região Metropolitana da Grande Vitória. Indica áreas com melhor relação de custo-efetividade para implantação da infraestrutura natural, corrobora a viabilidade econômica do investimento e faz recomendações de como fortalecer os programas e iniciativas de restauração florestal em curso no estado do Espírito Santo. 


\section{para segurança hídrica}

- Nas bacias dos rios Jucu e Santa Maria da Vitória - que formam a Unidade de Gerenciamento dos Recursos Hídricos do Litoral Central (UGRH Litoral Central) - , a combinação das infraestruturas natural e convencional poderia duplicar os benefícios oriundos do tratamento de água, se comparados com aqueles obtidos em infraestrutura convencional isoladamente.

- A Avaliação de Investimentos em Infraestrutura Natural (GGA/WRI) concluiu que a restauração florestal em 2.500 hectares de pastagens degradadas na UGRH Litoral Central poderia gerar, ao longo de 20 anos, benefícios de $\mathrm{R} \$ 92,9$ milhões em termos de custos evitados no tratamento de água, requerendo investimentos de $\mathrm{R} \$ 34,1$ milhões. 0 projeto apresentaria um valor presente líquido (VPL) de $\mathrm{R} \$ 11,1$ milhões, taxa interna de retorno (TIR) de 13,9\% e tempo de retorno de 11,6 anos.

- 0 Programa Reflorestar já investe em restauração florestal no Espírito Santo. Ainda assim, é possível potencializar o impacto positivo da infraestrutura natural no gerenciamento da qualidade da água a partir do engajamento de empresas de saneamento, como a Companhia Espírito-Santense de Saneamento (Cesan). Essas empresas, as maiores beneficiadas com a economia no tratamento de água, são instituiçõeschave na promoção de parcerias e investimentos para fortalecimento dos programas de restauração.

- Tomadores de decisão locais consideram fundamentais as análises aqui propostas, apontando para a necessidade de seguir com ações pragmáticas, incluindo melhorar o monitoramento de bacias hidrográficas, engajar proprietários rurais e atrair fontes contínuas e robustas de financiamento.
Desde 2014, a Região Metropolitana da Grande Vitória (RMGV) sofre com longos períodos de seca interrompidos por chuvas torrenciais. Isso representa um enorme desafio para a gestão da água (Inmet, 2021). Em resposta a esses desafios, a UGRH Litoral Central, responsável pelas Bacias do Jucu e do Santa Maria da Vitória (SMV), tem proposto um conjunto de planos e ações para promover a segurança hídrica da região (AGERH e Seama, 2018). Isso cria uma oportunidade para se repensar o papel que a natureza desempenha no sistema de abastecimento de água.

\section{Atualmente a água que abastece a RMGV provém das Bacias do Jucu, do SMV e do Reis Magos. Jucu e SMV respondem,} respectivamente, pelo suprimento de $59 \%$ e $38 \%$ do abastecimento da RMGV. O planejamento integrado dessas bacias tem sido fundamental para as estratégias de segurança hídrica e inclui importantes investimentos em infraestrutura convencional (infraestrutura cinza) - a principal delas a construção do reservatório dos Imigrantes, na Bacia do Jucu (AGERH e Seama, 2018).

\section{Florestas saudáveis podem ajudar a} manter os sistemas de abastecimento de água, controlando a erosão e a turbidez. Os reservatórios são importantes para armazenar água e reter sedimentos, enquanto as florestas, por sua vez, reduzem os sedimentos exportados para reservatórios e sistemas de captação, reduzindo assim os custos de tratamento de água, dragagem e depreciação e desgaste de equipamentos (Ozment et al., 2018). Essas economias nos custos do saneamento se revertem principalmente para a Cesan, responsável pelo abastecimento da RMGV.

O Espírito Santo já tem uma rica experiência de restauração florestal através de seu Programa Reflorestar, uma iniciativa estadual de conservação e restauração que ajuda a recuperação dos recursos hídricos e apoia os proprietários rurais a cumprir a legislação ambiental. $O$ Reflorestar reconhece os benefícios das florestas nativas para os sistemas hidrológicos e oferece pagamentos por serviços ambientais (Seama, 2020). O programa 
é o principal executor da restauração florestal de outros programas estratégicos liderados pelo estado do Espírito Santo, como o Programa de Gestão Integrada das Águas da Paisagem e o projeto Florestas para a Vida (Governo ES, Banco Mundial, Cesan, 2013).

\section{Para aproveitar os benefícios gerados pela} restauração florestal na gestão dos recursos hídricos, o Programa Reflorestar e a gestão da UGRH Litoral Central precisam saber onde a restauração florestal deve ser priorizada, a fim de otimizar a melhoria da qualidade da água. Para atender essa necessidade, este estudo aponta áreas prioritárias para restauração, assim como analisa de que maneira as estratégias de restauração do Programa Reflorestar poderiam beneficiar financeiramente as empresas de saneamento, especialmente a Cesan, através da redução dos custos de tratamento de água. A combinação de restauração florestal com a construção do novo reservatório poderia prover uma economia $50 \%$ maior no tratamento de água em comparação com os benefícios obtidos apenas com a instalação do reservatório.

\section{Avaliação do papel da Infraestrutura} Natural no abastecimento de água

O presente estudo consiste em uma análise financeira utilizando o método de Avaliação de Investimento em Infraestrutura Natural (Green-Gray Assessment - GGA/WRI), composta por seis etapas que ajudam a incorporar a infraestrutura natural restauração florestal - nas decisões de investimento em saneamento. Neste caso, utilizou-se a GGA/WRI para estimar custos e benefícios que seriam agregados ao sistema de saneamento a partir da implementação de estratégias de restauração de florestas nativas em áreas atualmente ocupadas por pastagens degradadas, em comparação com um cenário em que apenas a infraestrutura cinza é utilizada.

\section{O tipo e a localização ideais para} investimentos em infraestrutura natural dependem de quais benefícios são buscados. Para maximizar o controle de erosão do solo e turbidez da água foram identificadas áreas

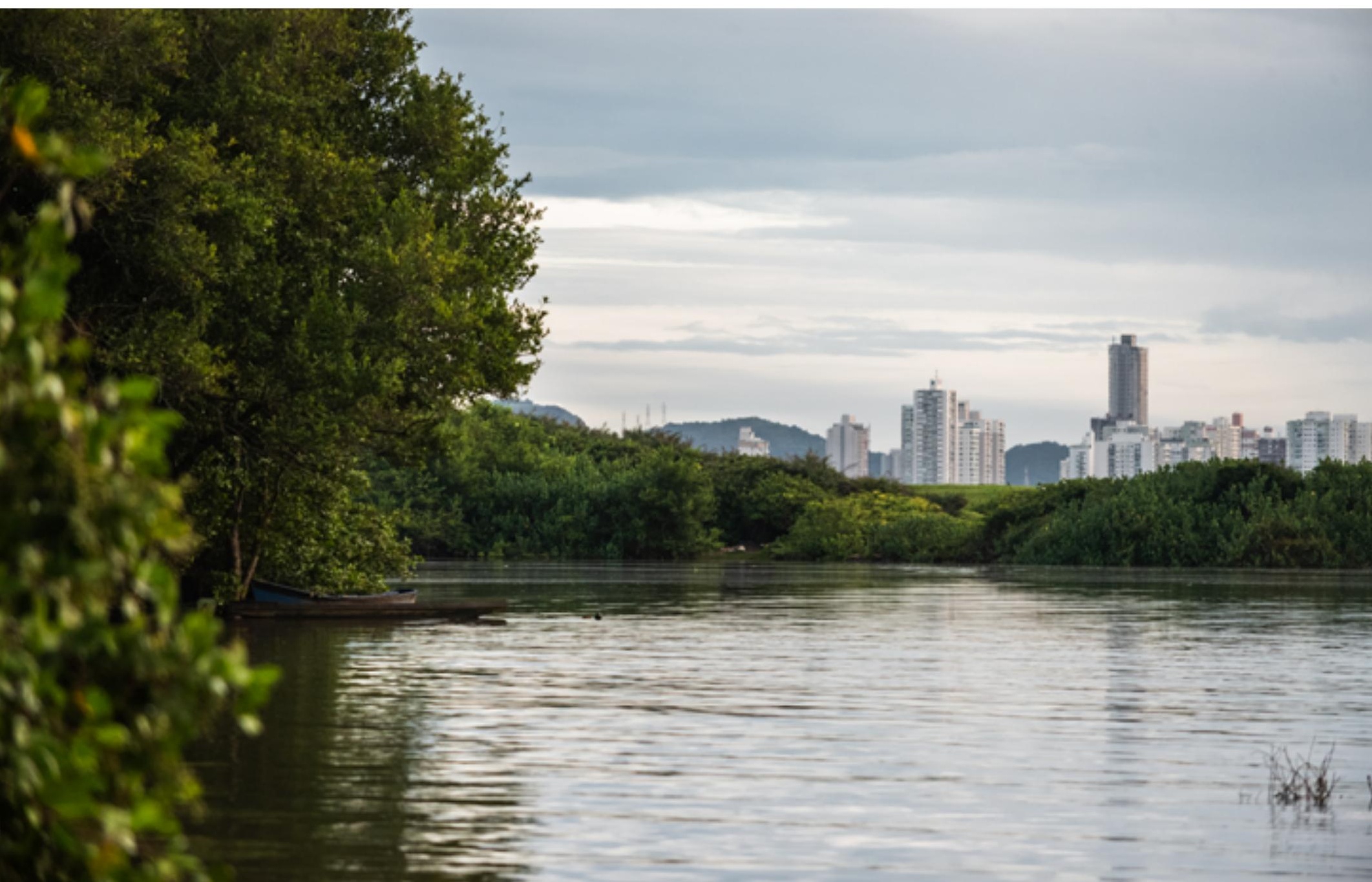


prioritárias, utilizando a ferramenta InVEST, focando na restauração florestal de pastagens altamente degradadas. Outros tipos de intervenção, como a conservação florestal, os sistemas agroflorestais, silvipastoris ou o próprio manejo de áreas naturais podem também contribuir no controle da erosão. Tais sistemas podem trazer muitos outros benefícios para as comunidades, como produção de alimentos, sequestro de carbono, mitigação de riscos de desastres, recreação etc., mas não foram analisados neste documento.

\section{Este relatório se baseia em estimativas,} sendo uma análise de ordens de grandeza.

Idealmente, uma análise da performance financeira da infraestrutura natural consideraria dados biofísicos e financeiros primários. Não foi possível obter dados primários de custos de tratamento de água, tendo sido estimados em entrevistas com funcionários da Cesan, além de especialistas locais e literatura publicada. Embora os resultados representem uma magnitude realista, são aproximações que podem ser aprimoradas na presença de dados primários.

\section{A Infraestrutura Natural protege a Infraestrutura Convencional}

\section{A restauração florestal em áreas estratégicas reduziria significativamente os custos de tratamento de água. A restauração florestal de} 2.500 hectares ocupados por pastagens degradadas (cenário LC2500), dos quais 1.600 hectares na Bacia do Jucu e 900 hectares na Bacia do SMV, demandaria um investimento de $\mathrm{R} \$ 34,1$ milhões, gerando economia no tratamento de água da ordem de $\mathrm{R} \$$ 92,9 milhões. Tal investimento reduziria a turbidez média em $9 \%$, gerando benefícios líquidos de R $\$ 58,8$ milhões ao longo de 20 anos, com VPL de $\mathrm{R} \$ 11,1$ milhões sob taxa de desconto de $8,5 \%$ ao ano (Tabela 1).

Tabela 1 | Desempenho Econômico da Infraestrutura Natural, horizonte de 20 anos

\begin{tabular}{l|c|c|c}
\hline BENEFíCIOS LíquIDOS & \multicolumn{1}{l}{} \\
\hline & LC2500 & JUCU1600 & SMV900 \\
\hline TOTAL & $\mathbf{5 8 . 8 0 2}$ & $\mathbf{4 4 . 0 0 9}$ & $\mathbf{1 4 . 7 9 3}$ \\
\hline BENEFíCIOS/CUSTO EVITADO (R\$) & & & \\
\hline TOTAL & $\mathbf{9 2 . 9 3 8}$ & $\mathbf{6 5 . 8 5 6}$ & $\mathbf{2 7 . 0 8 2}$ \\
\hline Produtos químicos & 9.115 & 6.240 & 2.875 \\
\hline Material e produtos filtrantes & 549 & 385 & 164 \\
\hline Dragagem e remoção de lodo & 10.566 & 7.397 & 3.169 \\
\hline Energia elétrica & 59.615 & 41.163 & 18.452 \\
\hline Depreciação evitada & 13.093 & 10.671 & 2.422 \\
\hline CUSTOS (R\$) & & & $\mathbf{1 2 . 2 8 9}$ \\
\hline TOTAL & $\mathbf{3 4 . 1 3 6}$ & $\mathbf{2 1 . 8 4 7}$ & 7.387 \\
\hline Investimentos & 20.520 & 13.133 & 74 \\
\hline Custos de transação & 205 & 131 & 4.828 \\
\hline Custos de oportunidade & 13.411 & 8.583 & \\
\hline PERFORMANCE FINANCEIRA (Taxa de desconto = 8,5\% a.a.) & & & $\mathbf{1 . 4 7 9}$ \\
\hline VPL (R\$) & $\mathbf{1 1 . 1 4 1}$ & $\mathbf{9 . 6 6 2}$ & $\mathbf{1 0 \%}$ \\
\hline TIR (\%) & $\mathbf{1 4 \%}$ & $\mathbf{1 5 \%}$ & $\mathbf{1 6}$ \\
\hline PAYBACK (ANOS) & $\mathbf{1 2}$ & $\mathbf{1 1}$ & \\
\hline
\end{tabular}

Nota: produtos químicos, material e produtos filtrantes e energia elétrica referem-se apenas aos custos incorridos no tratamento da turbidez da água. A depreciação é estimada pelo desgaste de equipamentos utilizados apenas nos processos de tratamento de turbidez. Para detalhes, ver Apêndice C.

Fonte: Elaborada pelos autores. 
Na Bacia do Jucu, a restauração de 1.60o hectares exigiria um investimento de aproximadamente $R \$ 21,8$ milhões (cenário JUCU1600). Esse investimento poderia reduzir a turbidez média em $15 \%$, gerando benefícios líquidos da ordem de R \$ 65,9 milhões e VPL de R \$ 9,7 milhões (Tabela 1, Figura 1). Já a restauração de 900 hectares no SMV (cenário SMV9oo) custaria aproximadamente $R \$ 12,3$ milhões, com benefícios líquidos de R $\$ 27,1$ milhões e VPL de $\mathrm{R} \$ 1,5$ milhão, com redução de turbidez de até $5 \%$.

Os cenários aqui avaliados consideram um esforço de restauração compatível com as propostas dos principais programas estaduais, como Programa Reflorestar, Programa de Gestão Integrada das Águas e da Paisagem e projeto Florestas para a Vida. Essas iniciativas planejam investir cerca de $\mathrm{R} \$ 190$ milhões na Bacia do Jucu e R \$ 134 milhões na Bacia do SMV para restauração florestal de nascentes, matas ciliares e áreas de recarga de aquíferos. Os investimentos necessários para a restauração de 2.500 hectares aqui propostos seriam equivalentes a um terço do planejado para as bacias hidrográficas por meio dessas três iniciativas.

\section{O reservatório dos Imigrantes deve} contribuir para o controle de sedimentos. Entre as infraestruturas planejadas na UGRH Litoral Central, a barragem do rio Jucu é a que mais alteraria a dinâmica de turbidez da água que segue para as estações de tratamento. Projetado com o principal objetivo de armazenar 20 milhões de metros cúbicos de água, o reservatório dos Imigrantes trará benefício adicional ao atuar também como tanque de sedimentação. Por outro lado, aumentará os custos de manutenção e manejo de assoreamento na ordem de $\mathrm{R} \$ 5$ milhões ao longo dos 20 anos.

\section{A infraestrutura natural pode} complementar e melhorar o desempenho da infraestrutura convencional de forma rentável. $O$ reservatório pode evitar que sedimentos cheguem às estações de tratamento, mas não pode alterar a erosão do solo da paisagem. A restauração florestal de 1.600 hectares de

Figura 1 | Desempenho econômico do cenário LC2500, horizonte de 20 anos

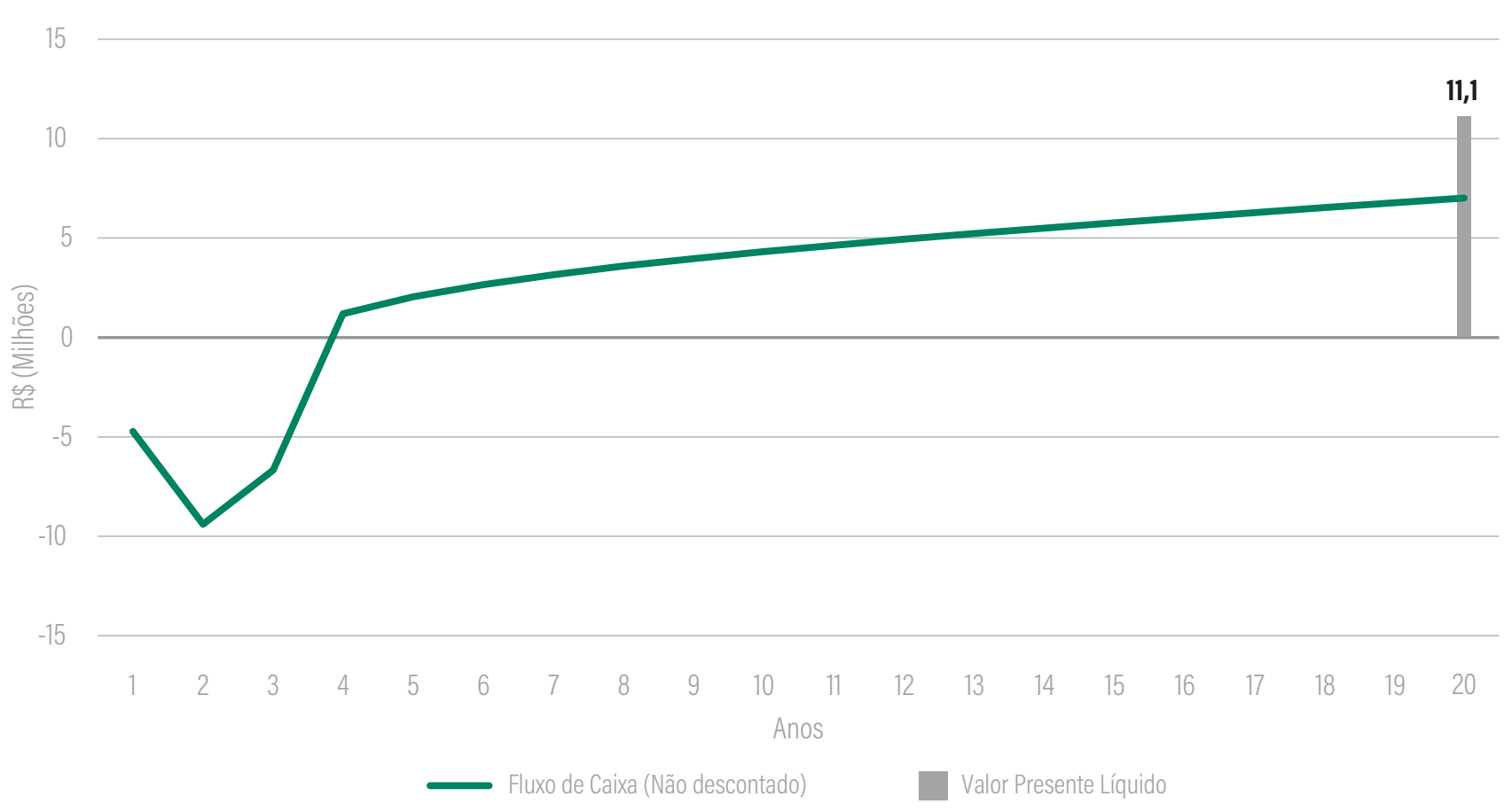

Nota: os custos incidem principalmente nos primeiros três anos do projeto com a implementação da restauração. Os benefícios (custos evitados no tratamento de água e depreciação e desgaste de equipamentos) são gradualmente acumulados e incrementados com o desenvolvimento da floresta e, consequentemente, dos serviços ecossistêmicos. 0 VPL resultante em 20 anos (usando uma taxa de desconto de 8,5\% a.a.) é de cerca de R\$11,1 milhões.

Fonte: Elaborada pelos autores. 
pastagens degradadas na Bacia do Jucu reduziria a descarga de sedimentos para o reservatório em aproximadamente 1.800 toneladas por ano, equivalente a uma carga de 40 caminhõescaçamba por ano. Os benefícios econômicos totais da economia de custos de tratamento de água, depreciação evitada e custos de dragagem e disposição desses sedimentos seriam de $\mathrm{R} \$$ 65,9 milhões em 20 anos, 50\% maiores do que os benefícios alcançados em custos de tratamento de água fornecidos apenas pelo reservatório.

\section{Programas públicos que já investem em infraestrutura natural podem ser parceiros dos proprietários rurais e compartilhar o risco com investidores do setor hídrico. $O$}

Programa Reflorestar estabeleceu a infraestrutura administrativa necessária para incentivar e gerenciar a restauração em todo o estado do Espírito Santo e, sem dúvida, é um dos grandes parceiros dos proprietários rurais dispostos a se adequarem ao Código Florestal. Mas o programa precisa de maiores financiamentos para contemplar o tamanho do desafio. A Agência Estadual de Recursos Hídricos (AGERH) tem a competência técnica e legal para atribuir os usos da água aos diferentes demandantes no estado, e os Comitês das Bacias Hidrográficas do rio Santa Maria da Vitória (CBH Santa Maria da Vitória) e do rio Jucu (CBH Jucu) já vêm consolidando um planejamento, representando o esforço conjunto dos múltiplos atores públicos e privados em prol da RMGV. A convergência de objetivos e ações dessas instituições com os proprietários rurais é fundamental para potencializar a captação de recursos para investimento em restauração e maximizar os benefícios ambientais e sociais buscados por elas.

\section{Riscos e incertezas}

\section{A análise de sensibilidade demonstra que a capacidade da floresta em reter sedimentos é o principal fator de risco. A infraestrutura} natural demonstrou sólido desempenho financeiro mesmo sob variações em taxas de desconto, custo da restauração e custo de oportunidade da terra. Entretanto, o desempenho dos projetos é muito sensível às variações na capacidade de retenção de sedimentos estimados durante o crescimento da floresta restaurada. Se a floresta tiver uma capacidade $31 \%$ menor do que o estimado, o VPL começa a se tornar negativo. O custo da restauração é o segundo fator de variabilidade mais importante na performance econômica da infraestrutura natural. Variações no custo de tratamento dentro de um nível de turbidez têm impacto relativamente pequeno se comparado às variações dos custos entre diferentes níveis de turbidez - os quais são determinados pela própria capacidade de floresta na retenção de sedimentos.
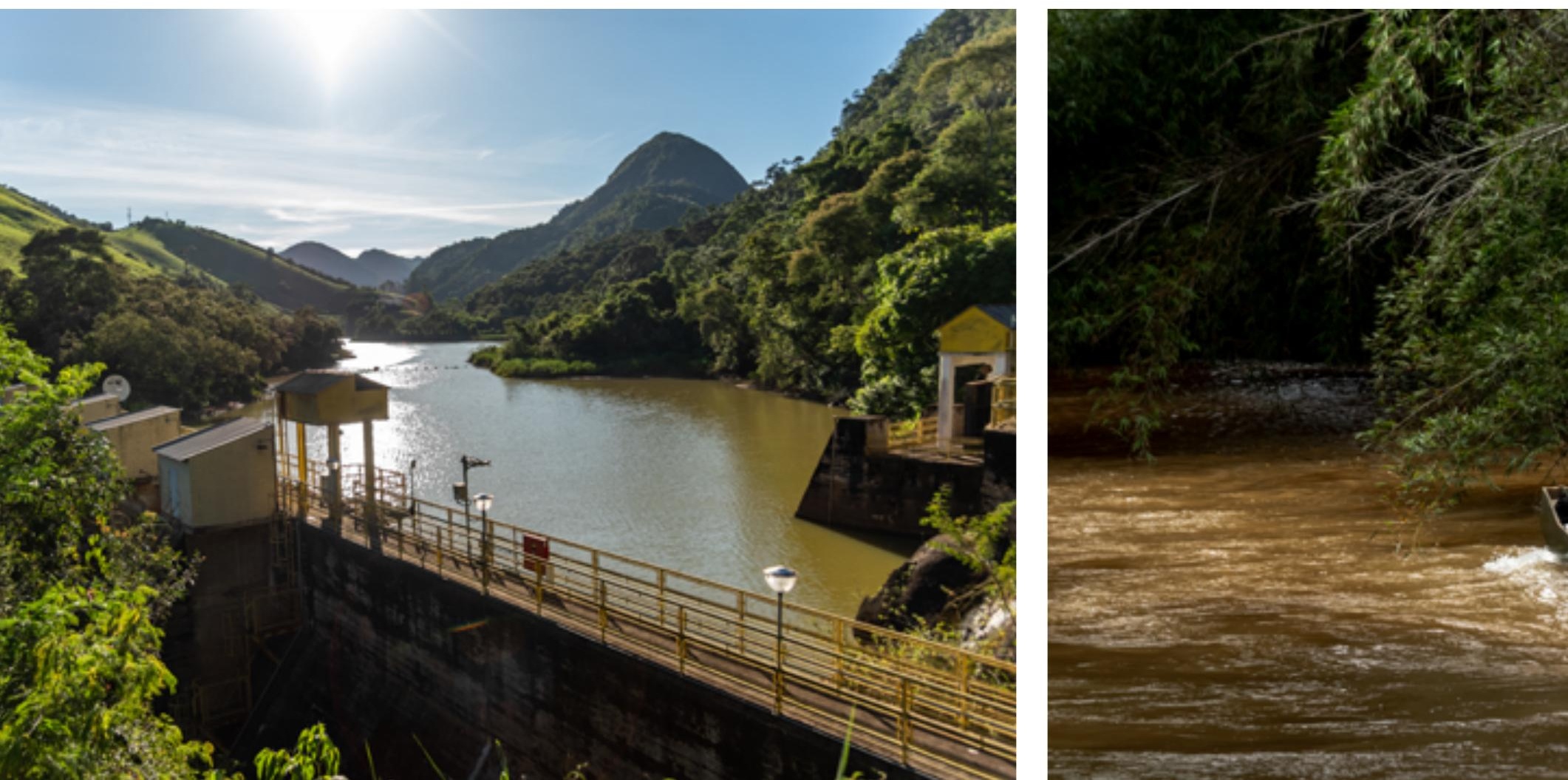


\section{A localização e o ritmo da restauração impactam o desempenho financeiro da infraestrutura natural. O cenário LC2500 foi} projetado para maximizar a retenção de sedimentos em áreas criticamente erodidas - os 2.500 hectares prioritários contribuem com mais de um terço de todos os sedimentos oriundos de pastagens degradadas nas Bacias do Jucu e do SMV. Se, ao contrário, os 2.500 hectares fossem restaurados aleatoriamente entre as áreas de pastagens degradadas, sem priorização pelo grau de erosão, a restauração não teria capacidade de reter mais do que $5 \%$ dos sedimentos produzidos na paisagem.

O ritmo de implementação também tem um grande impacto nos resultados - se o LC250o fosse concluído no primeiro ano do projeto (em vez de seguir um cronograma de restauração de três anos), o VPL do projeto seria 20\% maior. Acelerar o ritmo de restauração ou visar áreas específicas podem não ser viáveis se os proprietários das áreas não estiverem dispostos a restaurar.

Figura 2 | Bandas esperadas de VPL sob variações no desempenho e nos custos da restauração para o cenário LC2500, horizonte de 20 anos
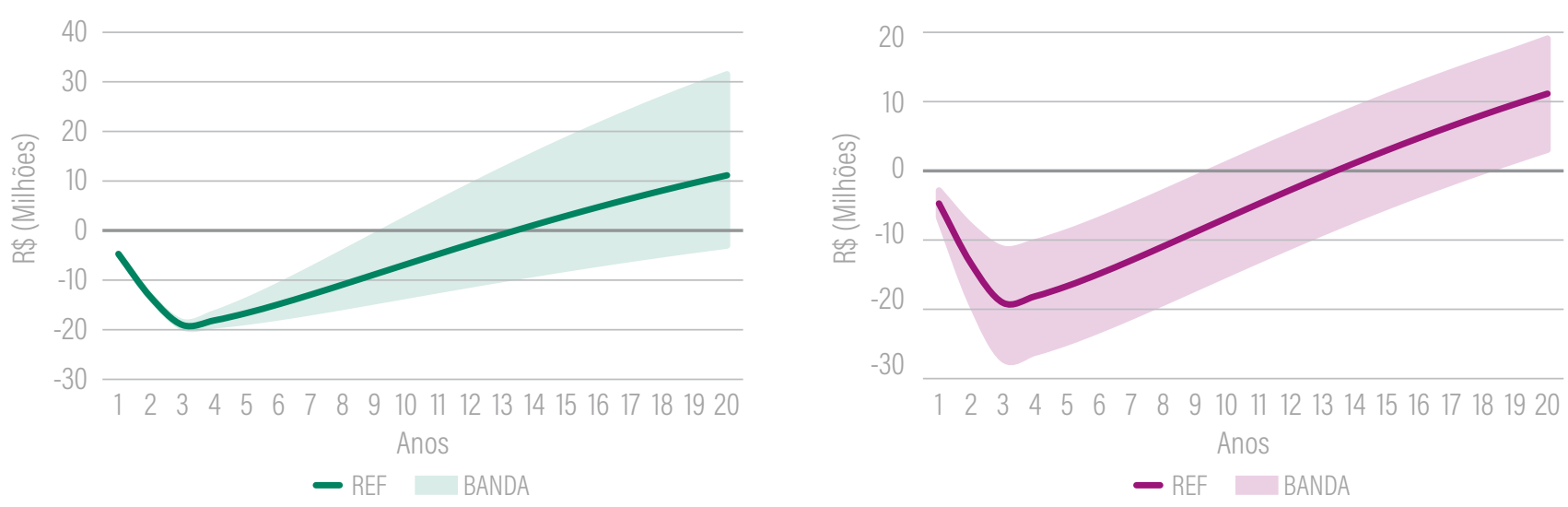

Nota: 0 gráfico à esquerda mostra o VPL sob variação na capacidade de retenção de sedimentos da infraestrutura natural. 0 gráfico à direita denota o VPL sob variação no custo da implantação da infraestrutura natural. REF é o VPL conforme valores adotados como referenciais. BANDA denota a faixa de VPL sob variações dessas premissas. A variação na BANDA é de $-50 \%$ a $+33 \%$ sobre o REF para a capacidade de retenção de sedimentos e de $-48 \%$ a $+50 \%$ para 0 custo de implementação.

Fonte: Elaborada pelos autores.
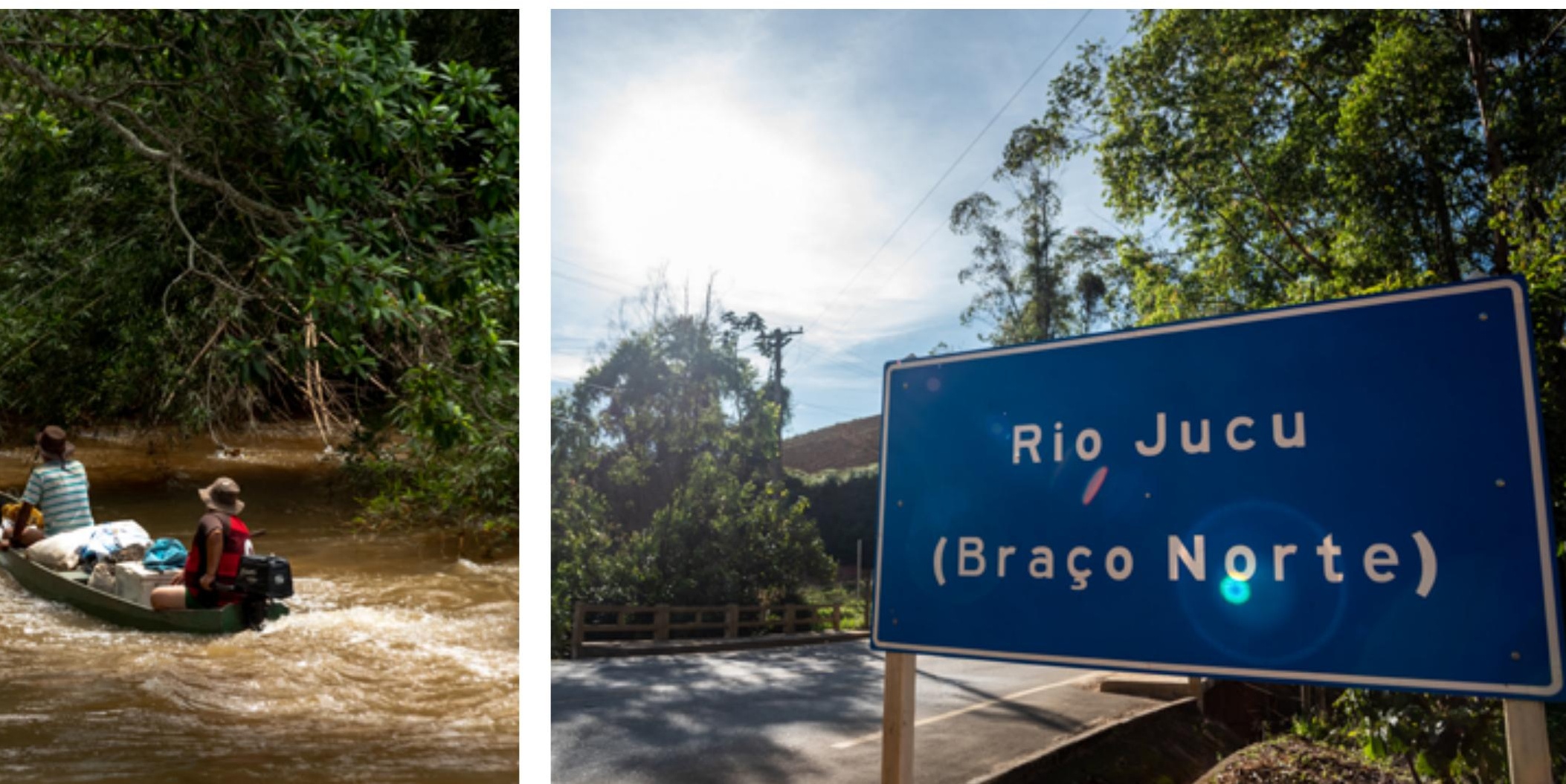


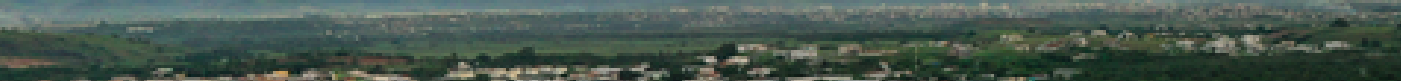

- ven-

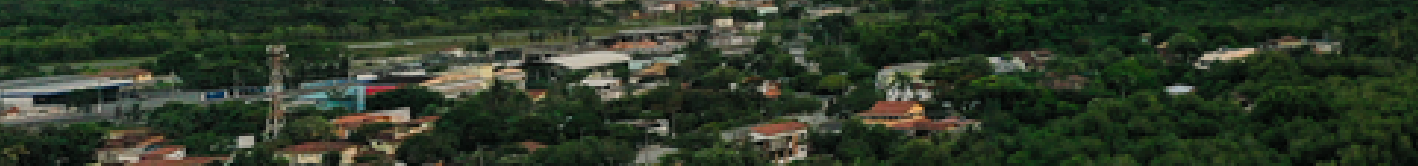

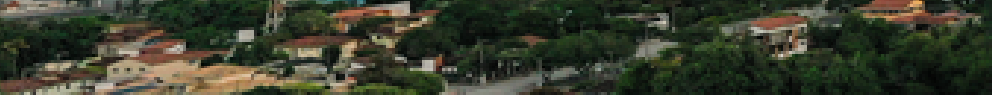

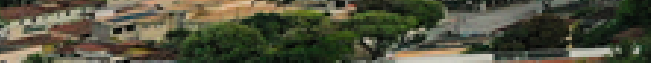

(5)

$2=\frac{1}{20}$ S

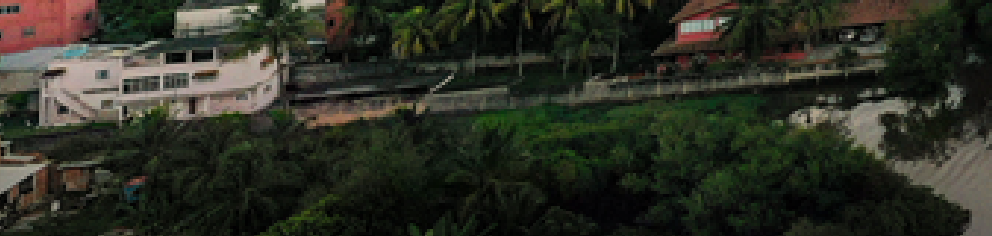
T.

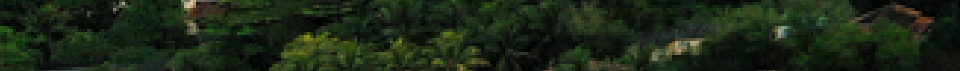

2

to

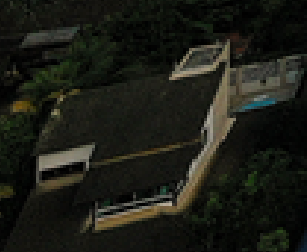

1.

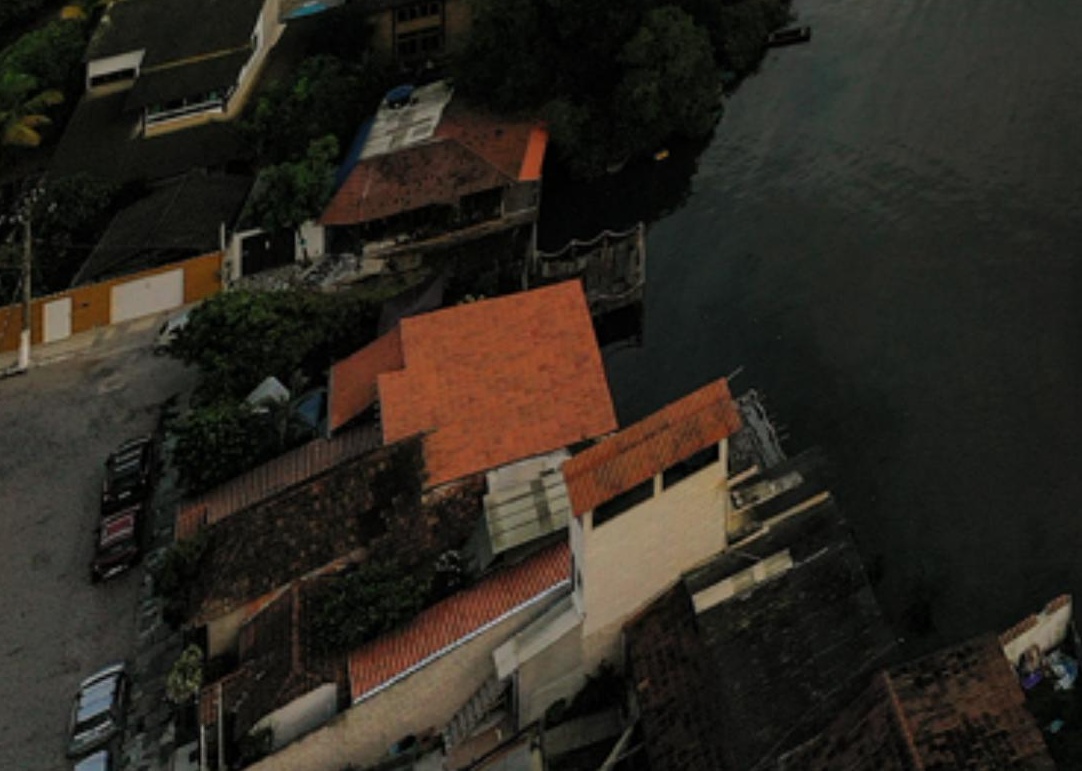


CAPÍTULO I

\section{CONTEXTUALIZAÇÃO}

A Região Metropolitana da Grande Vitória é composta por 7

municípios e reúne mais da metade dos 4 milhões de habitantes

do Espírito Santo. As Bacias do Jucu e do Santa Maria da Vitória respondem por $97 \%$ do abastecimento urbano da região através dos serviços de saneamento prestados pela Cesan. Cerca de 500 milhões de litros de água são tratados diariamente com uso de quase 20 toneladas de produtos químicos. 0 presente estudo examina opções de investimento em infraestrutura natural para auxiliar a gestão do abastecimento de água, avaliando a performance financeira da restauração de florestas para a melhoria da qualidade da água como estratégias auxiliares aos investimentos em infraestruturas convencionais, como 0 reservatório dos Imigrantes. 
Entre 2014 e 2020, a RMGV sofreu com secas severas e prolongadas. Durante quatro anos consecutivos - entre 2014 e 2017 - a média anual de chuvas foi inferior a $65 \%$ da média histórica e, em 2015, o pior ano da crise, choveu apenas 730 milímetros quando o esperado era de 1.500 milímetros (Inmet, 2021). A fim de mitigar os riscos de insegurança hídrica, o estado do Espírito Santo lançou, em 2017, o Programa Estadual de Construção de Barragens, que visa à construção de 40 reservatórios em todo o estado, incluindo o dos Imigrantes, na Bacia do Jucu, o maior já projetado (Seag, 2018).

Já durante os anos de 2018 a 2020, a precipitação anual na RMGV oscilou entre 5\% e 10\% acima da média, mas ainda assim insuficiente para recuperar os déficits dos anos anteriores. Além disso, as chuvas foram muito mal distribuídas, com 679 dias sem chuva e 48 dias de chuvas fortes (acima de 30 milímetros) (Inmet, 2021). Enquanto secas severas impõem sérias restrições ao bem-estar e à economia - exigindo racionamento, parando indústrias e arriscando a produção agrícola -, chuvas fortes causam desastres, como deslizamentos de terra e inundações, desalojando e desabrigando populações vulneráveis, aumentando a proliferação de doenças infecciosas e, em casos mais graves, causando mortes. Entre 2003 e 2018, o estado do Espírito Santo registrou 154 eventos de desastres naturais, sendo $52 \%$ relacionados a secas e $45 \%$ a chuvas, em sua maioria deslizamentos de terra e enchentes. As perdas totalizaram US $\$ 830$ milhões somente durante o período 2016-2017 (CNM, 2018).

Os sistemas de tratamento de água também são impactados por eventos meteorológicos. As secas levam ao aumento dos custos de bombeamento nos reservatórios ou na captação de água, enquanto as chuvas fortes podem levar a um aumento acentuado no custo de tratamento de turbidez e poluentes e podem até implicar na paralização do sistema (Taffarello et al., 2016; Frame et al., 2020). Nesse contexto, os investimentos em infraestrutura convencional de captação, armazenamento e tratamento de água são fundamentais para proporcionar redundância e melhorar a capacidade de gerenciamento de crises. Entretanto, esse tipo de infraestrutura cinza não altera a capacidade da paisagem de produzir água com maior estabilidade sazonal ou de melhor qualidade. A infraestrutura natural pode.

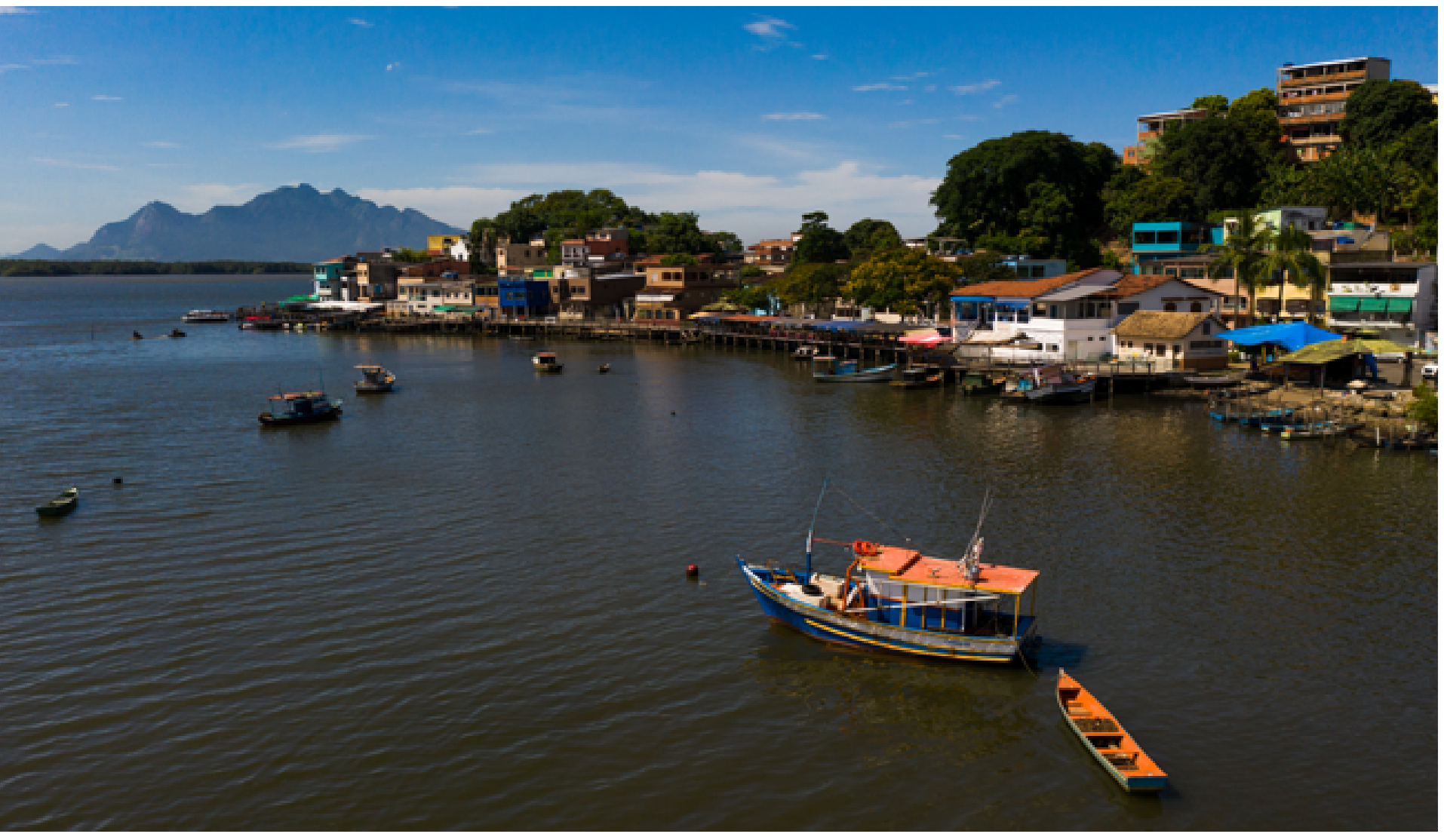


Infraestrutura natural é o conjunto de

ecossistemas íntegros, manejados ou restaurados, estrategicamente planejados e gerenciados para habilitar ou reabilitar a paisagem a fornecer serviços ambientais essenciais ao desenvolvimento das atividades econômicas e ao bem-estar da comunidade (Benedict e McMahon, 2006). Nesse contexto, a implementação de infraestrutura natural para água é aqui entendida como a restauração de florestas e outras formas de vegetação nativa em áreas atualmente ocupadas por pastagens com altos níveis de degradação - indicadas pela perda de solo por erosão e sedimentação -, com intuito de recuperar a capacidade da paisagem de entregar água com menor turbidez aos sistemas de tratamento.

O presente relatório examina opções para investir em infraestrutura natural como uma estratégia de gerenciamento hídrico para a RMGV. Foca na UGRH Litoral Central, composta pelas Bacias do Jucu e do SMV, responsáveis, respectivamente, pelo fornecimento de $59 \%$ e $38 \%$ da água tratada e distribuída à população da RMGV. Uma terceira bacia, Reis Magos, é sem dúvida uma importante aliada, respondendo por quase $2 \%$ do abastecimento da RMGV, mas não foi incluída neste estudo, bem como não foram incluídos os sistemas isolados que servem aos municípios da região (AGERH e Seama, 2018).

O estudo avalia como a infraestrutura natural pode complementar e proteger as infraestruturas existentes e planejadas para o abastecimento de água, especialmente focando nos impactos da poluição por sedimentos e consequente turbidez. O estudo provê, também, recomendações para projetar programas de infraestrutura natural de maneira a aumentar a probabilidade de sucesso se o objetivo principal da restauração florestal for manejo de sedimentos. Por meio dessa análise, evidencia-se como as concessionárias locais especialmente a Cesan - e a própria população poderiam se beneficiar do investimento em infraestrutura natural para obter benefícios na segurança hídrica.

\section{BOX 1 | BENEFÍCIOS DA INTEGRAÇÃO DA INFRAESTRUTURA NATURAL NA GESTÃO DA ÁGUA}

Investimentos em infraestrutura natural

correspondem à proteção, à restauração ou ao gerenciamento estratégico de sistemas naturais florestais ou outras formas de vegetação,

visando contribuir com os principais serviços de infraestrutura, como 0 abastecimento de água. A infraestrutura natural pode gerar uma série de benefícios: do sequestro de carbono ao habitat de espécies raras; do controle de enchentes à resiliência à seca. Ela pode ser multifuncional buscando reduzir simultaneamente as inundações e criar um espaço para recreação ou, ainda, focar em apenas um ou dois resultados.

Os gestores de infraestrutura convencional, como as empresas de abastecimento de água, lucram potencialmente com o investimento em infraestrutura natural em virtude da economia e da segurança em termos de custos de tratamento de água, estabilidade no abastecimento, risco reduzido de inundações e, consequentemente, de desgastes, depreciação ou perdas causadas por danos à infraestrutura. 0 envolvimento dos setores de infraestrutura, como investidores, empresas de abastecimento de água e hidrelétricas, por exemplo, pode impulsionar os programas de reabilitação da paisagem e restauração ambiental, gerando uma fonte durável de recursos advindos dos usuários de água que se beneficiam diretamente do programa.

Embora os benefícios da infraestrutura natural sejam amplamente compreendidos, o papel que ela pode desempenhar como estratégia central de gestão da água depende do contexto local e, portanto, requer uma avaliação específica e que leve em conta os atributos regionais. Como a infraestrutura natural não é rotineiramente considerada no planejamento hidrológico, em geral, gestores ignoram oportunidades promissoras de usá-la para melhorar a segurança hídrica. Desse modo, é necessário analisar os custos, benefícios, riscos e retorno da infraestrutura natural para investimentos em água.

Fonte: Browder et al. (2019) 


\section{Gerenciamento de água na UGRH Litoral Central (Bacias do Jucu e do SMV)}

As Bacias do Jucu e do SMV são contíguas, conformam a UGRH Litoral Central e estão localizadas na Bacia Hidrográfica do Atlântico Sudeste, Bioma Mata Atlântica (AGERH e Seama, 2018). São atualmente a principal fonte de captação, tratamento e distribuição de água para abastecimento público da RMGV, com população atendida superior a 1,7 milhão de pessoas (Pagiola, Platais e Sossai, 2019).

O reconhecimento da necessidade de gestão descentralizada dos recursos hídricos e de autonomia dos processos decisórios nas bacias é garantido por dois comitês independentes, ambos criados em 2007. O Decreto $\mathrm{n}^{0}$ 1934-R estabeleceu o Comitê da Bacia Hidrográfica do Rio Santa Maria da Vitória (CBH Santa Maria da Vitória) e o Decreto $\mathrm{n}^{0}$ 1935-R criou o Comitê da Bacia Hidrográfica do Rio Jucu (CBH Jucu), dissolvendo-se o então Consórcio Intermunicipal das Bacias dos Rios Santa Maria da Vitória e Jucu (Oliveira, 2011).

Entretanto, o planejamento das ações que exigem harmonização de estratégias e convergência de metas em prol da população da RMGV têm sido executado pelos dois comitês em conjunto com órgãos estaduais, como o Instituto Estadual de Meio Ambiente e Recursos Hídricos (Iema), a Secretaria de Estado do Meio Ambiente e Recursos Hídricos (Seama) e a Agência Estadual de Recursos Hídricos (AGERH). Entre as principais ações conjuntas estão os planos de enquadramento dos recursos hídricos das duas bacias (CBH SMV, CBH Jucu e Iema, 2016), o Plano Estadual de Recursos Hídricos (PERH-ES) (AGERH e Seama, 2018) e o Programa de Gestão Integrada das Águas e da Paisagem (Governo ES, Banco Mundial e Cesan, 2013).

A empresa responsável pelos serviços de saneamento é a Cesan, que nas Bacias do Jucu e do SMV conta com uma estrutura de cinco Estações de Tratamento de Água (ETAs), das quais três captam água diretamente do rio Jucu e duas têm captação direta no rio Santa Maria da Vitória. Apesar das ETAs apresentarem capacidades instaladas distintas e diferentes sistemas de tratamento, todas se enquadram no mesmo nível de intensidade tecnológica (Gonzales-Perez, Persson e Lipnizky, 2018). O mais recente relatório de sustentabilidade da Cesan aponta que em 2017, somente para atendimento da RMGV, foram consumidos entre as cinco ETAs aproximadamente 7,6 mil toneladas de produtos químicos para tratamento de água e mais de 97 Gigawatt-hora de energia elétrica, com tratamento de quase 180 milhões de metros cúbicos de água (Cesan [2019a, 2019b, 2020]). A Tabela 2 traz detalhes das cinco ETAs.

Tabela 2 | Detalhes das estações de tratamento de água dos Sistemas Jucu e Santa Maria da Vitória

\begin{tabular}{|c|c|c|c|}
\hline САРТAÇÃO & ETA & VOLUME DE ÁGUA TRATADA (M³/S) & SISTEMA DE TRATAMENTO \\
\hline \multirow{5}{*}{ Rio Jucu } & Cobi & 1 & Convencional \\
\hline & Caçaroca & 0,4 & Flotação com recirculação \\
\hline & \multirow{2}{*}{ Vale Esperança } & 1,5 & Convencional \\
\hline & & 1,8 & Direta descendente com flotação \\
\hline & TOTAL & 4,7 & \\
\hline \multirow{4}{*}{ Rio Santa Maria da Vitória } & Santa Maria & 0,3 & Flotação \\
\hline & \multirow{2}{*}{ Carapina } & 1,4 & Filtração direta \\
\hline & & 0,9 & Flotação \\
\hline & TOTAL & 2,6 & \\
\hline UGRH Litoral Central & TOTAL GERAL & 7,3 & \\
\hline
\end{tabular}

Fonte: Elaborada pelos autores com base nos dados de Cesarino e Lima (2012); Pagiola, Platais e Sossai (2018); Cesan (2019a, 2019b, 2020). Informações complementadas por entrevistas Linhalis (2019); Ahnert (2020); Pagiola (2020). 


\section{Infraestrutura Cinza projetada para a UGRH Litoral Central}

Atualmente $91 \%$ da população da RMGV é atendida por serviços de água e 60\%, por serviços de esgotamento sanitário (Instituto Trata Brasil, 2020). O desafio que mais chama atenção é a ampliação do sistema de tratamento de esgoto, tendo sido destinado para esse fim o maior volume dos US\$ 323 milhões provisionados para o Programa de Gestão Integrada das Águas e da Paisagem, em execução pelo Governo do Estado do Espírito Santo, pela Cesan e financiado pelo Banco Mundial (Governo ES, 2013).

A urgência dos investimentos no tratamento de esgoto não relaxa, entretanto, a necessidade de gerenciamento da segurança hídrica. A região tem sofrido crises hídricas sistêmicas, tendo sido forçada a racionar água constantemente (Elesbon, 2020). A escassez é pontuada por chuvas excessivas, o que causa suas próprias crises: inundações e poluição severa da água. Em 2017, o Espírito Santo lançou o Programa Estadual de Construção de Barragens com a meta de construir 40 reservatórios em todo o estado com a aplicação de quase $\mathrm{R} \$ 700$ milhões. Dentre os principais investimentos previstos - que incluem a extensão da rede de distribuição e novas ligações -, o barramento do rio Jucu e a construção do reservatório dos Imigrantes, primeiro grande reservatório destinado ao abastecimento público da RMGV, trarão as maiores mudanças operacionais na gestão hídrica da região. Os investimentos estão na casa dos R $\$ 100$ milhões, e a estrutura deve entrar em operação no final de 2022 (Cesan, 2019a).

Como frisado anteriormente, tanto nas ETAs da Bacia do Jucu quanto nas da Bacia do SMV, hoje a captação é feita diretamente nos rios. Chuvas fortes carreiam grandes quantidades de sedimentos para os cursos d'água que fluem diretamente para as estações de tratamento. Isso exige que a Cesan aumente de maneira considerável a quantidade de produtos químicos utilizados no tratamento da água e, em casos extremos, suspenda temporariamente suas operações (Cesan, 2010; Governo ES, 2017).
Essa poluição sedimentar - que se materializa na turbidez - é um fator-chave nos custos de tratamento de água e causam abrasividade que desgastam os equipamentos, diminuindo a vida útil e aumentando a depreciação.

Com o novo reservatório no rio Jucu, a dinâmica muda. Ele será capaz de reservar cerca de 20 milhões de metros cúbicos de água, o que equivale a cerca de quatro meses de consumo na RMGV, formando um espelho d'água de aproximadamente 150 hectares (Scalzer, 2016). Além de promover maior redundância na disponibilidade hídrica, um cobenefício do reservatório será a contenção de sedimentos, atuando como um grande tanque de sedimentação. Estudos realizados nos trópicos revelaram que entre 10\% e 95\% dos sedimentos que chegam aos reservatórios ficam retidos (Pagioro e Thomaz, 2002; Kummu e Varis, 2007; Ran et al., 2013). Na Região Sudeste do Brasil, estudos apontam para uma capacidade de retenção em torno de 32\% (Condé et al., 2019). Para efeito deste estudo, considerou-se que o reservatório dos Imigrantes deve ter essa capacidade de retenção.

Com o barramento do rio, a bacia de captação do Jucu apresentará duas regiões principais em termos de dinâmica de turbidez, a saber:

Montante da barragem: parte da bacia a montante do reservatório ( $75 \%$ da área terrestre da bacia);

- Jusante da barragem: parte da bacia entre a barragem e as estações de tratamento (a captação de água ocorre $20 \mathrm{~km}$ a jusante do vertedouro do reservatório).

Assumindo que o reservatório dos Imigrantes retenha $32 \%$ dos sedimentos produzidos a montante da barragem, a turbidez da água nas ETAs será dada pela média ponderada entre a turbidez da água na saída do reservatório e a turbidez da água oriunda da bacia a jusante. A Figura 3 simula o reservatório na Bacia do Jucu, com superfície estimada em 150 hectares e volume de 20 milhões de metros cúbicos. 

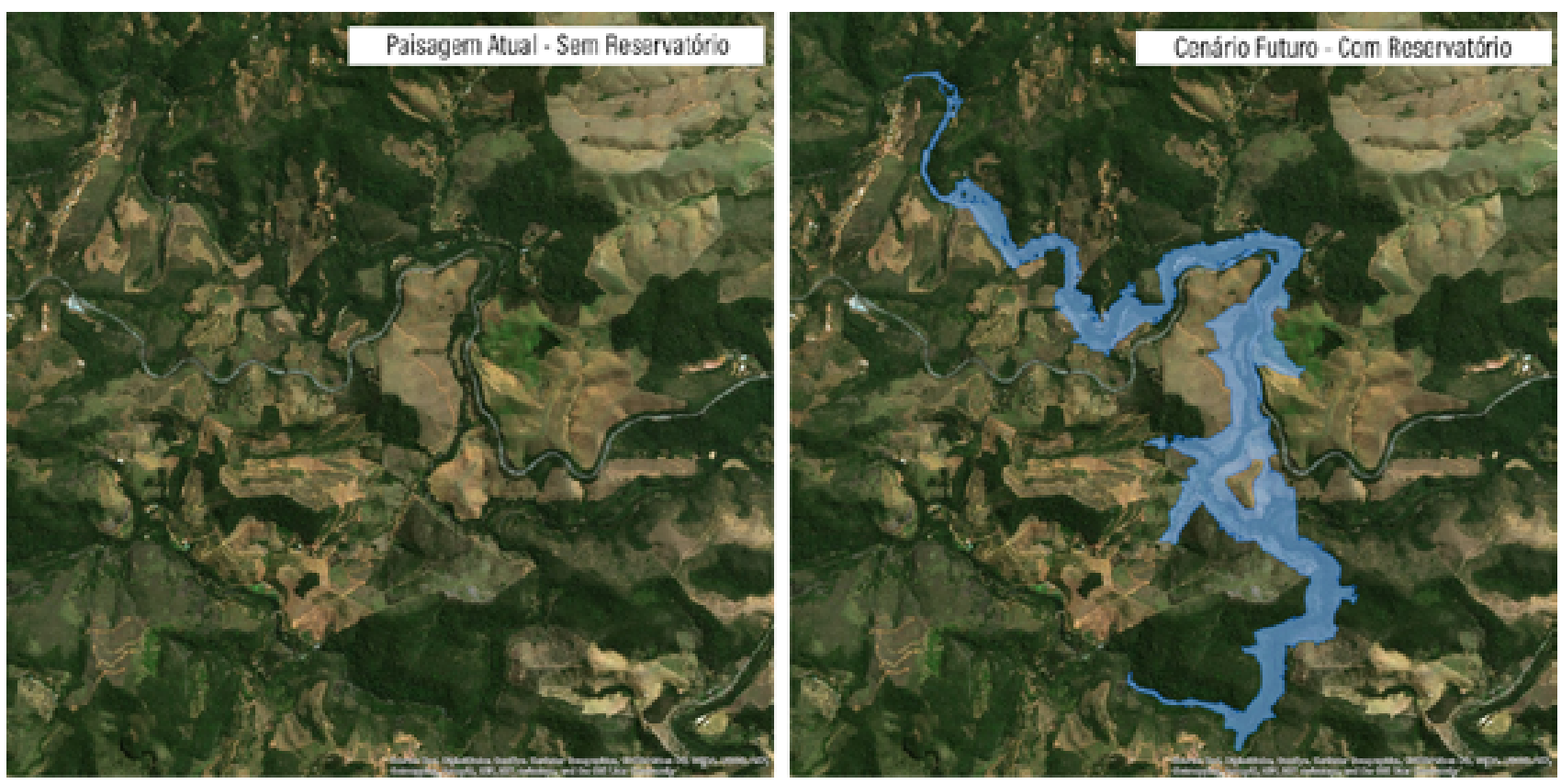

Fonte: Elaborada pelos autores, a partir de simulação baseada em Modelo de Elevação Digital (Digital Elevation Model - DEM). Ver Apêndice B.

\section{Estratégias de Infraestrutura Natural para a UGRH Litoral Central (Bacias do Jucu e do SMV)}

O novo reservatório aumentará a segurança hídrica, além de reter o sedimento e reduzir a turbidez nos pontos de captação das ETAs, mas não poderá mudar a dinâmica de erosão do solo e o processo de descarga de sedimentos nos cursos d’água. Como destacado por Dargahi (2012), a retenção de sedimentos em reservatórios é apenas uma recolocação do problema do assoreamento. Por outro lado, a infraestrutura natural pode desempenhar um papel no controle da erosão em sua fonte primária (Neary, Ice e Jackson, 2009).

Florestas e demais formas de vegetação natural absorvem o impacto das chuvas e auxiliam na estruturação do solo - via sistemas radiculares - , diminuindo o potencial de erosividade e erodibilidade. Os benefícios do controle da erosão para os sistemas de abastecimento se traduzem no menor escoamento de sedimentos, menor concentração de sólidos na água e, finalmente, menor turbidez, o que redunda em economia no uso de produtos químicos. Benefícios adicionais são melhoria na regulação dos fluxos hídricos, manutenção do microclima, proteção de polinizadores, conservação da biodiversidade e sequestro de carbono (Assad et al., 2019).

Globalmente, a infraestrutura natural tem sido valorizada e adotada como estratégia de complementação ou potencialização da infraestrutura cinza (Browder et al., 2019). Há razões para acreditar que a infraestrutura natural poderia ser potencialmente eficaz também na UGRH Litoral Central: a cobertura vegetal nativa da região, a Mata Atlântica, tem uma capacidade inata de regular os fluxos de água, controlar a erosão, aumentar a estabilidade do solo e filtrar os poluentes da água, salvaguardando assim a infraestrutura hídrica e melhorando a qualidade da água (Ozment et al., 2018).

Historicamente, a Mata Atlântica cobria toda a região, mas restam atualmente apenas $36 \%$ na Bacia do Jucu e 39\% na Bacia do SMV (Figura 4). Entre as classes de uso da terra, a pastagem é a mais comum, das quais mais de metade apresenta alto nível de degradação (Lapig, 2020). Em 2018, 8\% da área das bacias apresentava processos de regeneração florestal (para detalhes, ver Apêndice B). Há uma oportunidade considerável para promover a restauração de forma inteligente e estratégica e que poderia proteger e melhorar o desempenho da infraestrutura convencional. 


\section{Esforços de Infraestrutura Natural em andamento na UGRH Litoral Central}

Os principais tomadores de decisão e stakeholders das Bacias do Jucu e do SMV já estão dando demonstrações firmes para a restauração florestal e implementação da infraestrutura natural (Kissinger, 2014). Em 2008, o Espírito Santo foi o primeiro estado do Brasil a estabelecer uma lei de Pagamentos por Serviços Ambientais (PSA) (Sossai et al., 2013). Em 2009, o Fundo Estadual de Recursos Hídricos (Fundágua) foi criado para consignar recursos provenientes de royalties de petróleo e gás e de outras fontes para conservação florestal e hídrica. A lei aloca 2,5\% dos royalties de

Figura 4 | Uso e cobertura do solo na UGRH Litoral Central

Limite das bacias

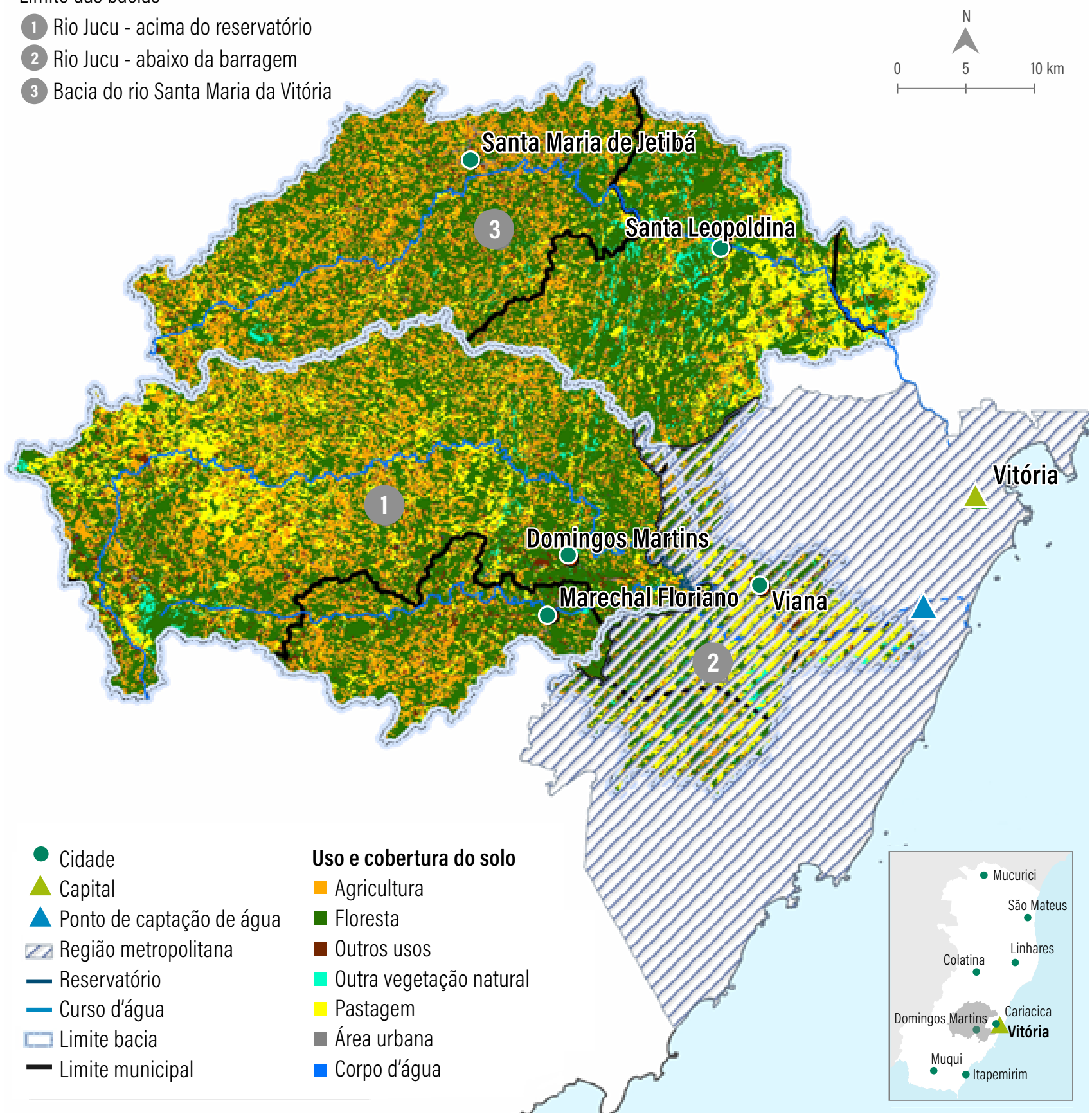

Fonte: Elaborada pelos autores com base nos dados de Geobases-ES (2018). 
petróleo para PSA e para o gerenciamento de terras em todo o estado. Estima-se que esses royalties devem ter provido aproximadamente US\$ 4,6 milhões por ano.

Atualmente, vários programas e importantes iniciativas locais estão desenvolvendo e/ou implementando planos de infraestrutura natural e definindo metas de investimento. Destacam-se:

\section{Programa Reflorestar}

Programa estatal para aumentar a cobertura florestal, cujo objetivo é restaurar e proteger 80 mil hectares de floresta no estado do Espírito Santo (Seama, 2020). Os recursos provêm de royalties de petróleo e gás por meio do Fundágua, além do apoio do Banco Mundial e do Fundo Mundial para o Ambiente (Sossai et al., 2013). O Programa Reflorestar apoia vários tipos de práticas sustentáveis de manejo da paisagem, incluindo conservação, reflorestamento através de plantio, regeneração natural da vegetação, sistemas agroflorestais e silvipastoris e manejo de florestas. O programa oferece PSA para incentivar a participação de proprietários rurais, auxiliando-os no cumprimento do Código Florestal. Os investimentos previstos para restauração por plantio eram, no momento da conclusão deste relatório, de $\mathrm{R} \$ 10.666$ por hectare e, para regeneração natural, de $\mathrm{R} \$ 3.438$ por hectare. Já os pagamentos por serviços ambientais eram de $\mathrm{R} \$ 281$ e $\mathrm{R} \$ 267$ por hectare por ano para as respectivas modalidades. Até dezembro de 2020, o Reflorestar havia apoiado a restauração de $10 \mathrm{mil}$ hectares (Seama, 2020).

O Programa Reflorestar já investiu, desde sua fundação, $\mathrm{R}$ \$ 52 milhões, dos quais $\mathrm{R}$ \$ 18 milhões entre 2019 e 2020; e tem reservado para execução outros R \$ 21 milhões para a restauração e conservação de florestas, dos quais aproximadamente R $\$ 5$ milhões nas Bacias do Jucu, do SMV e dos Reis Magos (Sossai, 2020). Com recursos financeiros oriundos de doação do Fundo Global para o Meio Ambiente (Global Environment Facility - GEF), por meio do projeto Florestas para a Vida (Espirito Santo Biodiversity and Watershed Conservation and Restoration Project), o Programa Reflorestar angariou fundos para aplicação exclusiva em propriedades rurais localizadas nas Bacias do Jucu e do SMV (Seama, 2020).
Comitês das Bacias Hidrográficas do rio Jucu e do rio Santa Maria da Vitória

Compõem as duas bacias da UGRH Litoral Central e são responsáveis pela gestão de $97 \%$ das fontes hídricas da RMGV. Foram estabelecidos em 2007 e desenvolveram seus planos em 2016 (CHB Jucu e CBH SMV, 2017). O projeto Florestas para a Vida, parceria entre os comitês das duas bacias, Governo do Espírito Santo e GEF, estimou um investimento necessário total $\mathrm{R} \$ 1,2$ bilhão em 10 anos para gestão dos recursos hídricos, dos quais $\mathrm{R} \$ 690$ milhões para o Jucu e R \$ 521 milhões para o SMV. Ações diretas de restauração florestal e conservação de vegetação nativa para infraestrutura natural estão contempladas em duas grandes frentes. No componente Gestão da Oferta Hídrica, a recuperação de nascentes, matas ciliares e áreas de recarga de aquífero estimam necessidade de investimento de $\mathrm{R} \$ 189$ milhões no Jucu e R \$ 134 milhões no SMV. Já no componente Gestão Ambiental e Desenvolvimento Regional, estima-se a provisão de $\mathrm{R} \$$ 4,4 milhões para criação de Unidades de Conservação de Proteção Integral, recursos que seriam divididos igualmente entre as duas bacias. Os valores destinados à infraestrutura natural representam $26 \%$ do orçamento total de investimentos no SMV e 27,5\% no Jucu (CBH SMV, CBH Jucu, Iema, 2016).

Notavelmente, esses investimentos dependem de maneira crucial do estabelecimento da cobrança pelo uso da água, fundamental para a gestão compartilhada dos recursos hídricos e gerenciamento territorial dos mananciais. Ainda assim, os recursos que poderiam ser arrecadados com a cobrança pelo uso da água cobririam, na melhor das hipóteses, $18 \%$ dos programas. Isso implica que, embora os esforços desses programas possam ter uma base sólida, é necessária uma combinação de financiamentos para fazer frente aos desafios dessas bacias hidrográficas.

\section{Programa de Gestão Integrada das Águas e Paisagens}

Programa do Governo do Estado do Espírito Santo, Cesan e Banco Mundial focado nos municípios da microrregião do Caparaó e Bacias do Jucu e do SMV, com investimentos programados de US $\$$ 323 milhões. Possui cinco componentes, dos quais o Componente 3 objetiva ampliar a cobertura 
florestal em 8,5 mil hectares em 31 municípios da microrregião do Caparaó e nas Bacias do Jucu e do SMV. A ação se dá essencialmente pelo financiamento de US\$ 35 milhões para o Programa Reflorestar e implantação da Unidade Demonstrativa de Mangaraí, Bacia do SMV, com suporte técnico e financeiro da Cesan (Governo ES, Banco Mundial e Cesan, 2013). Ao final de 2019, cerca de 50 hectares tinham sido restaurados ou tiveram suas áreas isoladas e preparadas para receber a restauração, com investimentos da ordem de R 730 mil (Cesan, 2019a). Em função da paralisação das atividades de campo devido à Covid-19, não houve avanço significativo no projeto durante $\mathrm{o}$ ano de 2020.

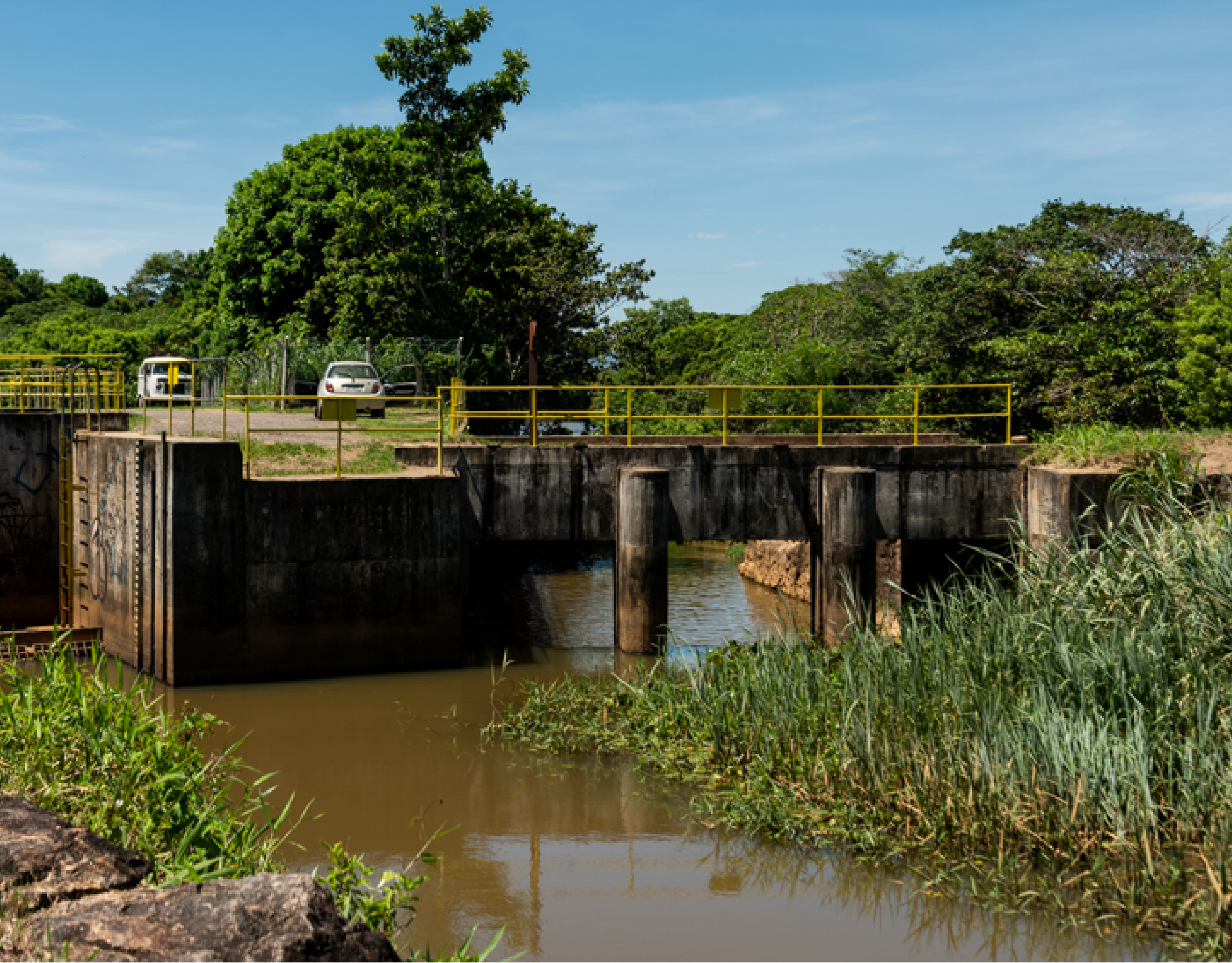




\section{Demandas para a ampliação da} infraestrutura natural

Muitas iniciativas no Espírito Santo estão deliberando sobre formas de acelerar os projetos de infraestrutura natural. Foi realizada uma ampla pesquisa com tomadores de decisão locais, incluindo setores de água e saneamento, meio ambiente e agricultura, contemplando organizações governamentais, investidores e ONGs, para identificar atividades de alta prioridade que poderiam impactar o uso da infraestrutura natural para água na UGRH Litoral Central (ver descrição no Apêndice A). As demandas mais mencionadas foram:

1. Avaliar o modelo de negócios para investimento: estimar os custos e benefícios financeiros do programa para determinar se empresas dependentes de água, gerentes públicos de água ou outros interessados poderiam se beneficiar.

2. Monitorar a implementação do projeto e avaliar seus impactos: acompanhar e apreciar o progresso, medindo os benefícios hidrológicos, ambientais e sociais dos esforços de infraestrutura natural. As partes interessadas observaram que é preciso estabelecer condições de referência para a infraestrutura natural (isto é, os níveis de benefícios hídricos gerados a partir da paisagem atual).

3. Engajar proprietários e administradores rurais para conservar, restaurar e gerenciar a infraestrutura natural: envolver e priorizar a participação de proprietários rurais e administradores de terras públicas e privadas. Obter os incentivos adequados para desenvolver a cooperação entre as comunidades, a montante e a jusante da barragem.

4. Garantir e ampliar financiamento para infraestrutura natural: os programas de restauração têm sido ambiciosos mas, como na maior parte do mundo, acessar recursos suficientes para operacionalizar projetos de infraestrutura natural é um desafio contínuo. Essa insegurança quanto ao financiamento levanta questões sobre a viabilidade da implementação de planos de infraestrutura natural, bem como sobre a sustentabilidade em longo prazo. Dessa maneira, um modelo financeiro robusto para a Cesan ou para outras entidades do setor hídrico investirem em infraestrutura natural poderia disponibilizar mais recursos para o programa de restauração. Esse modelo também serviria como exemplo para o desenvolvimento de outras bacias hidrográficas no estado; atualmente, planeja-se a construção de mais 40 barragens em todo o Espírito Santo (Seag, 2018).

Ao observar essas demandas para acelerar o investimento em restauração florestal, concentrou-se neste relatório a avaliação de modelo de negócios da restauração (Demanda 1). Para abordar essa primeira demanda, é necessária uma avaliação local para determinar se os benefícios hídricos da restauração florestal a partir da infraestrutura natural superariam os custos e, também, para verificar a viabilidade de vários projetos potenciais de programas. Avaliações referentes à performance financeira da infraestrutura natural foram realizadas em outras bacias hidrográficas brasileiras, incluindo a própria Bacia do SMV (Pagiola, Platais e Sossai, 2019), além de outras regiões como Camboriú (Kroeger et al., 2017), São Paulo (Ozment et al., 2018) e Rio de Janeiro (Feltran-Barbieri et al., 2018).

Utilizando dados locais, revisão de literatura, consultas às partes interessadas e modelos biofísicos e financeiros, foram avaliados cenários de investimentos em infraestrutura natural na UGRH Litoral Central e, quando aplicável, estratégias que possibilitem esse investimento. Seguiu-se o método de Avaliação de Investimento em Infraestrutura Natural (GGA/WRI), que aprecia o desempenho financeiro geral de diferentes opções de investimento em infraestruturas natural (verde) e convencional (cinza), examina cada uma das prioridades comuns identificadas pelas partes interessadas locais e provê recomendações para o projeto (Gray et al., 2019).

O capítulo a seguir discute os resultados dessa avaliação, mostrando o potencial estratégico da combinação das infraestruturas natural e convencional. O Capítulo 3 apresenta os resultados da análise de sensibilidade, fornecendo recomendações e insights sobre as Demandas 2, 3 e 4 da lista de prioridades elencadas pelos agentes locais consultados. 
Para avaliar o desempenho financeiro de opções de investimento em infraestrutura, incluindo as de infraestrutura natural, aplicou-se a Avaliação de Investimento em Infraestrutura Natural para Água (GGA) WRI). Esse é um método conceitual para analisar como a infraestrutura natural (verde) pode complementar e auxiliar a infraestrutura convencional (cinza) na produção de bens e serviços para as comunidades (Gray et al,, 2019).

Cada etapa da GGA/WRI é resumida abaixo e discutida ao longo deste estudo:

1. Define o objetivo do investimento: esta análise definiu como objetivo a maximização do retorno sobre 0 investimento (ROI) nas estratégias de controle de sedimentos ao longo de 20 anos, refletindo a tomada de decisão típica da gestão da água.

2. Especifica portfólios de investimento: as partes interessadas locais consideram plausível a meta de restauração de 2.500 hectares em pastagens com alto nível de degradação, identificando o horizonte de seis anos para implementação.
Desse total, 1.600 hectares no projeto do Jucu e 900 hectares no projeto do SMV. Adotou-se o Modelo de Produção de Sedimentos InVEST para identificar as pastagens com maior nível de produção de sedimentos como as áreas mais erodidas a serem priorizadas (Sharp et al, 2016).

3. Estima resultados biofísicos: utilizouse o Modelo de Produção de Sedimentos InVEST para estimar as taxas de retenção de sedimentos da paisagem em cada portfólio. Em seguida, essas taxas foram convertidas em medidas de qualidade da água e volumes de sedimentos capturados no reservatório.

4. Avalia custos e benefícios: calcularam-se os custos totais do projeto de cada portfólio de investimentos, considerando custos iniciais, custos de transação e custos de oportunidade. Calcularam-se ainda os possíveis custos evitados de cada portfólio (ou seja, benefícios) em termos de tratamento de água e desgaste de equipamentos (representado por depreciação).
5. Compara custos e benefícios entre portfólios: aplicando uma taxa de desconto de $8,5 \%$, que reflete 0 custo médio ponderado do capital (WACC) para a maioria das concessionárias de água no Brasil, foram examinados e comparados os desempenhos de cada portfólio de investimentos em termos de valor presente líquido (VPL), retorno sobre o investimento (ROI), período de retorno (payback) e taxa interna de retorno (TIR).

6. Analisa riscos: como esse projeto pode atrair uma série de investidores públicos e privados no setor hídrico, com diferentes limites de aversão a riscos, variou-se a taxa de desconto de $5 \%$ a $12 \%$ ao ano, representando 0 prêmio de risco do Brasil. Avaliou-se a sensibilidade de nossos resultados a algumas das variáveis mais incertas em nossa análise, a saber: a capacidade das florestas nativas de controlar a erosão, o custo de oportunidade da terra e os custos de restauração florestal.

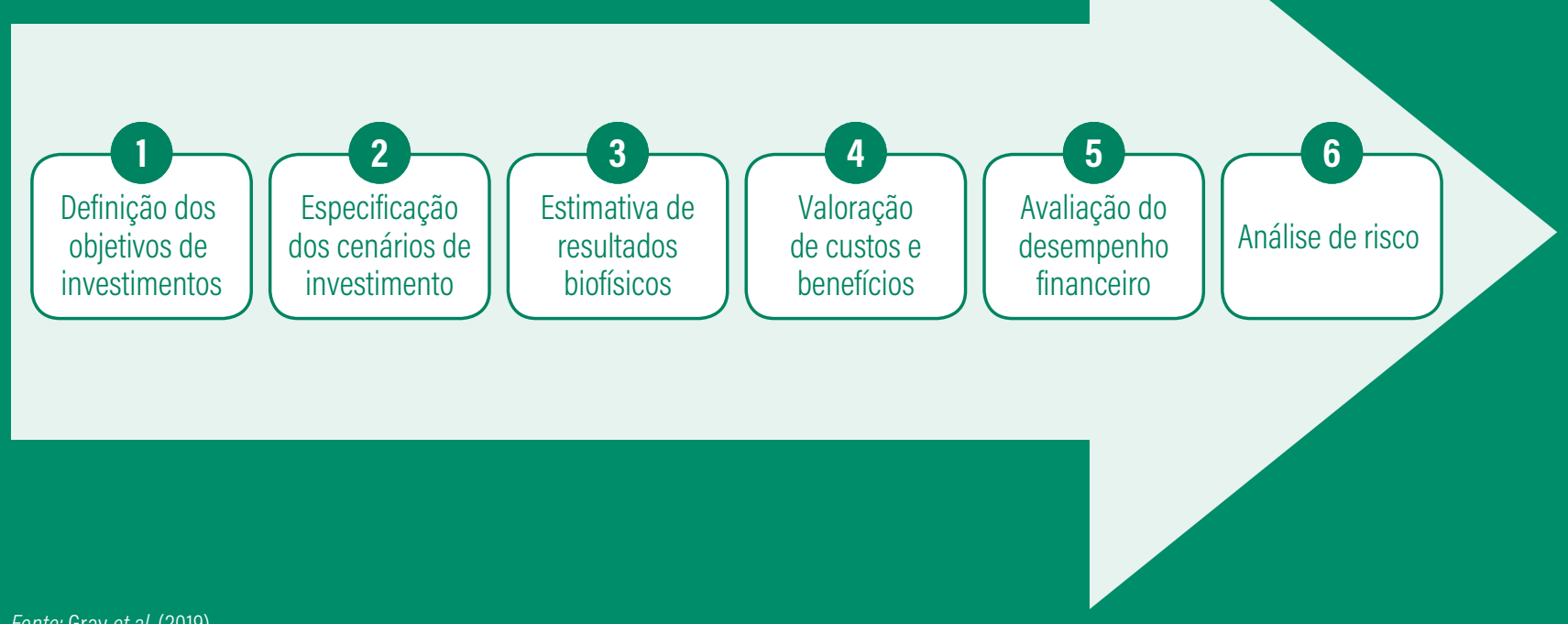

Fonte: Gray et al. (2019). 


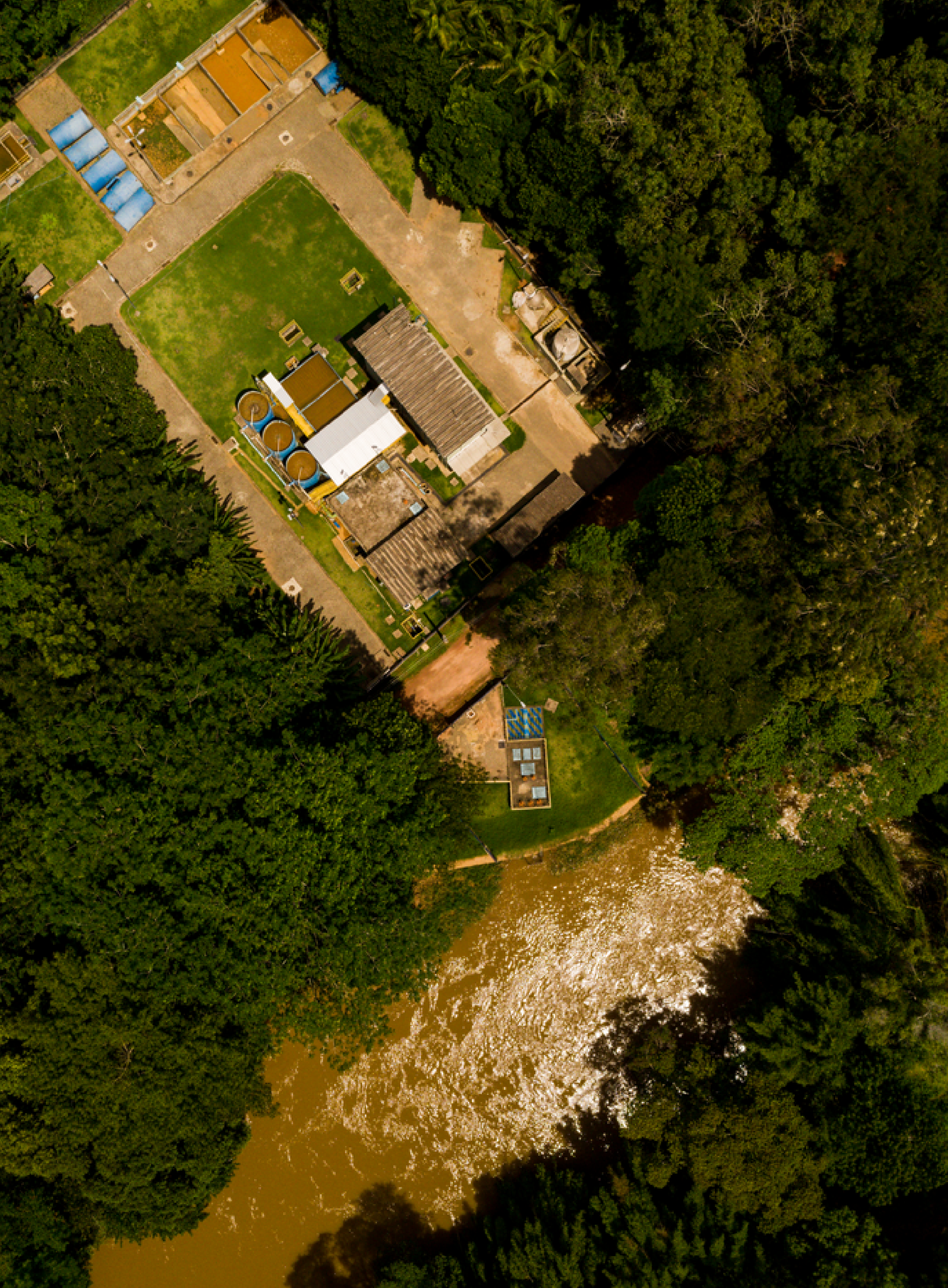


CAPÍTULO ॥

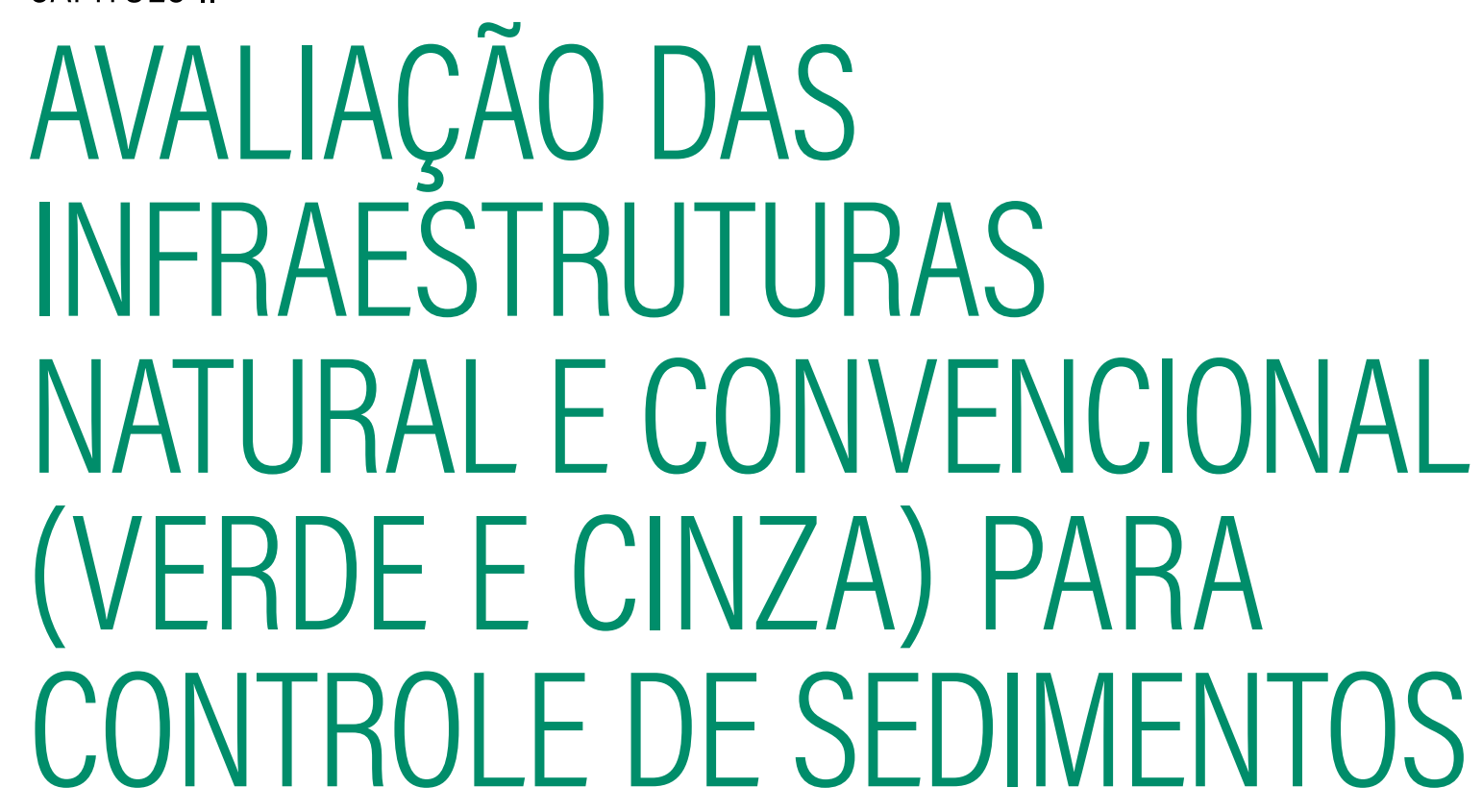

Este capítulo resume os cenários de investimentos, os resultados biofísicos estimados e o desempenho financeiro em termos de custos evitados no tratamento de água decorrentes da implementação da infraestrutura natural. Também destaca insights para subsidiar programas de infraestrutura natural e apoiar decisões de investimento. Por fim, avalia os impactos da restauração nas Bacias do Jucu e do SMV separadamente e agrega os resultados para refletir custos e benefícios para toda a RMGV. 
A fim de estimar os custos da implantação da infraestrutura natural, tomou-se por base $o$ Programa Reflorestar em dois tipos de restauração: restauração ativa (plantio completo) e regeneração natural. Adicionou-se o custo de oportunidade da terra como equivalente aos valores anuais praticados pelo Reflorestar no âmbito da modalidade de PSA. Foram incluídos também custos de transação equivalentes a $1 \%$ sobre o valor total dos investimentos. Optou-se por percentual baixo uma vez que projetos em andamento já planejam cobrir o envolvimento dos agricultores e a extensão rural que poderiam ser considerados como custos de transação, a exemplo dos quase R \$ 350 milhões do Programa de Gestão Integrada das Águas e Paisagens e do Florestas para a Vida, reservados para esse fim (Sossai, 2020).

Os custos de mão de obra associados à restauração não foram contabilizados porque o Programa Reflorestar exige que os produtores participantes cubram esses custos como contrapartida.

Entretanto, no Capítulo 3 deste estudo, dedicado à análise de sensibilidade, foram incluídos os custos de mão de obra para avaliar eventuais impactos na performance financeira dos cenários.

\section{Objetivos de investimento em infraestrutura natural (Passo 1)}

O objetivo de investimento em infraestrutura natural foi reduzir os custos da gestão de sedimentos (especialmente os custos incorridos devido à turbidez) via restauração de pastagens com alto grau de degradação, evidenciados pela erosão, em um horizonte de 20 anos.

\section{Cenários de investimento (Passo 2)}

Para cada bacia (Jucu e SMV), foram lançados cenários com e sem restauração florestal para comparar custos e benefícios decorrentes da infraestrutura natural. Para o Jucu, foi também desenhado um cenário com os impactos esperados da construção do reservatório dos Imigrantes. A avaliação do desempenho da infraestrutura natural na UGRH Litoral Central foi tomada como a agregação dos resultados obtidos para cada uma das bacias, conforme descrito nas Tabelas 4, 5 e 6 .

Tabela 3 | Custos estimados de restauração ativa e regeneração natural

INTERVENÇõES E INVESTIMENTOS

Restauração ativa (total)

Cercamento

Preparação do solo

Controle de formigas e pragas

Agroquímicos

Transporte de mudas

Compra de mudas

Plantio

Custos de transação

Custos de oportunidade da terra (PSA)

Regeneração natural (total)

Cercamento

Custos de transação

Custo de oportunidade da terra (PSA)
CUSTO (RS/HA)

19.543

3.500

576

198

771

84

2.267

3.270

3.257

5.620

10.534

3.438

1.756

5.340

Fonte: Elaborada pelos autores. 
Tabela 4 | Cenários de investimento na Bacia do Jucu

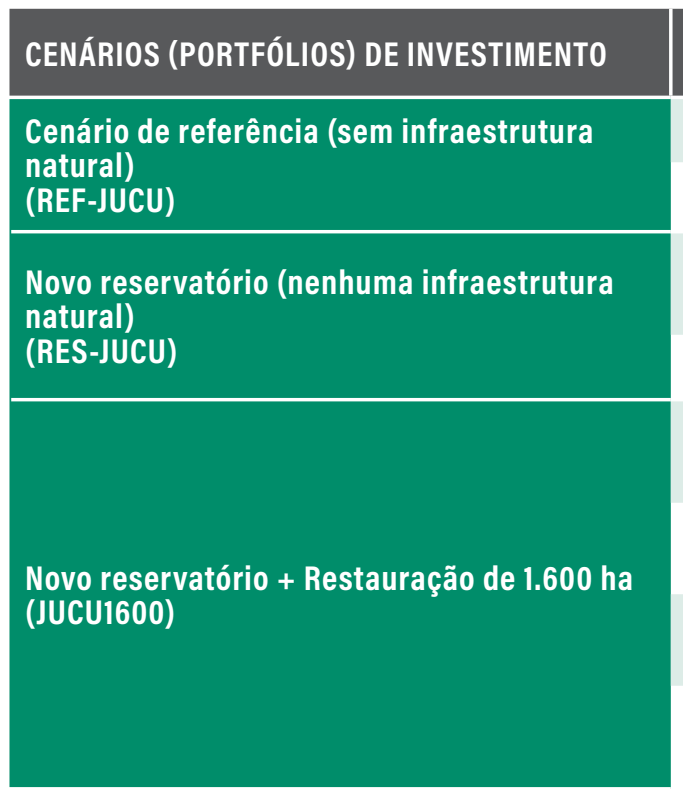

\section{DESCRIÇÃO E PREMISSAS}

Infraestrutura convencional mantida

Nenhum investimento em restauração florestal

Reservatório dos Imigrantes entra em operação. Toda demanda adicional por água é atendida pelas estruturas existentes combinadas com o reservatório

Nenhum investimento em restauração florestal

Reservatório dos Imigrantes entra em operação. Toda demanda adicional por água é atendida pelas estruturas existentes combinadas com o reservatório

Investimento em restauração florestal ocorre nos 1.600 ha de pastagens com maior nível de produção de sedimentos

67\% das áreas prioritárias são recuperadas através de restauração ativa (plantio total) e 33\% são restauradas por regeneração natural

A restauração florestal ocorre em 3 anos, sendo restaurados 360 ha (Ano 1), 720 ha (Ano 2) e 520 ha (Ano 3)

Fonte: Elaborada pelos autores.

Tabela 5 | Cenários de investimento na Bacia do SMV

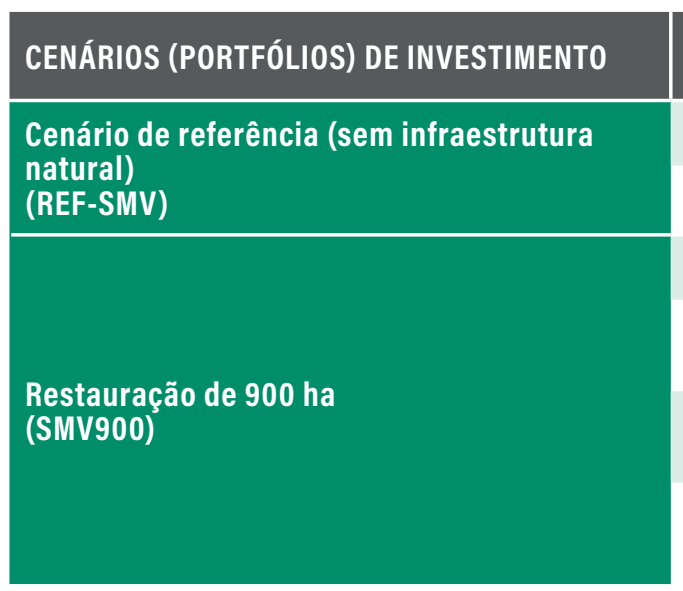

\section{DESCRIÇÃO E PREMISSAS}

Infraestrutura convencional mantida

Nenhum investimento em restauração florestal

Infraestrutura convencional mantida

Investimento em restauração florestal ocorre nos 900 ha de pastagens com maior nível de produção de sedimentos

67\% das áreas prioritárias são recuperadas através de restauração ativa (plantio total) e 33\% são restauradas por regeneração natural

A restauração florestal ocorre em 3 anos, sendo restaurados 200 ha (Ano 1), 400 ha (Ano 2) e 300 ha (Ano 3)

Fonte: Elaborada pelos autores.

Tabela 6 | Cenários de investimento na UGRH Litoral Central (Jucu + SMV)

\begin{tabular}{l} 
CENÁRIOS (PORTFÓLIOS) DE INVESTIMENTO \\
\hline Cenário de referência (REF-LC) \\
\hline Novo reservatório (RES-LC) \\
\hline $\begin{array}{l}\text { Novo reservatório + Restauração de } 2.500 \text { ha } \\
\text { (LC2500) }\end{array}$ \\
\hline
\end{tabular}

\section{DESCRIÇÃO E PREMISSAS}

REF-JUCU + REF-SMV

RES-JUCU + REF-SMV

JUCU1600 + SMV900

Fonte: Elaborada pelos autores. 


\begin{tabular}{lccc} 
CUSTOS OPERACIONAIS (RS/ $\left.\mathbf{M}^{3}\right)$ & & \\
Operação & REF-JUCU & RES-JUCU & REF-SMV \\
\hline Tratamento químico & 9,50 & 8,61 & 9,88 \\
\hline Reposição de areia filtrante & 0,06 & 0,05 & 0,05 \\
\hline Reposição de antracito & 0,09 & 0,08 & 0,09 \\
\hline Dragagem e retirada de lodo & 2,77 & 2,50 & 2,70 \\
\hline Energia elétrica & 15,43 & 13,91 & 15,72 \\
\hline TOTAL & $\mathbf{2 7 , 8 5}$ & $\mathbf{2 5 , 1 5}$ & $\mathbf{2 8 , 4 4}$ \\
\hline Depreciação & 1,71 & 1,91 & 1,76 \\
\hline
\end{tabular}

Fonte: Elaborada pelos autores, a partir de informações compiladas de Pagiola, Platais e Sossai (2019), Cesan (2020), Pagiola (2020).

Em todos os cenários, foram considerados constantes os fatores climáticos, enquanto que as demandas por água foram assumidas como uma função do crescimento populacional e da elasticidade do consumo, resultando demandas próximas às previstas no PERH-ES (AGERH e Seama, 2018). Assumiu-se também que não haveria desmatamento ou qualquer outra mudança drástica no uso e cobertura do solo, com exceção das áreas restauradas para os projetos de infraestrutura natural.

Sabe-se que a demanda futura da RMGV por água pode ser atendida por outras bacias hidrográficas utilizando tecnologias muito diferentes das disponíveis atualmente. A despeito disso, considerou-se que a demanda deve ser atendida pela UGRH Litoral Central com tecnologias e custos compatíveis com as atuais, a fim de medir o impacto potencial da infraestrutura natural evitando variáveis exógenas. Sabe-se também que os custos operacionais de cada ETA podem variar sensivelmente, mas considerou-se que as três ETAs no Jucu teriam custos operacionais idênticos, o mesmo valendo para as duas ETAs do SMV. Diferenciaram-se os custos entre ETAs das diferentes bacias apenas pelo nível corrente de turbidez de cada uma delas, sem efeito de escala ou tecnologia. A Tabela 7 descreve os custos aplicados aos cenários referenciais (REF-JUCU, RES-JUCU e REF-SMV). 


\section{Os benefícios da restauração na} diminuição da sedimentação (Passo 3)

0 Jucu e o SMV poderiam ser significativamente beneficiados pela combinação das infraestruturas natural e convencional

Utilizando o modelo InVEST, identificou-se que, entre os 1.600 hectares prioritários para restauração, 1.200 hectares estão na região a montante do local de construção do novo reservatório e 400 hectares na porção entre esse reservatório e pontos atuais de captação de água. O modelo InVEST prevê que esses 1.600 hectares são responsáveis atualmente por cerca de $26 \%$ da produção de sedimentos provenientes de pastagens degradadas da Bacia do Jucu.

Atualmente, no cenário REF-JUCU, o total de sedimentos exportados para a Bacia do Jucu foi estimado em aproximadamente 30 mil toneladas por ano. Desse total, 26,3 mil toneladas são produzidas na porção que estaria postada acima do reservatório planejado e 3,3 mil toneladas na porção abaixo. Como essas porções são contíguas, a concentração média de sólidos em suspensão no Jucu foi estimada em cerca de 45 miligramas por litro e uma turbidez média de 34 Unidades Nefelométricas de Turbidez (UNT). Com a construção do reservatório dos Imigrantes, e supondo que $32 \%$ dos sedimentos a montante fiquem retidos, a concentração média de sólidos em suspensão que fluiriam para os pontos de captação das ETAs cairia para 32 miligramas por litro e a turbidez média ficaria em 23 UNT.

Não obstante, à medida que os sedimentos se acumulariam no novo reservatório, novas operações de manutenção seriam necessárias para evitar queda de performance ou diminuição da vida útil, implicando novas contas de depreciação e custos de

Figura 5 | Áreas prioritárias para restauração no Jucu (cenário JUCU1600)

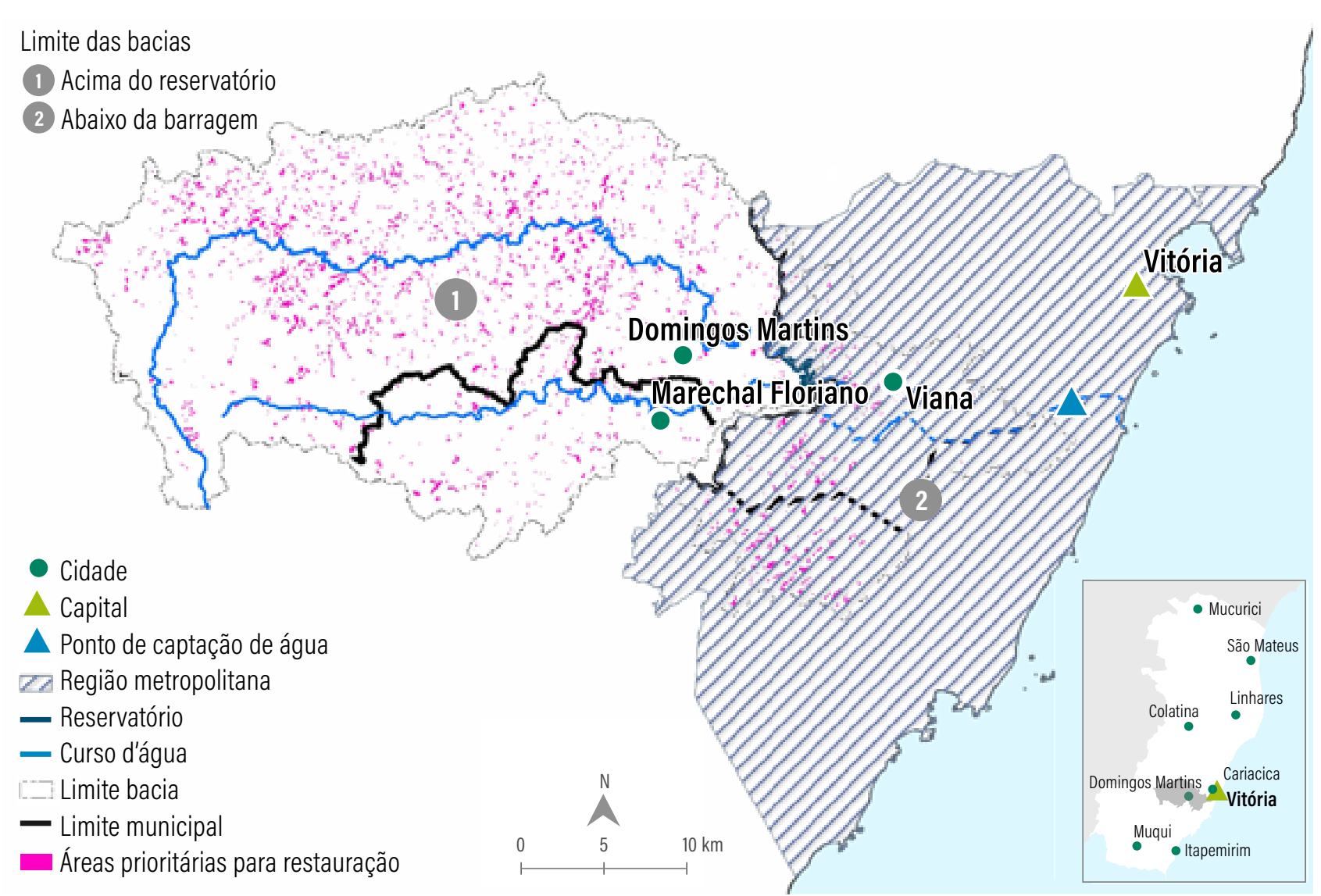

Fonte: Elaborada pelos autores. Para detalhes, ver Apêndice B. 
manutenção. A depreciação do capital imobilizado na represa e de todos os seus equipamentos e construções, bem como a provisão de recursos para contenção de assoreamento ou dragagem, elevariam as contas de depreciação em até $7,7 \%$ ao final de 20 anos.

\section{A infraestrutura natural reduziria a turbidez em 27\% para além do que seria possível apenas com o novo reservatório}

Com a restauração de 1.600 hectares em áreas prioritárias (pastagens altamente degradadas), o total de sedimentos exportados da paisagem para os cursos d'água da Bacia do Jucu diminuiria 6\% em 20 anos. Isso reduziria de forma significativa a turbidez em 9\%, além das reduções obtidas com a instalação do reservatório. Notavelmente, essas reduções no potencial de exportação de sedimentos seriam ainda mais relevantes após o horizonte de tempo deste estudo, atingindo até $10 \%$ a partir do $40^{\circ}$ ano. Isso ocorre porque são necessários cerca de 40 anos para as florestas restauradas na Mata Atlântica recuperarem sua estrutura à semelhança de florestas clímax (Poorter et al., 2016). Embora presuma-se que os serviços de controle de erosão devam se desenvolver da mesma forma, apreciando ainda mais a estrutura natural e oferecendo maior capacidade de filtragem, foram considerados nesta análise os resultados obtidos até o $20^{\circ}$ ano como análises conservadoras. A Tabela 8 mostra prováveis níveis de sedimentos evitados em 20 anos nos diferentes cenários.
No SMV, a restauração de 900 hectares poderia reduzir a produção de 1.975 toneladas de sedimento por ano e reduzir a turbidez em $5 \%$

Atualmente, no cenário REF-SMV, o total de sedimentos exportados para a Bacia do SMV foi estimado em aproximadamente 36 mil toneladas por ano, com concentração média de sólidos em suspensão de cerca de 70 miligramas por litro e turbidez de 39 UNT. Com a restauração florestal dos 900 hectares de pastagens altamente degradadas, a exportação de sedimentos cairia para média de 34 mil toneladas por ano, baixando a concentração de sólidos suspensos para 66 miligramas por litro e turbidez para 37 UNT.

Os 900 hectares prioritários para restauração florestal com ênfase em solos erodidos são atualmente responsáveis por cerca de $31 \%$ da produção de sedimentos provenientes de pastagens da Bacia do SMV. Ao longo do horizonte de 20 anos, um total de 40 mil toneladas de sedimentos deixariam de ser produzidas. A Tabela 9 indica as mudanças que poderiam ser esperadas com a restauração florestal.

Tabela 8 | Sedimentos exportados, sólidos suspensos e turbidez, nos cenários REF-JUCU, RES-JUCU e JUCU1600

\begin{tabular}{|c|c|c|c|c|}
\hline RESULTADOS BIOFÍSICOS & REF-JUCU & RES-JUCU & JUCU1600 & $\begin{array}{l}\text { MUDANÇAS (JUCU1600 EM } \\
\text { RELAÇẪO AO REF-JUCU) }\end{array}$ \\
\hline Sedimento total exportado para a bacia (toneladas/ano) & 29.659 & 29.659 & 27.871 & $-6 \%$ \\
\hline $\begin{array}{l}\text { Sedimento total exportado para os pontos de captação } \\
\text { (toneladas/ano) }\end{array}$ & 29.659 & 21.232 & 19.445 & $-34 \%$ \\
\hline Sólidos suspensos totais na captação (mg/L) & 45 & 32 & 29 & $-36 \%$ \\
\hline Turbidez na captação (UNT) & 34 & 23 & 20 & $-41 \%$ \\
\hline
\end{tabular}

Fonte: Elaborada pelos autores.

Nota: A exportação de sedimentos se refere à quantidade que a paisagem produz e não é afetada pela criação de um reservatório. Portanto, os cenários REF-JUCU e RES-JUCU experimentam as mesmas taxas de exportação de sedimentos em toda a bacia. Média de sedimentos exportados estimada em 20 anos, considerando 0 intervalo de tempo associado aos cronogramas de implementação e o tempo necessário para a floresta crescer e atingir a maturidade (para detalhes, ver Apêndice C). 


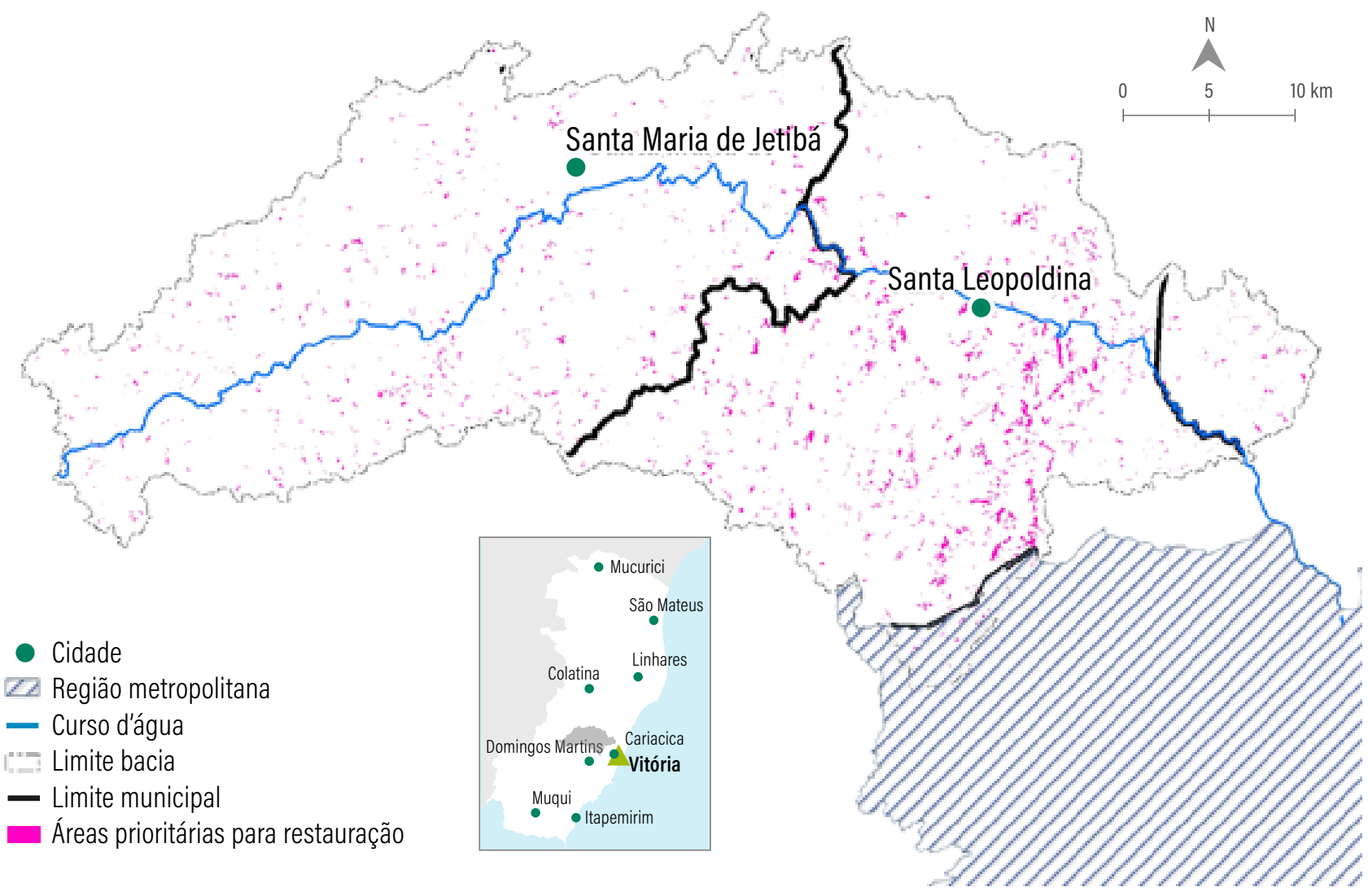

Fonte: Elaborada pelos autores.

Tabela 9 | Sedimentos exportados, sólidos suspensos e turbidez, nos cenários REF-SMV e SMV900

\begin{tabular}{|c|c|c|c|}
\hline RESULTADOS BIOFÍSICOS & REF-SMV & SMV900 & $\begin{array}{l}\text { MUDANÇAS (SMV900 EM } \\
\text { RELAÇÄO AO REF-SMV) }\end{array}$ \\
\hline Sedimento total exportado para a bacia (toneladas/ano) & 36.000 & 34.025 & $-5 \%$ \\
\hline Sedimento total exportado para os pontos de captação (toneladas/ano) & 36.000 & 34.025 & $-5 \%$ \\
\hline Sólidos suspensos totais na captação (mg/L) & 70 & 66 & $-6 \%$ \\
\hline Turbidez na captação (UNT) & 39 & 37 & $-5 \%$ \\
\hline
\end{tabular}

Fonte: Elaborada pelos autores. 
Custos e benefícios econômicos da restauração (Passo 4)

\section{A infraestrutura natural na Bacia do Jucu custaria $\mathrm{R} \$$ 21,8 milhões em 20 anos}

Com base no Programa Reflorestar (Seama, 2020; Sossai, 2020), o custo total da restauração de 1.600 hectares na Bacia do Jucu seria de aproximadamente $\mathrm{R} \$ 21,8$ milhões, com valores incorridos principalmente durante os primeiros três anos de investimento na implementação da restauração. Como mencionado anteriormente, o Programa Reflorestar oferece pagamentos únicos aos agricultores participantes a fim de cobrir os custos de conversão de pastagens para florestas naturais. Até a conclusão deste relatório, os pagamentos previstos para o investimento em conversão de pasto via restauração ativa eram de $\mathrm{R}$ \$ 10.666 por hectare, enquanto os de restauração por regeneração natural eram de $\mathrm{R} \$ 3.438$ por hectare (Seama, 2020).

Com base em mapas de potencial de regeneração natural (ver Apêndice C), estimou-se que dois terços das áreas prioritárias do JUCU160o precisariam ser restauradas ativamente (plantio) devido à grande distância em relação a fragmentos remanescentes, bancos de sementes florestais existentes e outros atributos que dificultariam a regeneração natural. O outro terço, no entanto, foi identificado como de alto potencial para regeneração natural, assumindo-se, portanto, que poderia contar com esse método passivo de restauração. Com relação aos custos de oportunidade da terra, o Reflorestar também paga anualmente aos agricultores participantes pelos serviços ecossistêmicos com o intuito de compensar os custos de oportunidade perdidos na transição de suas terras de pastagens para florestas naturais. Os PSA previstos, até a conclusão deste relatório, eram de $\mathrm{R} \$ 281$ por hectare por ano para locais restaurados de forma ativa e $\mathrm{R} \$ 267$ por hectare por ano para regeneração natural (Seama, 2020).

Custos de transação, como, por exemplo, custos de engajamento de proprietários rurais, de monitoramento de resultados e de administração geral do programa, também devem ser levados em conta. Considera-se que esses custos correspondiam a apenas $1 \%$ dos custos totais de infraestrutura natural. Somando os investimentos iniciais necessários, custos de oportunidade e custos de transação, a restauração ativa custaria cerca de $\mathrm{R}$ \$ 19,5 mil por hectare, enquanto a regeneração natural custaria $\mathrm{R} \$ 10,5$ mil por hectare.

Importante salientar que esses são valores médios devido à restauração florestal ser implantada ao longo de três anos, sendo que, nas áreas implementadas logo no primeiro ano, os custos de oportunidade e transação incidiram por 20 anos; enquanto que nas áreas implementadas no terceiro ano, tais valores seriam aplicados por 18 anos.

\section{A restauração pode reduzir significativamente os custos de tratamento de água na Bacia do Jucu}

Os custos estimados do tratamento de turbidez da água para os três cenários mostram que o novo reservatório economizaria $\mathrm{R} \$ 48,7$ milhões no tratamento de água, em 20 anos, mas acrescentaria $\mathrm{R} \$ 5$ milhões em depreciação de capital pela compensação de perda de capacidade de reservação. Ao funcionar como um tanque de sedimentação, reduziria o total de sólidos em suspensão que fluiriam para as estações de tratamento, mas acumularia os sedimentos em sua estrutura. Ainda assim, o benefício líquido obtido seria positivo em $\mathrm{R} \$$ 43,7 milhões. Conciliando a construção do novo reservatório com a restauração da infraestrutura natural (cenário JUCU160o), a economia no tratamento de turbidez da água aumentaria significativamente para $\mathrm{R} \$ 55,2$ milhões, e a depreciação evitada seria de $\mathrm{R} \$ 10,7$ milhões pela diminuição de abrasividade dos equipamentos de tratamento e assoreamento evitado do reservatório. Benefícios totalizariam $\mathrm{R} \$$ 65,9 milhões em relação ao referencial, ou $\mathrm{R} \$ 22$ milhões adicionais ao cenário com reservatório, conforme se pode deduzir da Figura 7.

No horizonte de 20 anos do projeto, a demanda por água tratada seria equivalente a 3,4 bilhões de metros cúbicos (4,6 metros cúbicos por segundo no início do projeto e 6,0 metros cúbicos no último ano). Enquanto no cenário referencial há consumo total de 111 mil toneladas de produtos químicos (policloreto de alumínio - PAC, sulfato de alumínio, cal e hidróxido de cálcio), o que significa um consumo médio de 33,3 gramas por metro cúbico, no cenário JUCU160o, esse consumo cairia para 32,6 gramas por metro cúbico, correspondendo a uma economia de 2,4 mil toneladas. Já para os sistemas de bombeamento e filtragem, cuja 
Figura 7 | Custos de tratamento de água por grupo de custo e cenário na Bacia do Jucu, horizonte de 20 anos

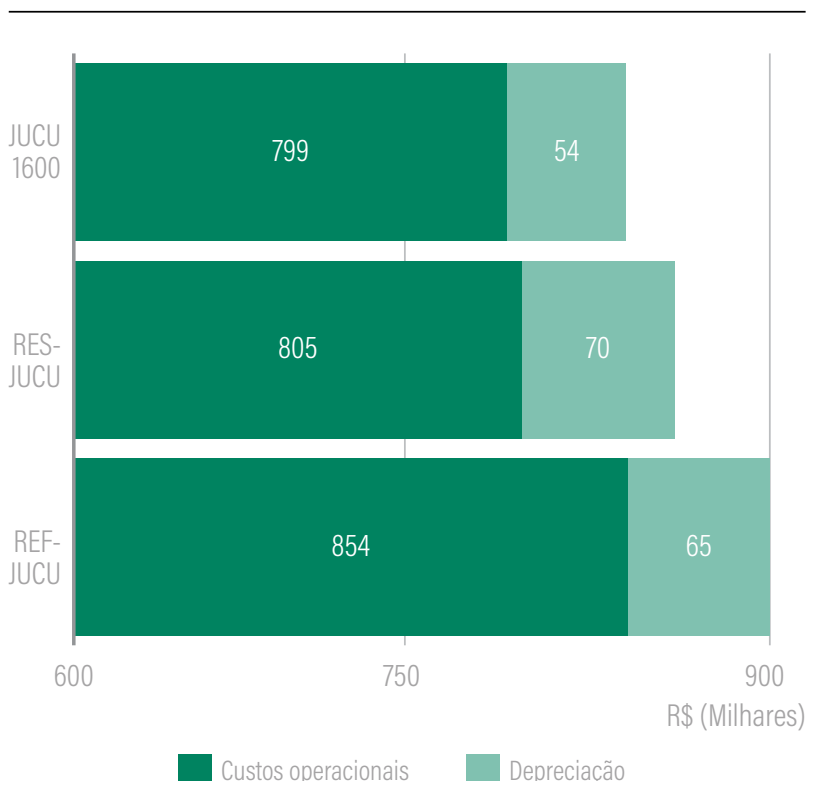

Fonte: Elaborada pelos autores. Para detalhes, ver Apêndice C

eficiência depende da densidade da água tratada (Pagiola, 2020), o consumo médio de energia cairia dos atuais 139 Megawatt-hora/mil metros cúbicos $\left(\mathrm{MWh} / \mathrm{mil} \mathrm{m}^{3}\right.$ ) para $135 \mathrm{MWh} / \mathrm{mil} \mathrm{m}^{3}$, gerando uma economia de 13,5 Gigawatt-hora em 20 anos (para detalhes, ver Apêndice C).

Esses resultados mostram claramente que a infraestrutura natural poderia funcionar como uma estrutura auxiliar, aumentando a eficiência da infraestrutura convencional no controle de sedimentos, melhorando a qualidade da água na Bacia do Jucu e potencializando os custos evitados com tratamento de água. A estratégia de restaurar florestas em concomitância com a construção do reservatório para aumentar a segurança hídrica, e ainda controlar os sedimentos, não apenas aborda simultaneamente os dois principais problemas no gerenciamento da água, como também é um projeto cujo desempenho financeiro é superior. O desgaste de equipamentos e as taxas de depreciação também têm uma leve redução, em função de uma água com menos sólidos suspensos - e, portanto, menos abrasiva - do que no cenário referencial.

Para tanto, o cenário JUCU160o teria um custo total de $\mathrm{R} \$ 21,8$ milhões, mas benefícios líquidos de $\mathrm{R} \$ 65,9$ milhões, considerando valores atuais. Para um horizonte de 20 anos, utilizando uma taxa de desconto de 8,5\% ao ano, o JUCU160o geraria um VPL de R \$ 9,7 milhões e uma TIR de 15,2\%. Os resultados mostram que, apesar de parecer uma mudança discreta, o impacto positivo na economia de produtos químicos e de energia seria relevante.

\section{A restauração pode reduzir significativamente 0 consumo de produtos químicos e de energia na Bacia do SMV}

Na Bacia do SMV, o consumo atual de produtos químicos foi estimado em 38,2 gramas por metro cúbico, enquanto o consumo de energia, em 157 $\mathrm{MWh} / \mathrm{mil} \mathrm{m}^{3}$. Com a restauração dos 900 hectares, os consumos cairiam, respectivamente, para 34,5 gramas por metro cúbico e $154 \mathrm{MWh} / \mathrm{mil}$ $\mathrm{m}^{3}$, resultando em economia de mil toneladas de produtos químicos e $6 \mathrm{GWh}$, vez que o volume de água tratada no período de 20 anos foi estimado em 2,1 bilhões de metros cúbicos (tratamento de 2,8 metros cúbicos por segundo no início do projeto e de 3,7 metros cúbicos por segundo ao final dos 20 anos).

Embora pareçam modestos, os benefícios da restauração florestal ao longo de 20 anos somariam R $\$ 27$ milhões em termos de custos evitados com tratamento da turbidez - produtos químicos, reposição de elementos filtrantes e energia elétrica - e desgaste e depreciação de equipamentos. A restauração florestal exigiria investimentos e custos de manutenção dos projetos da ordem de $\mathrm{R} \$ 12,3$ milhões, gerando benefícios líquidos de $\mathrm{R} \$ 14,8$ milhões.

Figura 8 | Custos de tratamento de água por grupo de custo e cenário na Bacia do SMV, horizonte de 20 anos

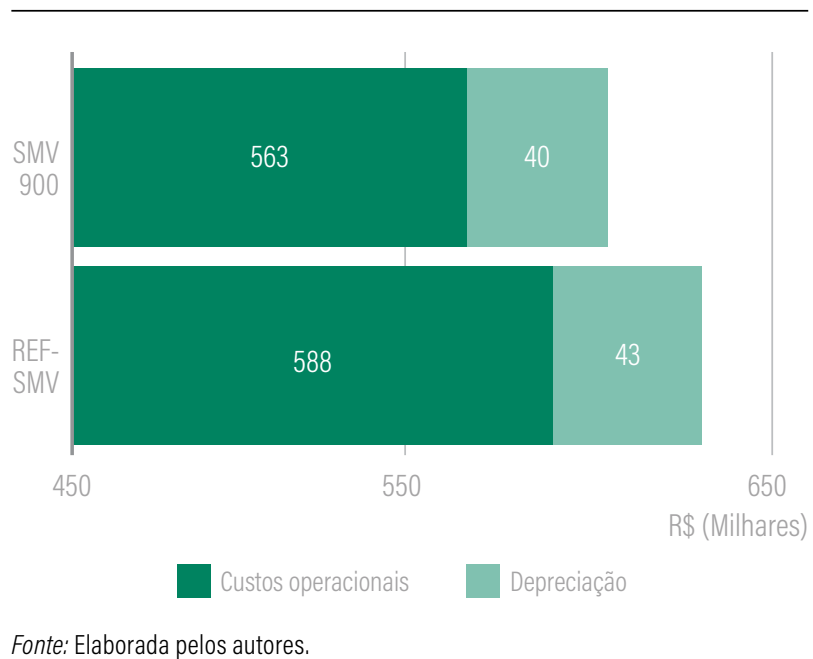

Fonte: Elaborada pelos autores. 


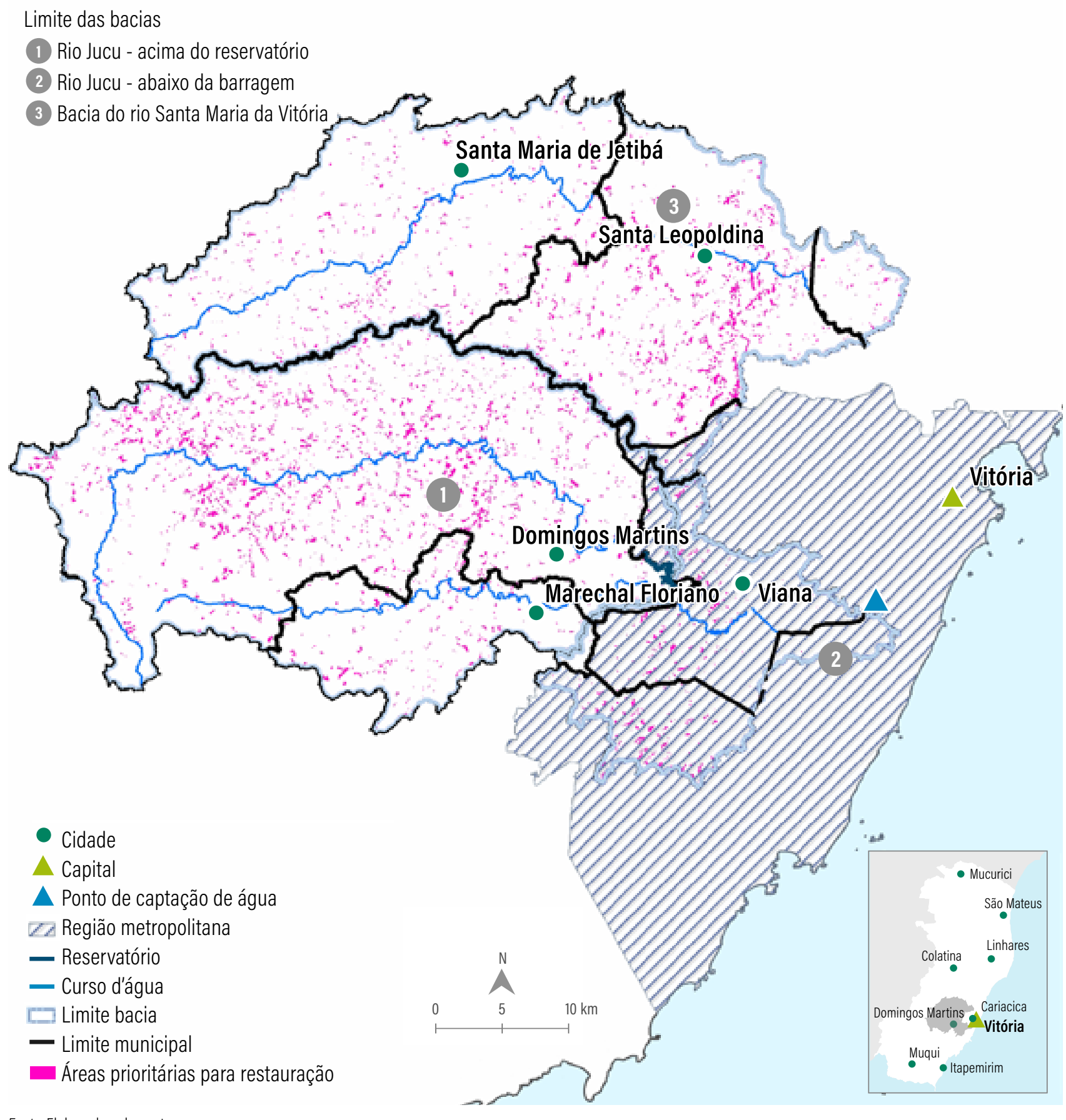

Fonte: Elaborada pelos autores. 


\section{Benefícios para toda a UGRH Litoral Central}

As restaurações das duas bacias que compõem a UGRH Litoral Central podem ser feitas de maneira independente, em ritmos que respeitem as deliberações dos respectivos comitês e urgências das partes interessadas, bem como podem ser limitadas às restrições orçamentárias que cada uma deve enfrentar separadamente.

Entretanto, como abordado anteriormente, esforços de promover a restauração conjunta já têm sido a tônica da restauração na região, desde as ações planejadas pelo Programa de Gestão Integrada das Águas e Paisagens, Programa Reflorestar, PERH-ES e o projeto Florestas para a Vida. Ações simultâneas são importantes para que se possa compartilhar aprendizados, potencializar ganhos de escala e, principalmente, beneficiar o maior número de moradores da RMGV.

Do ponto de vista da identificação das áreas prioritárias para a restauração, bem como da quantificação dos custos e benefícios do tratamento de água, os resultados para a UGRH Litoral Central correspondem à agregação daqueles obtidos para cada uma das bacias, respeitando as particulares características biofísicas e de atributos operacionais das estações de tratamento de água. Para além disso, a visão geral dos resultados é importante a fim de que tomadores de decisão, comunidade da RMGV e gerenciadores dos planos, programas e projetos possam entender melhor os impactos concomitantes das intervenções.

Nota-se que a distribuição dos 2.500 hectares prioritários para restauração não apresenta ruptura perceptível entre as bacias, sugerindo uma paisagem relativamente homogênea, sinalizando que as ações no interior da UGRH Litoral Central poderiam ser em boa medida concatenadas, especialmente ao longo dos limites de suas divisões administrativas. Chama atenção também a concentração de áreas prioritárias nas porções leste das duas bacias, formando um cinturão prioritário no entorno da área urbana da RMGV, que poderia conformar um arco de restauração. Esse arco teria como pontos de referência o ribeirão Juara, no extremo norte, seguindo a oeste para Mangaraí, São Paulo de Cima, Biriricas de Baixo, Glória e, fechando ao sul, a região de Rio Calçado.
Considerando os custos de restauração conforme os valores de referência do Programa Reflorestar, adicionando-se os PSA a serem desembolsados anualmente à guisa de custo de oportunidade da terra e custos de transação, o custo total do projeto de infraestrutura natural na UGRH Litoral Central totalizaria R \$ 34,1 milhões. Esse valor corresponde a pouco mais de $10 \%$ do orçamento previsto pelo projeto Florestas para a Vida ao componente destinado à recuperação de nascentes, matas ciliares e zonas de recarga de aquífero. Desse total, $\mathrm{R} \$$ 20,8 milhões deveriam ser desembolsados nos três primeiros anos para implantação da restauração, enquanto aproximadamente $\mathrm{R} \$ 14$ milhões seriam despendidos em pagamentos equivalentes ao arrendamento da terra ou PSA e transação.

A infraestrutura natural materializada na restauração dos 2.500 hectares seria capaz de poupar o uso de 35 mil toneladas de produtos químicos (PAC, sulfato de alumínio, cal e hidróxido de cálcio), além de economizar 19,5 GWh de energia elétrica. Os custos evitados com tratamento de turbidez (produtos químicos, filtrantes e disposição de lodo) somariam R \$ 20,2 milhões, a depreciação evitada do capital imobilizado (incluindo a do reservatório dos Imigrantes) e desgastes de equipamentos foram estimados em $\mathrm{R} \$ 13$ milhões e a economia de energia elétrica em R \$ 59,6 milhões, totalizando benefícios de $\mathrm{R} \$$ 92,9 milhões em 20 anos.

Existe um grande desequilíbrio ao longo do projeto não apenas porque os três anos iniciais absorvem mais de $60 \%$ de todo o custo, em função da implementação da restauração, mas também porque a floresta restaurada leva cerca de 40 anos para adquirir estrutura capaz de prover todo seu potencial de retenção de sedimentos (ver Apêndice C). O descompasso esperado entre entradas e saídas de caixa implicam maior penalização dos benefícios pelas taxas de desconto nos fluxos de caixa. Ainda assim, a infraestrutura natural na UGRH Litoral Central geraria um VPL de R \$ 11,1 milhões, sob taxa de desconto de $8,5 \%$ ao ano e TIR de $13,9 \%$, compatível com investimentos em estruturas convencionais. O projeto de infraestrutura natural é viável e deveria ser considerado nos planos e programas de segurança e melhoria da qualidade da água para a população da RMGV. 
Figura 10 | Painel de desempenho da infraestrutura natural no cenário LC2500, no horizonte de 20 anos

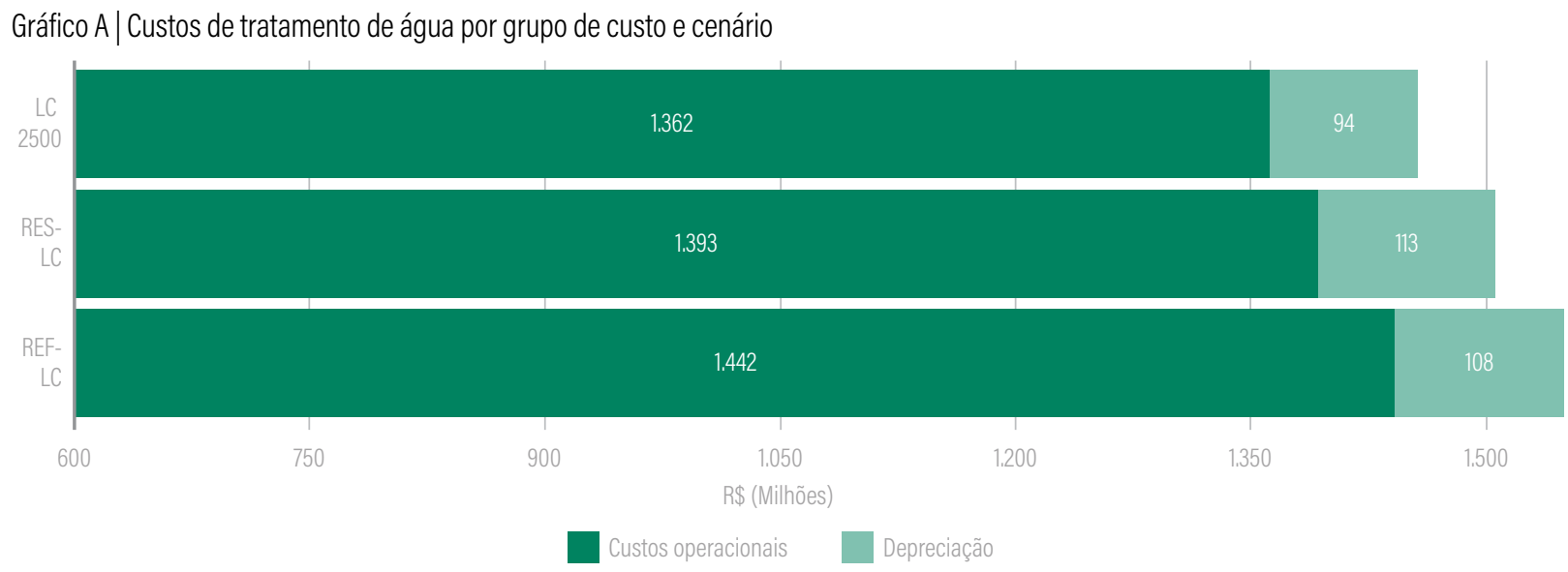

Gráfico B | Turbidez (UTN) e custos ( $\mathrm{R} \$ / \mathrm{m}^{3}$ ) na Bacia do Jucu

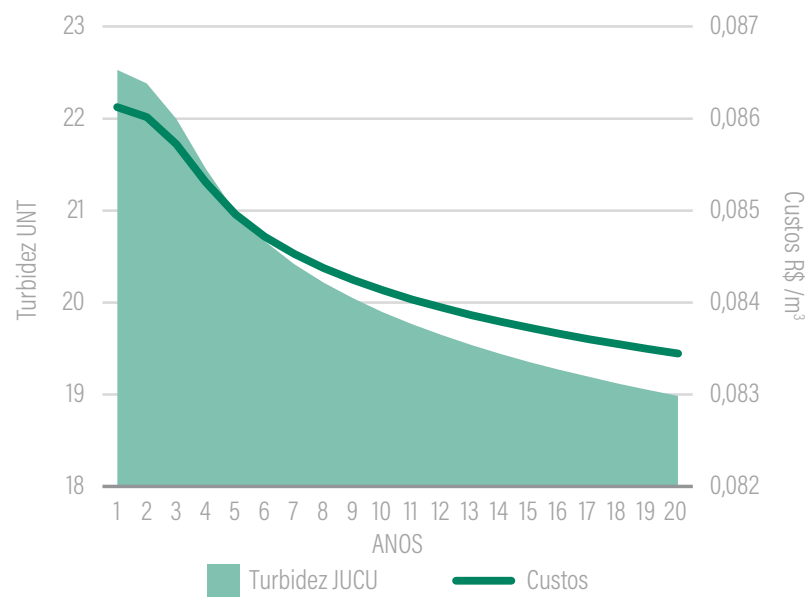

Gráfico C | Turbidez (UTN) e custos $\left(\mathrm{R} \$ / \mathrm{m}^{3}\right.$ ) na Bacia do SMV

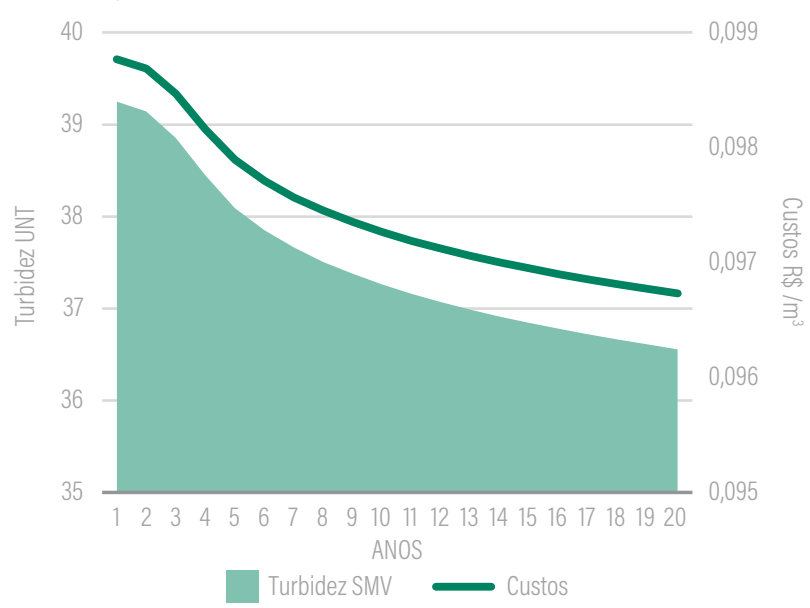

Gráfico D | Valor presente líquido (R\$) para o cenário LC2500

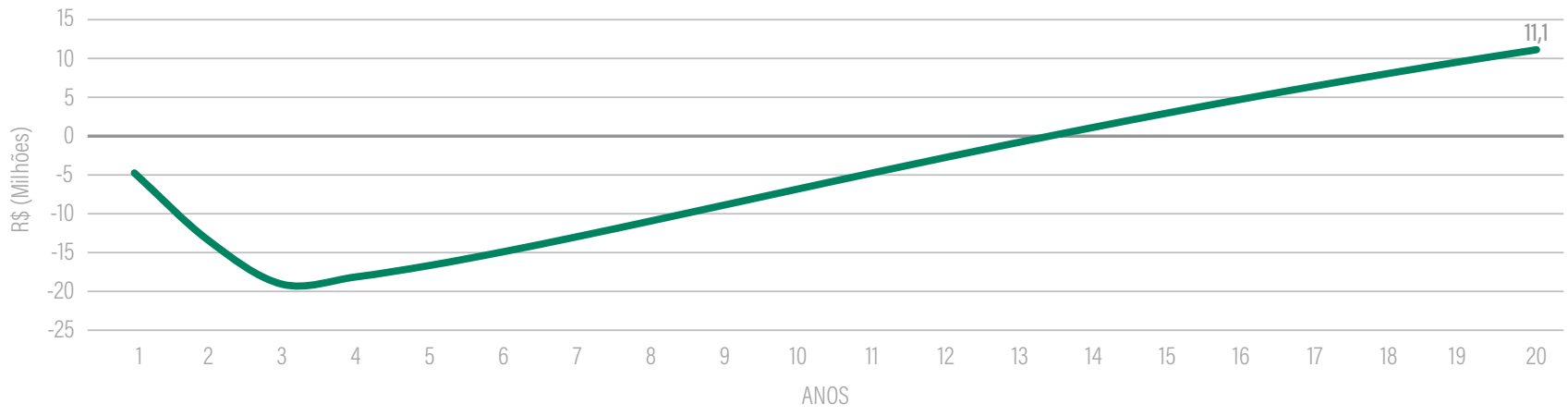

Fonte: Elaborada pelos autores 


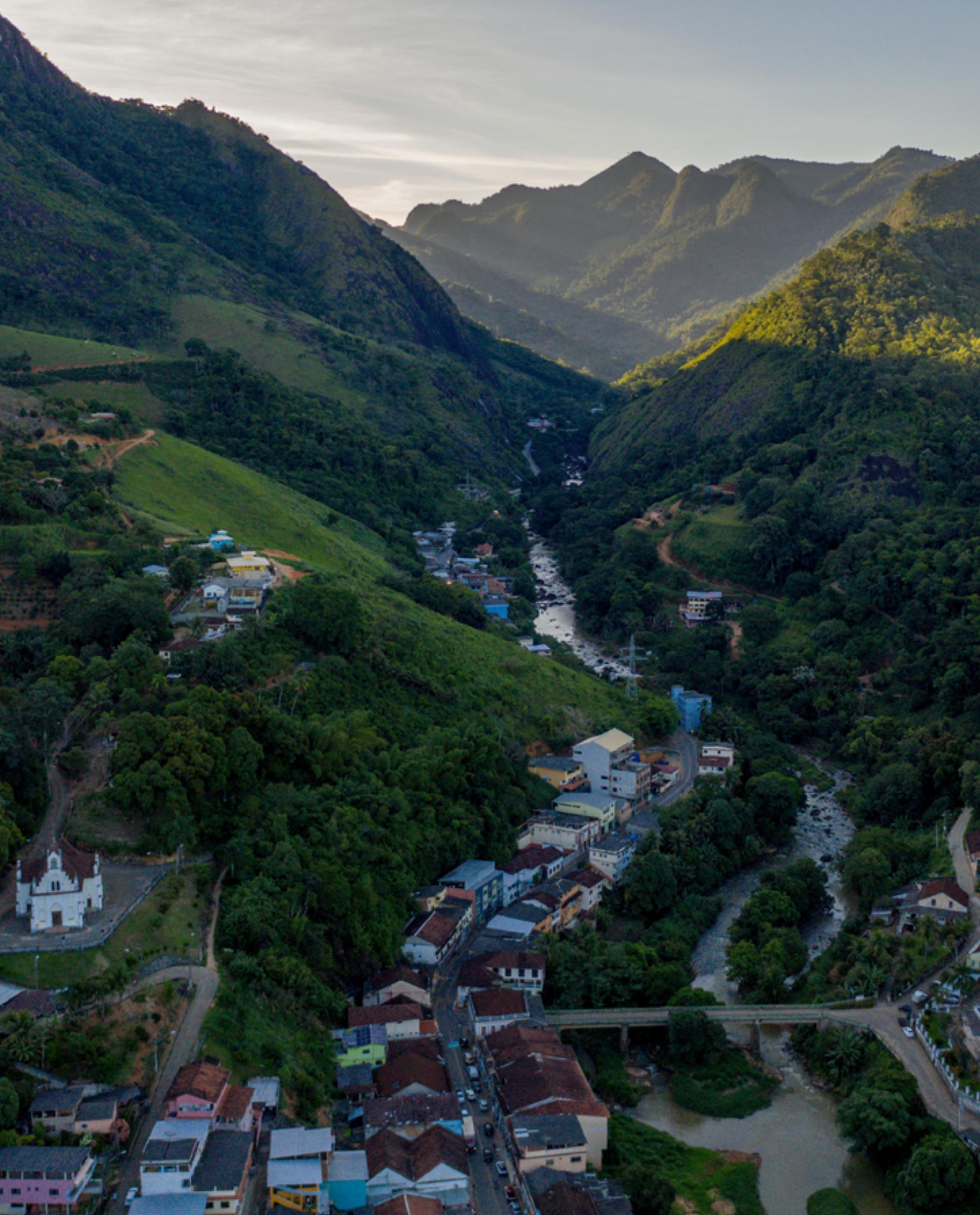



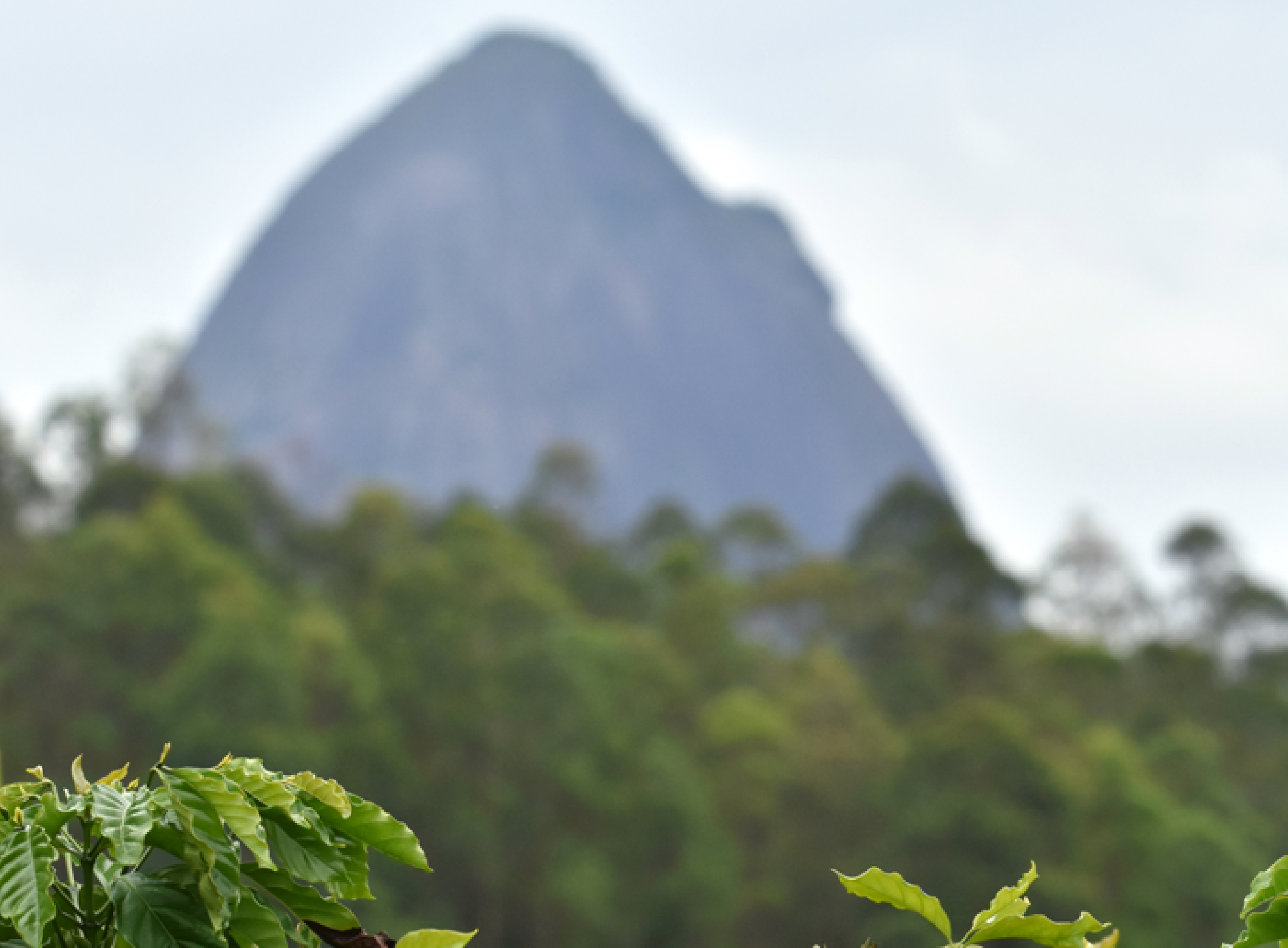

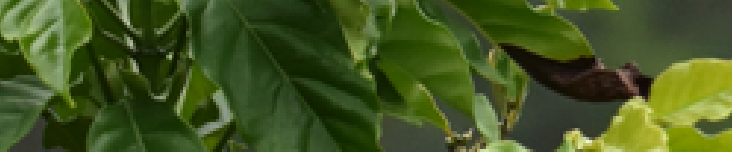

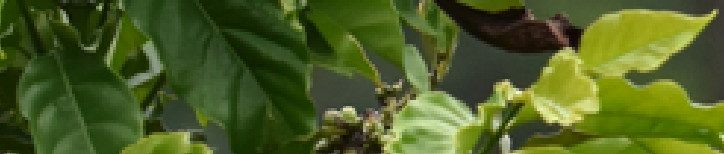

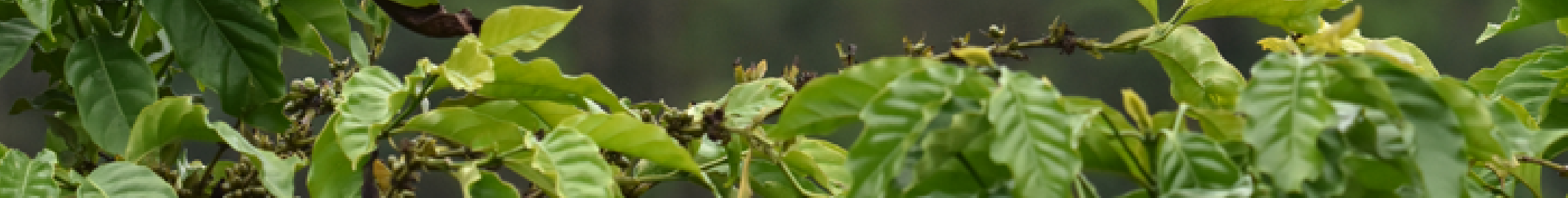

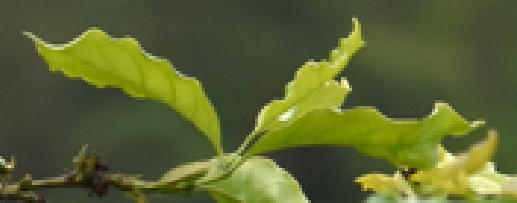

$\int_{2}$

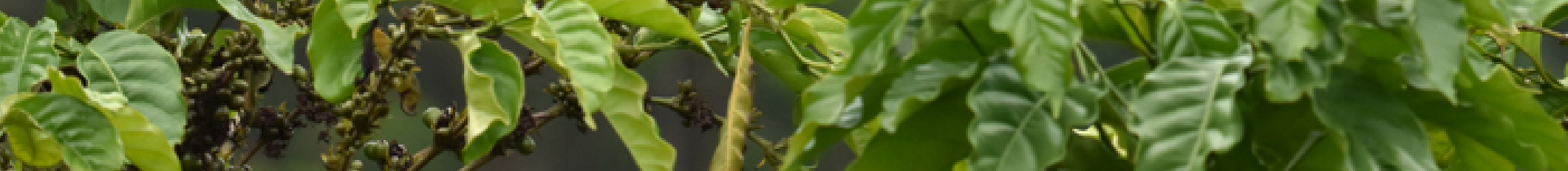

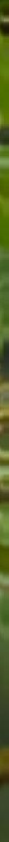


CAPÍTULO III

\section{ANÁLISE DE \\ SENSIBILIDADE}

A infraestrutura natural é viável tanto na Bacia do Jucu quanto na Bacia do SMV, e, portanto, na UGRH Litoral Central. Porém, é fundamental proceder à análise de sensibilidade, procurandose avaliar a eficácia financeira dos cenários de restauração e identificar as principais variáveis a serem gerenciadas em função de riscos de superdimensionamento de benefícios. Este capítulo desenvolve o Passo 6 da metodologia GGA/WRI e aponta caminhos para a implantação da infraestrutura natural na UGRH Litoral Central. 
Como ponderado anteriormente, a análise de sensibilidade é discutida apenas para o cenário LC2500 por refletir os resultados que poderiam beneficiar toda a RMGV. Como esse cenário é representado pelo fluxo de caixa resultante da soma dos custos e benefícios das intervenções concomitantes nas duas bacias, os testes de sensibilidade foram feitos simultaneamente em ambas, obtendo-se os resultados parciais para, então, integrá-los aos resultados finais do LC2500. Cada uma das seções a seguir endereça um fator de risco, aqueles considerados relevantes pelas partes interessadas durante as consultas do projeto (descritas no Capítulo 1).

\section{Analisando riscos (Passo 6) Avaliação do foco estratégico e do modelo de investimentos}

Existem incertezas quanto ao custo do projeto. Por exemplo, o custo da restauração por plantio total (ativa) no sudeste do Brasil pode variar entre $\mathrm{R} \$ 10$ mil e R \$ 30 mil por hectare, em valores corrigidos para novembro de 2020 (IGP-DI), sendo os custos utilizados neste estudo, baseados no Programa Reflorestar, calculados coincidentemente na média desses extremos (Benini e Adeodato, 2017). Qual o impacto no projeto se os custos da restauração ativa fossem alterados? A análise de sensibilidade mostra que essa variabilidade nos custos de infraestrutura natural não apresentaria um risco financeiro sério. Mesmo com custos mais altos, o projeto ainda teria um VPL positivo (e, portanto, seria financeiramente compensado). Por outro lado, se for possível ganhar escala e diminuir os custos de restauração, colocando-os no limite inferior, o VPL do projeto aumentaria de $\mathrm{R} \$ 11$ milhões para $\mathrm{R} \$ 16$ milhões, com período de retorno (payback) antecipado em 2,5 anos.

\section{Desempenho da infraestrutura natural na retenção de sedimentos}

O desempenho da infraestrutura natural no controle de sedimentos depende de características biofísicas, manejo do solo e gestão da paisagem. Além disso, existem incertezas implícitas aos modelos de mensuração da produção de sedimentos e dos impactos da restauração nas áreas com alta erosão. Utilizando o modelo InVEST, o resultado mais frequente é de que a restauração no cenário LC2500 poderia reter $6 \%$ dos sedimentos, mas resultados extremos variaram de $3 \%$ a $8 \%$ (distribuição normal com inclinação positiva conforme ajustada pelas equações InVEST). Essas variações emulam o desempenho financeiro do projeto se as florestas restauradas tiverem capacidade de crescimento ou de retenção de sedimentos diferente daquela usada nas principais análises das seções anteriores. A Tabela 11 estima as implicações econômicas desses resultados extremos.

O projeto se mostrou altamente sensível à capacidade de retenção de sedimentos da floresta. Sob mínima capacidade normal de retenção de sedimentos, o projeto teria um VPL negativo em $\mathrm{R} \$$ 5,6 milhões e só se poderia esperar o retorno sobre os investimentos em 46 anos. Esses resultados poderiam refletir, por exemplo, condições em que houvesse climas mais secos do que o esperado, maior frequência de fogo ou utilização de mudas de baixa qualidade e, portanto, com alta taxa de mortalidade, retardando o crescimento da floresta. Condições não controláveis, como, por exemplo,

Tabela 10 | Desempenho financeiro do cenário LC2500 sob variações de custos de restauração

\begin{tabular}{|c|c|c|c|c|}
\hline \multicolumn{2}{|c|}{ MUDANÇAS NO CUSTO DA RESTAURAÇÃO ATIVA (TAXA DE DESCONTO = $8.5 \%$ A.A.) } & $\begin{array}{l}\text { TIR } \\
(\%)\end{array}$ & $\begin{array}{c}\text { PAYBACK } \\
\text { (ANOS) }\end{array}$ & $\begin{array}{c}\text { VPL } \\
\text { (RS, MILHÕES) }\end{array}$ \\
\hline LC2500 - Referencial & Custo de $\mathrm{R} \$ 10.666$ por hectare & 14 & 12 & 11,1 \\
\hline Custo da restauração é $50 \%$ mais caro & $\begin{array}{l}\text { Se os custos de restauração ativa são os } \\
\text { máximos encontrados na literatura para a Mata } \\
\text { Atlântica (Benini e Adeodato, 2017) }\end{array}$ & 11 & 14 & 6,0 \\
\hline Custo da restauração é $48 \%$ mais barato & $\begin{array}{l}\text { Se os custos de restauração ativa são os mínimos } \\
\text { encontrados na literatura para a Mata Atlântica } \\
\text { (Benini e Adeodato, 2017) }\end{array}$ & 18 & 10 & 16,2 \\
\hline
\end{tabular}

Fonte: Elaborada pelos autores 
Tabela 11 | Desempenho financeiro do cenário LC2500 sob variações de retenção de sedimentos

\begin{tabular}{|c|c|c|c|c|}
\hline \multicolumn{2}{|c|}{ MUDANÇAS NA RETENÇÃO DE SEDIMENTOS (TAXA DE DESCONTO = 8.5\% A.A.) } & $\begin{array}{l}\text { TIR } \\
(\%)\end{array}$ & $\begin{array}{l}\text { PAYBACK } \\
\text { (ANOS) }\end{array}$ & $\begin{array}{c}\text { VPL } \\
\text { (RS, MILHÕES) }\end{array}$ \\
\hline LC2500 - Referencial & $6 \%$ dos sedimentos são retidos & 14 & 12 & 11,1 \\
\hline $\begin{array}{l}\text { Capacidade de retenção de sedimentos da } \\
\text { infraestratura natural é } 50 \% \text { menor do que } \\
\text { no referencial }\end{array}$ & $3 \%$ dos sedimentos são retidos & 2 & 46 & $-5,6$ \\
\hline $\begin{array}{l}\text { Retenção de sedimentos da infraestrutura } \\
\text { natural é } 33 \% \text { maior do que no referencial }\end{array}$ & $8 \%$ dos sedimentos são retidos & 26 & 7 & 29,2 \\
\hline
\end{tabular}

Fonte: Elaborada pelos autores.

maior erosividade e erodibilidade natural do solo, poderiam explicar desempenhos inferiores como os apontados aqui, e devem ser considerados no processo de decisão antes da implementação dos projetos de restauração.

Por outro lado, se a capacidade de retenção for superior à considerada nas análises principais, o VPL saltaria para R $\$ 29$ milhões, adiantando-se o tempo de retorno para sete anos. Além de clima favorável e mudas selecionadas com melhor crescimento e resistência, esse cenário poderia ser alcançado com maior participação dos proprietários no cuidado com o isolamento da área, maior influência de polinizadores e dispersores de sementes, além de respostas mais efetivas do impacto dos sistemas radiculares na retenção da erosão.

Investir cedo em monitoramento amplo é uma ação importante para garantir que o risco financeiro representado pela incerteza do desempenho da restauração possa ser bem gerenciado. A variação sazonal em eventos hidrológicos e erosivos requer sistemas de monitoramento bem projetados. Monitorar e avaliar a infraestrutura natural não apenas oferece oportunidades para gerenciar o projeto, mas também contribui para o crescente corpo de evidências que podem ajudar a definir expectativas realistas para outros locais.

A criação de um plano de monitoramento do projeto poderia aumentar a confiança no desempenho da infraestrutura natural, mas é necessário adotar uma visão de longo prazo, porque, como discutido no Capítulo 2, pode levar anos até que os benefícios de controle de erosão comecem a ter efeito na economia de tratamento de água. As partes envolvidas expressaram muito interesse em desenvolver um sistema de monitoramento de forma colaborativa, mobilizando parceiros para coordenar as atividades nas organizações e, então, monitorar o desempenho do crescimento da floresta restaurada.

\section{Mais atratividade aos proprietários rurais}

Muitos stakeholders, inclusive representantes dos próprios produtores rurais, questionaram se os incentivos atuais são suficientes para que agricultores e pecuaristas se disponham a participar do Programa Reflorestar ou de esforços semelhantes. Indagaram, ainda, se o programa pode incorporar elementos que atenderiam melhor às necessidades e aos interesses dos produtores rurais e proprietários de terras. Essas necessidades poderiam ser endereçadas, de maneira mais simples, através do aumento dos valores encaminhados pelos PSA.

Atualmente, o Programa Reflorestar paga entre $\mathrm{R} \$ 267$ e $\mathrm{R} \$ 281$ por hectare por ano em forma de PSA - valor usado aqui como referência de custo da oportunidade da terra. No entanto, a partir de entrevistas locais, estimou-se que um proprietário de terras poderia ter uma renda equivalente a $\mathrm{R} \$$ 420 por hectare por ano se mantivesse a atividade pecuária - cerca de $35 \%$ a mais do que o oferecido pelo Reflorestar. Com base em nossas evidências e na perspectiva das partes consultadas, parece que um incentivo superior, ou um pacote de incentivos monetários e não monetários, pode despertar o interesse de um maior número de proprietários de terras.

Mesmo que os valores pagos pelo Programa Reflorestar fossem aumentados para refletir o custo de oportunidade da pecuária, $o$ 
investimento em infraestrutura natural se manteria viável e economicamente promissor, com VPL de R \$ 7,9 milhões.

Sob outra perspectiva, na implementação da restauração o Programa Reflorestar não paga pela mão de obra, pois projeta a participação dos agricultores e pecuaristas como um coinvestimento com contrapartida de tempo e trabalho. Por esse motivo, esse custo não foi coberto pela análise principal. Não obstante, os custos da força de trabalho podem ser incluídos como custos de oportunidade da mão de obra que afetam as decisões e a vontade do produtor rural de se envolver no programa. Considera-se que a implantação de um hectare custaria em média $\mathrm{R}$ \$ 3.60o, com a contratação de três trabalhadores em 12 diárias a $\mathrm{R} \$ 100$ cada uma. Ao incluir os custos de mão de obra na análise, o VPL cai $\mathrm{R}$ \$ 2 milhões em relação ao obtido pela variação no custo de oportunidade da terra, e o período de retorno (payback) é prorrogado por quatro anos. Ainda assim, implantar a infraestrutura natural seria um bom negócio.

Finalmente, considerou-se que a restauração dos 2.50o hectares levaria três anos. Contudo, pode-se imaginar que, se os recursos financeiros para investimento na restauração fossem liberados de uma só vez e houvesse capacidade técnica de implantação, o horizonte de implementação do projeto poderia ser encurtado. Caso fosse implementado em um ano em vez de três, o VPL atingiria $\mathrm{R} \$ 13,1$ milhões, enquanto ações mais tímidas, por exemplo, executar o projeto de restauração em 10 anos com 250 hectares por ano, resultaria em um VPL de R \$ 6,1 milhões. O cronograma de efetivação tem um alto impacto no desempenho financeiro do projeto; quanto mais rápido for posto em prática, mais benefícios poderão ser obtidos em um horizonte de 20 anos.

\section{Taxas de desconto e custos do financiamento}

Diversificar fontes de financiamento e reunir recursos de vários grupos são ações que também podem ampliar o engajamento de proprietários rurais na UGRH Litoral Central, além de melhorar o desempenho financeiro geral do projeto. As partes interessadas expressaram preocupação quanto aos fundos fornecidos pelo governo sofrerem restrições após 2020. Da mesma forma, os comitês de bacias ainda não têm acesso aos fundos necessários para executar esses planos. Por lei, os comitês devem receber fundos por meio de uma taxa de uso da água aplicada a todos os usuários; entretanto, esses comitês ainda precisam aprovar essa taxa. $\mathrm{O}$ envolvimento da Cesan no programa pode dirimir essas preocupações e ajudar a superar esses desafios.

O cenário de referência modela o desempenho do projeto a partir da perspectiva de um único investidor, a empresa de água (refletida na taxa de desconto de $8,5 \%$, que é o custo médio ponderado de capital da empresa). Contudo, investimentos em infraestrutura natural são ainda em pequena escala, sendo os custos de larga escala incorridos no Programa Reflorestar, que é administrado pelo governo e totalmente pago pelo Fundágua.

A fim de testar o desempenho financeiro sob variações de taxa de desconto em diferentes perspectivas de custos de capital, considerou-se um "cenário de baixo risco" (5\%) e um "cenário de alto risco" (12\%). A seleção dessas taxas de desconto

Tabela 12 | Desempenho financeiro do cenário LC2500 sob outras variações de custos

\begin{tabular}{|c|c|c|c|c|}
\hline \multicolumn{2}{|c|}{ MUDANÇAS NO PSA E CUSTOS DE MÃO DE OBRA (TAXA DE DESCONTO =8,5\% A.A.) } & $\underset{(\%)}{\operatorname{TIR}}$ & $\begin{array}{l}\text { PAYBACK } \\
\text { (ANOS) }\end{array}$ & $\begin{array}{c}\text { VPL } \\
\text { (RS, MILHÕES) }\end{array}$ \\
\hline LC2500 - Referencial & Sem custo de mão de obra & 14 & 12 & 11,1 \\
\hline $\begin{array}{l}\text { O PSA cobre o valor do arrendamento da } \\
\text { pastagem }\end{array}$ & $\begin{array}{l}\text { Se os valores de PSA do Programa Reflorestar } \\
\text { fossem equivalentes aos valores do arrendamento de } \\
\text { pastagem }\end{array}$ & 10 & 13 & 7,7 \\
\hline Custos de mão de obra incluídos & $\begin{array}{l}0 \text { custo de oportunidade da mão de obra é de } \\
\mathrm{R} \$ 3.600 \text { durante a implementação do projeto, } \\
\text { incluindo a contratação de } 3 \text { trabalhadores por } \\
12 \text { dias para realizar a restauração ativa }\end{array}$ & 9 & 17 & 5,6 \\
\hline
\end{tabular}




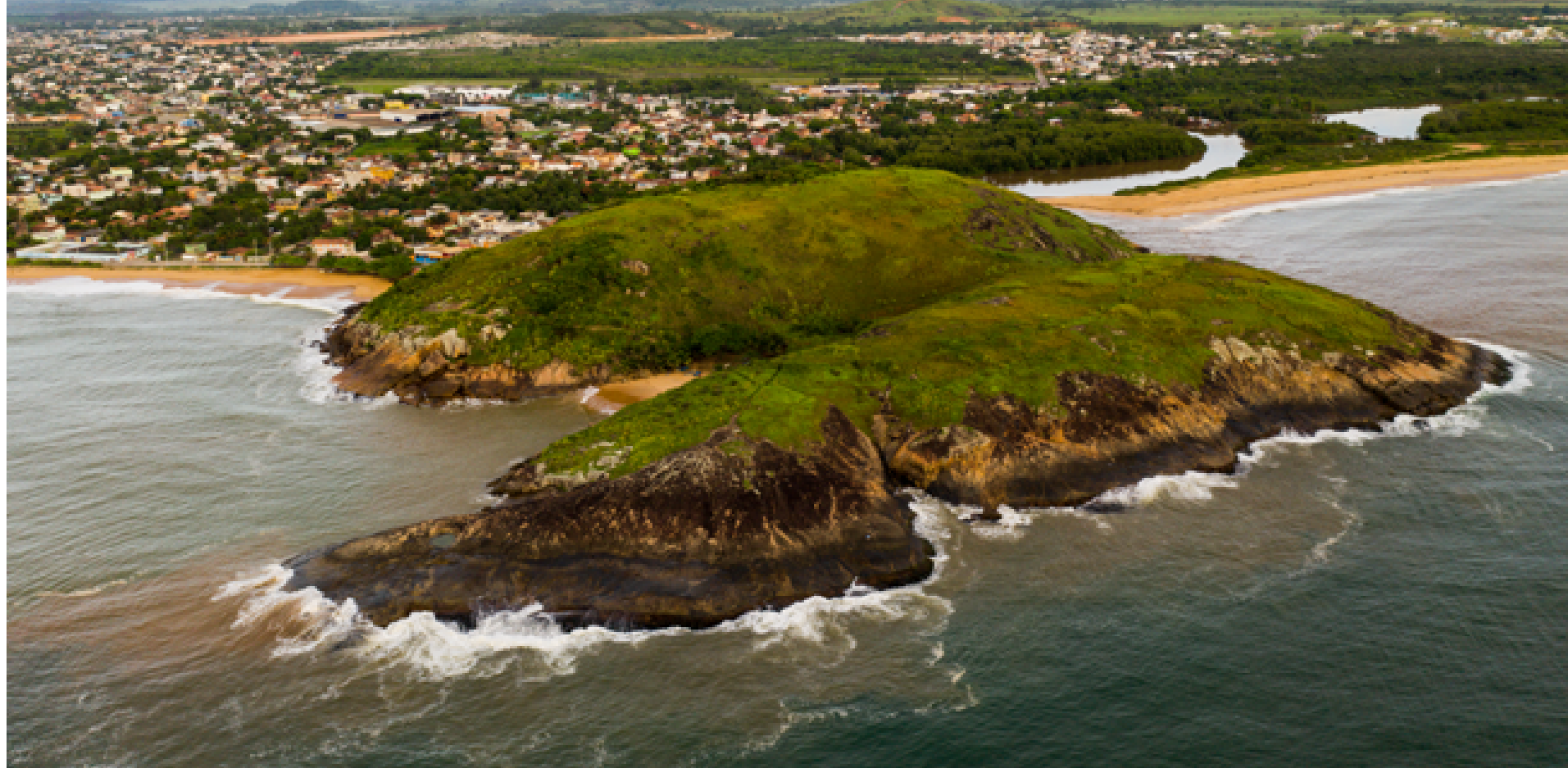

reflete a taxa social de desconto e uma taxa com prêmio de risco Brasil, respectivamente (para detalhes, ver Apêndice C).

O cenário LC2500 mostra uma moderada sensibilidade ao risco intrínseco representado pelas taxas de desconto. Em um cenário com riscos mais altos e/ou com maior capital privado investido, representado por uma taxa de desconto de $12 \%$, o desempenho financeiro do projeto é bem mais tímido, mas ainda viável, com um período de retorno de 14 anos. O BID e o Banco Mundial recomendam uma taxa de desconto de $12 \%$ para investimentos brasileiros no setor hídrico, e mesmo sob tal taxa o projeto resiste com VPL positivo, ainda que bem abaixo do referencial. Em um cenário com maior valorização e reconhecimento do investidor aos benefícios não econômicos, (como, por exemplo, maior participação de capital de investimento de impacto ou de investimentos capitaneados por Títulos Verdes (Green Bonds), representado por uma taxa de desconto de $5 \%$ ), o retorno é alcançado quase um ano e meio antes em comparação ao cenário de referência.

Pode-se, ainda, imaginar cenários em que o governo do estado e a companhia de água fazem uma parceria para financiar o projeto. A Tabela 13 apresenta esses cenários, onde o Programa Reflorestar cobriria 20\% dos custos do projeto,

Tabela 13 | Desempenho financeiro do cenário LC2500 sob variações na taxa de desconto

\begin{tabular}{|c|c|c|c|c|}
\hline \multicolumn{2}{|c|}{ MUDANÇAS NAS PERSPECTIVAS DE CUSTO DE CAPITAL } & $\begin{array}{l}\text { TIR } \\
(\%)\end{array}$ & $\begin{array}{l}\text { PAYBACK } \\
\text { (ANOS) }\end{array}$ & $\begin{array}{c}\text { VPL } \\
\text { (RS, MILHÕES) }\end{array}$ \\
\hline LC2500 - Referencial & Taxa de desconto 8,5\% ao ano & 14 & 12 & 11,1 \\
\hline Taxa social de desconto a 5\% а.а. & $\begin{array}{l}\text { Taxa de desconto mais baixa aceita por } \\
\text { investimentos de impacto, taxa de desconto } \\
\text { para investidores menos avessos ao risco, ou } \\
\text { investidores com horizonte temporal mais longo }\end{array}$ & 14 & 10 & 23,9 \\
\hline Taxa de desconto de $12 \%$ a.a. & $\begin{array}{l}\text { Taxa de desconto compatível com o setor hídrico, } \\
\text { como sugerido (Lopez, 2008) }\end{array}$ & 14 & 14 & 3,2 \\
\hline $\begin{array}{l}\text { Cenário de compartilhamento de custos/ } \\
\text { coinvestimento }\end{array}$ & $\begin{array}{l}0 \text { Custo Médio de Capital Ponderado (WACC) é } \\
7,8 \% \text {, assumindo que o Programa Reflorestar } \\
\text { cobre } 20 \% \text { do capital sob a taxa social de } \\
\text { desconto (5\%) e } 80 \% \text { do capital é dispendido pela } \\
\text { Cesan, sob taxa de desconto de } 8,5 \%\end{array}$ & 14 & 12 & 9,2 \\
\hline
\end{tabular}


assumindo uma taxa de desconto social de $5 \%$, enquanto a Cesan cobriria $80 \%$ dos custos do projeto, assumindo a taxa padrão de $8,5 \%$. O desempenho financeiro desse cenário é um pouco melhor em comparação ao cenário de referência, o que sugere que esse tipo de parceria poderia ser realmente vantajoso para ambas as partes.

As partes interessadas também apontaram que ainda devem ser ativados mecanismos que permitem fluxos financeiros em escala. Embora o Fundágua tenha sido fundamental para permitir a restauração da paisagem, nota-se a necessidade de diversificar as fontes de financiamento para garantir sustentabilidade financeira. Dessa forma, apontaram as seguintes fontes potenciais de financiamento:

- Taxa de cobrança pelo uso da água: a lei federal determina uma cobrança pelo uso da água, que ainda não foi promulgada nos Comitês de Bacias do Espírito Santo, apesar de dez anos de discussão. A aprovação dessa cobrança é fundamental para que esses comitês contribuam com os programas de infraestrutura natural e criem fontes sustentáveis de financiamento.

- Compensação ambiental: também é legalmente exigido que empresas que impactam o meio ambiente compensem-no através de restauração de ecossistemas em áreas definidas por leis estaduais. A construção do novo reservatório de abastecimento de água - reservatório dos Imigrantes, no rio Jucu -, deve inundar cerca de 61 hectares de florestas nativas, exigindo a restauração de 121 hectares (ver Apêndice B), o que poderia ocorrer nas áreas prioritárias identificadas no Capítulo 2. Apesar dessas oportunidades, grupos de defesa do meio ambiente em todo o Brasil criticaram a lei de compensação ambiental pelo fato de ela não ser transparente quanto ao uso de fundos levantados por meio de compensação.

- Investimento no setor hídrico: este estudo levantou uma oportunidade adicional para o financiamento de infraestrutura natural, demonstrando que a Cesan poderia alcançar um ROI apropriado com a restauração florestal a partir de investimentos em infraestrutura convencional. No entanto, a falta de dados locais quanto ao desempenho da infraestrutura natural pode inibir investimentos no setor.
Investidores de impacto: é crescente a preocupação de investidores em infraestruturas de qualidade que apresentem maior resiliência às mudanças do clima e, portanto, menos vulneráveis à ociosidade ou a sinistros climáticos. O mal dimensionamento da disponibilidade futura dos recursos hídricos implica sério risco de ociosidade de operações ou aumento no custo operacional. Eventos extremos afetam sobremaneira os custos emergenciais de controle e remediação, como os provocados por estiagens prolongadas ou chuvas torrenciais. Investidores de impacto se interessam por infraestruturas projetadas para lidar com essas contingências e, ao mesmo tempo, fornecem externalidades positivas, como neutralização das emissões de carbono, proteção da biodiversidade etc. Como esses investidores enxergam para além das taxas de retorno convencionais, a infraestrutura natural para água é um investimento adequado para esse perfil, capitaneado por Títulos Verdes (Green Bonds). Mas é preciso que comitês de bacias e poder público garantam transparência quanto aos riscos e retornos esperados, o que este relatório pode ajudar.

\section{Compartilhamento de riscos no tempo: a} combinação de diferentes tipos de investidores ao longo do projeto é um arranjo cada vez mais comum. Investidores de impacto associados a investidores públicos podem assumir maior risco imputado pelas etapas de implantação do projeto, compensando-os por retornos maiores ao longo da consolidação do provimento dos serviços ecossistêmicos, uma vez que infraestruturas naturais se apreciam na medida da maturação do projeto enquanto as infraestruturas convencionais se depreciam. Assim, o prêmio de risco se compensa nas taxas de apreciação. 


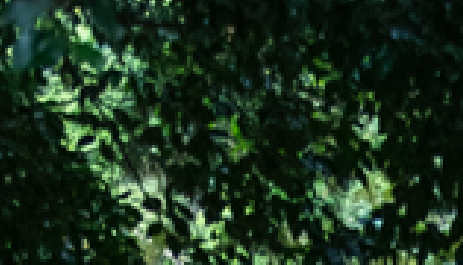

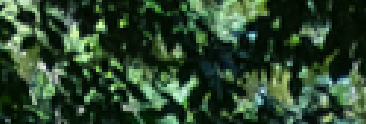

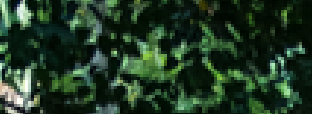

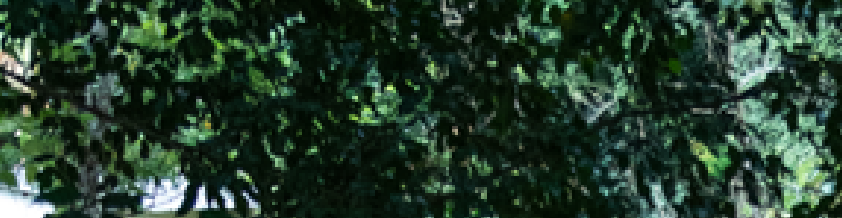

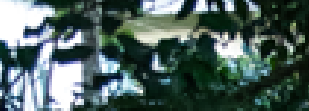

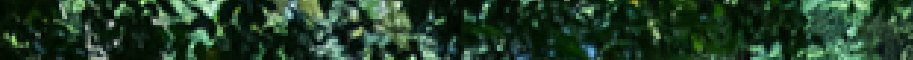

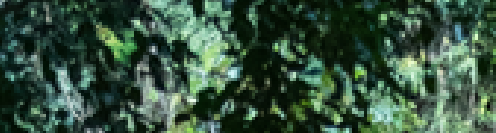

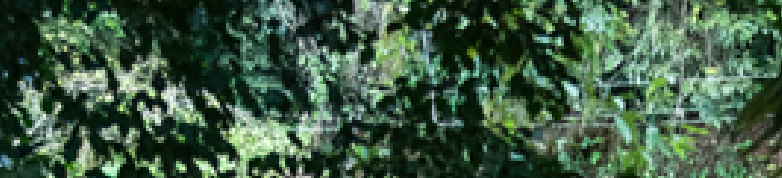

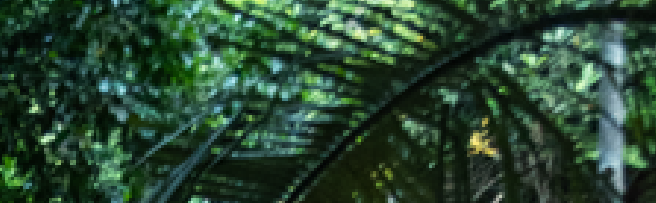

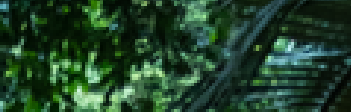

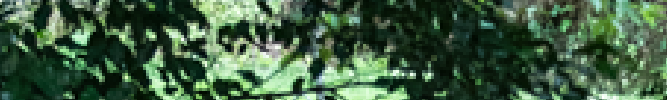

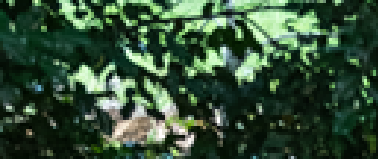

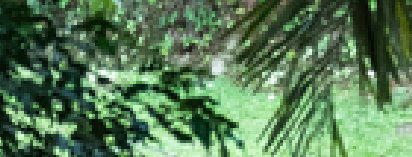

Ain.

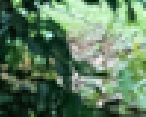

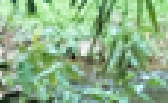

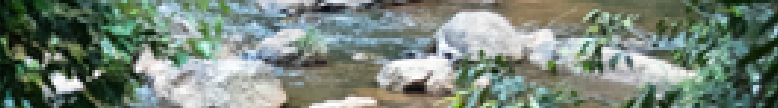

कest

F. 2 . (2)

sites

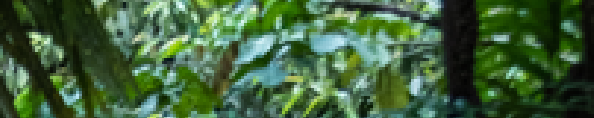
to $\frac{1}{3}$. 32 . ivaris?

(5) Ifosesh

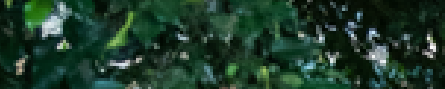

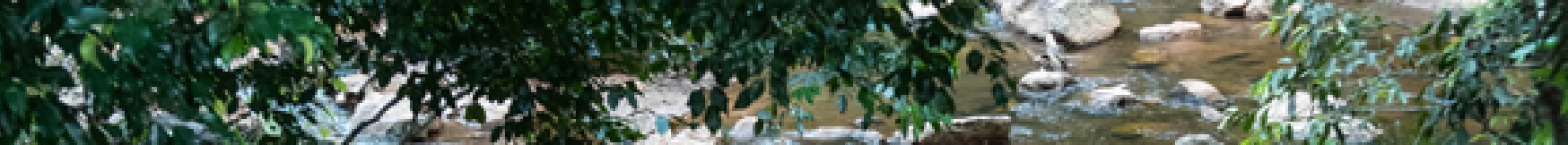

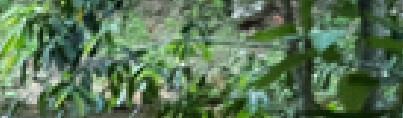
in

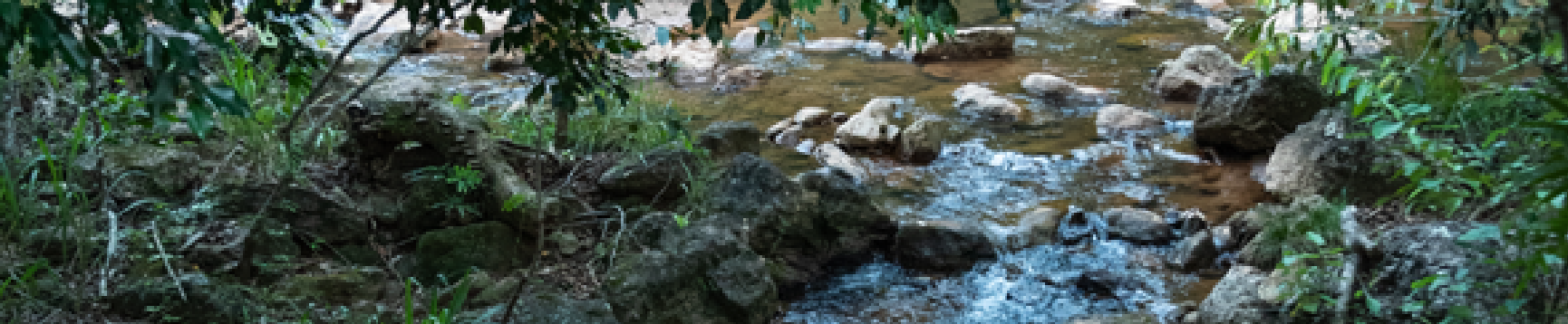
$2 x^{2}$

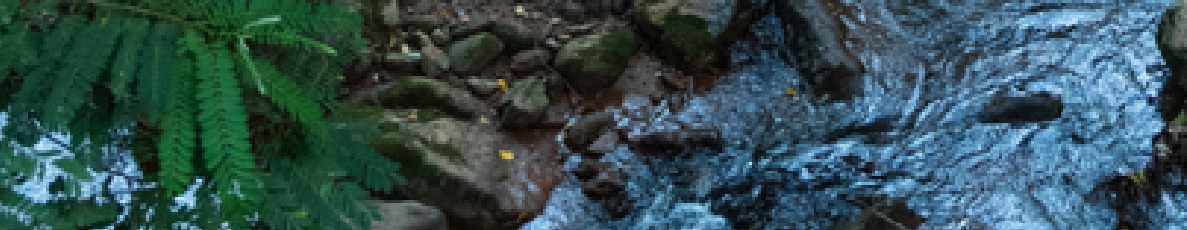

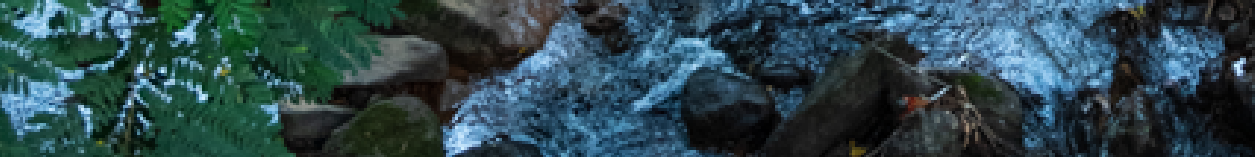

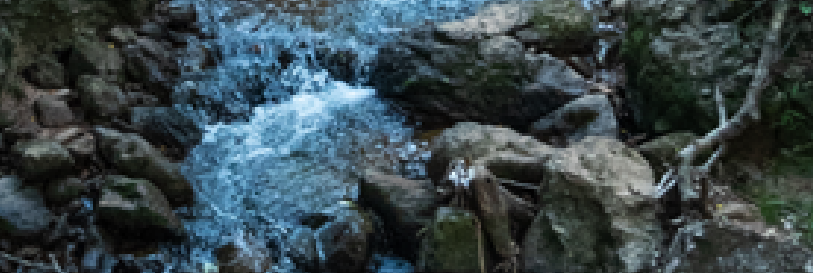
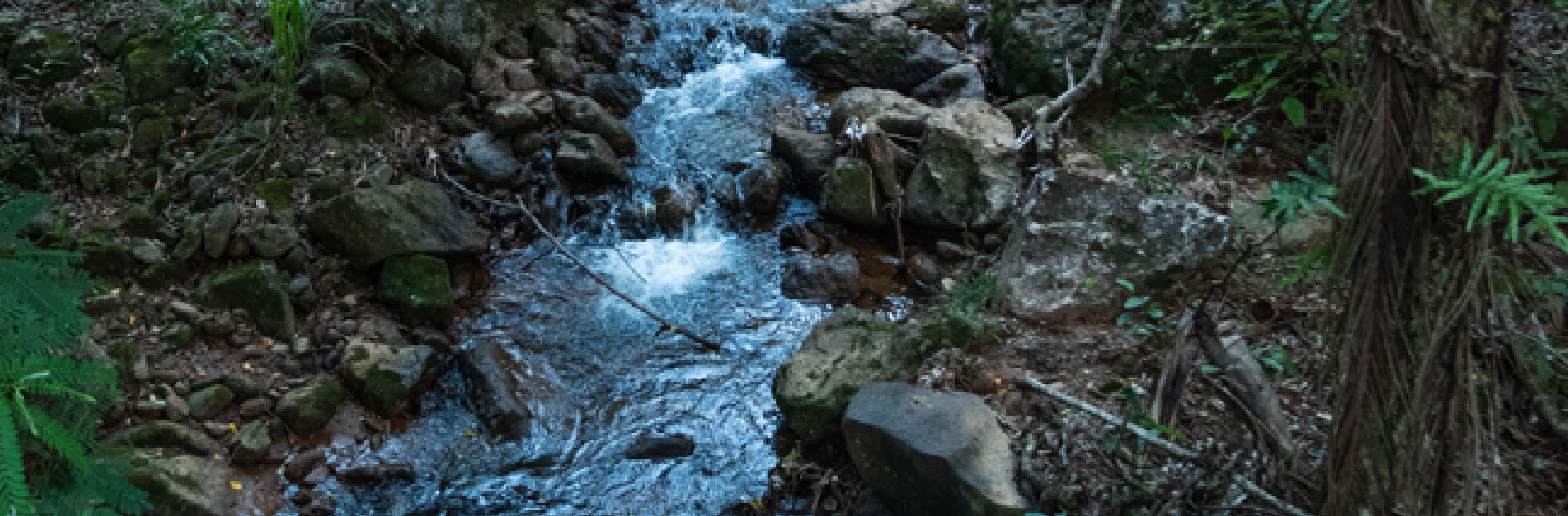

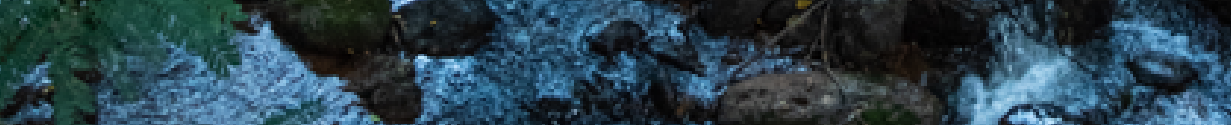

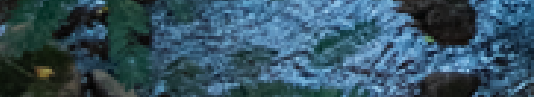



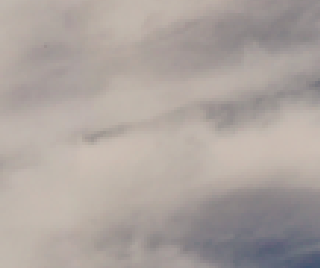

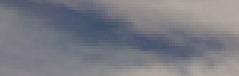

$+2$

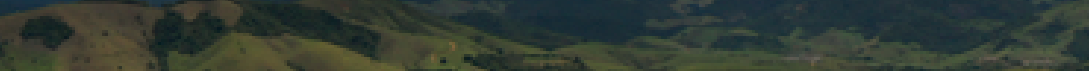

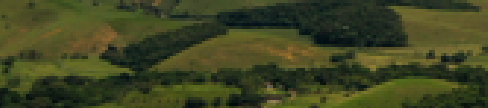

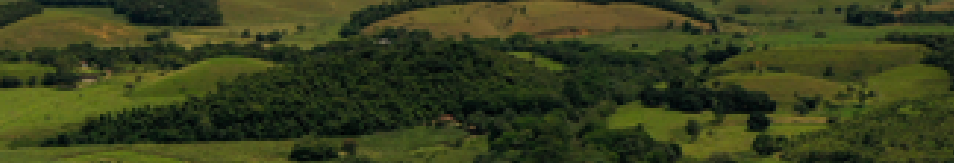

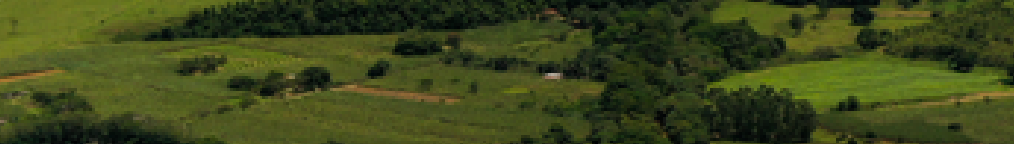

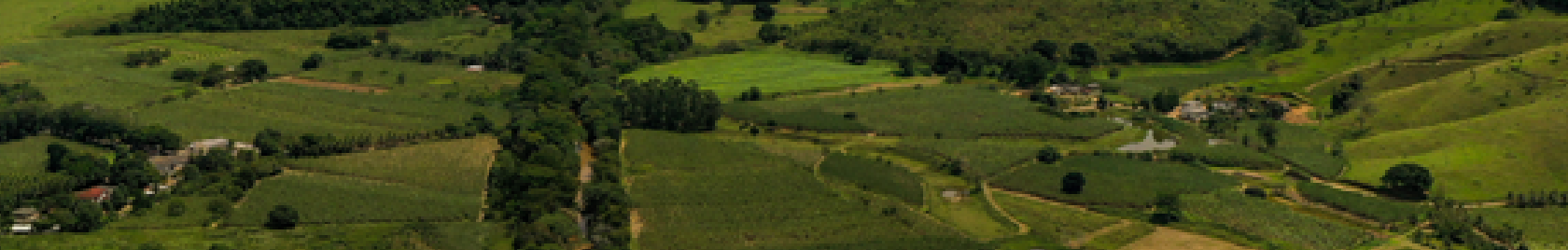

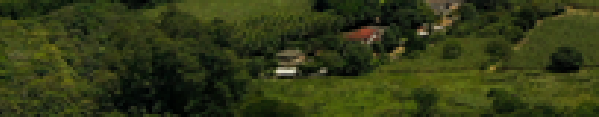

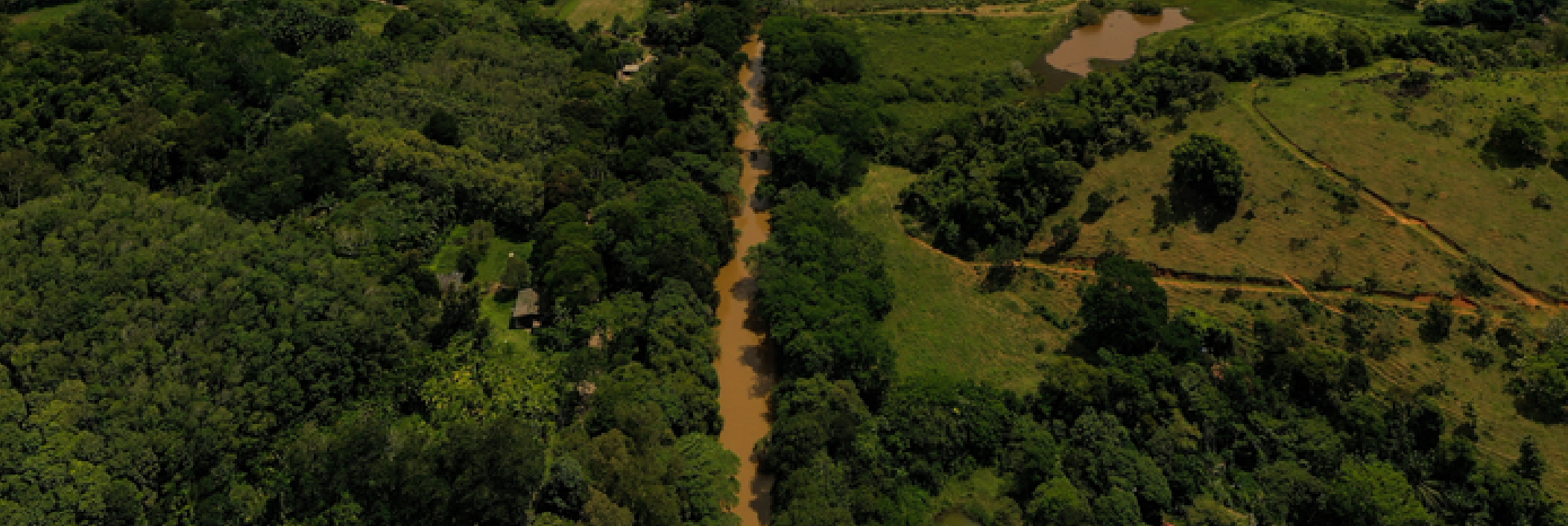

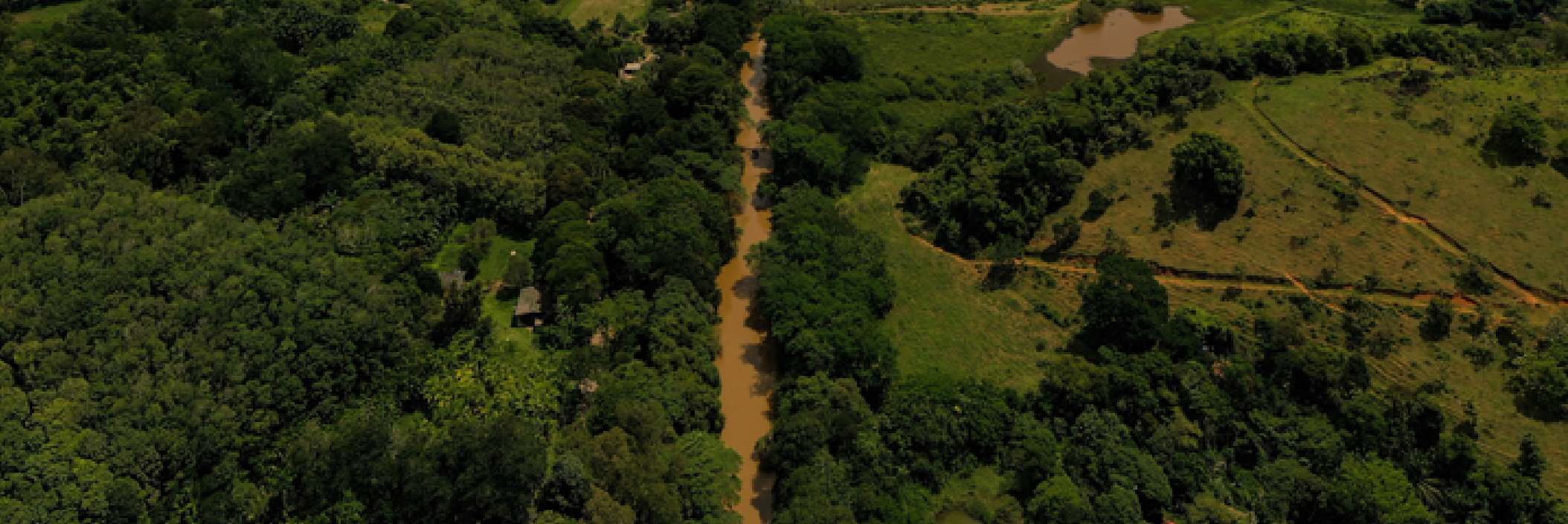

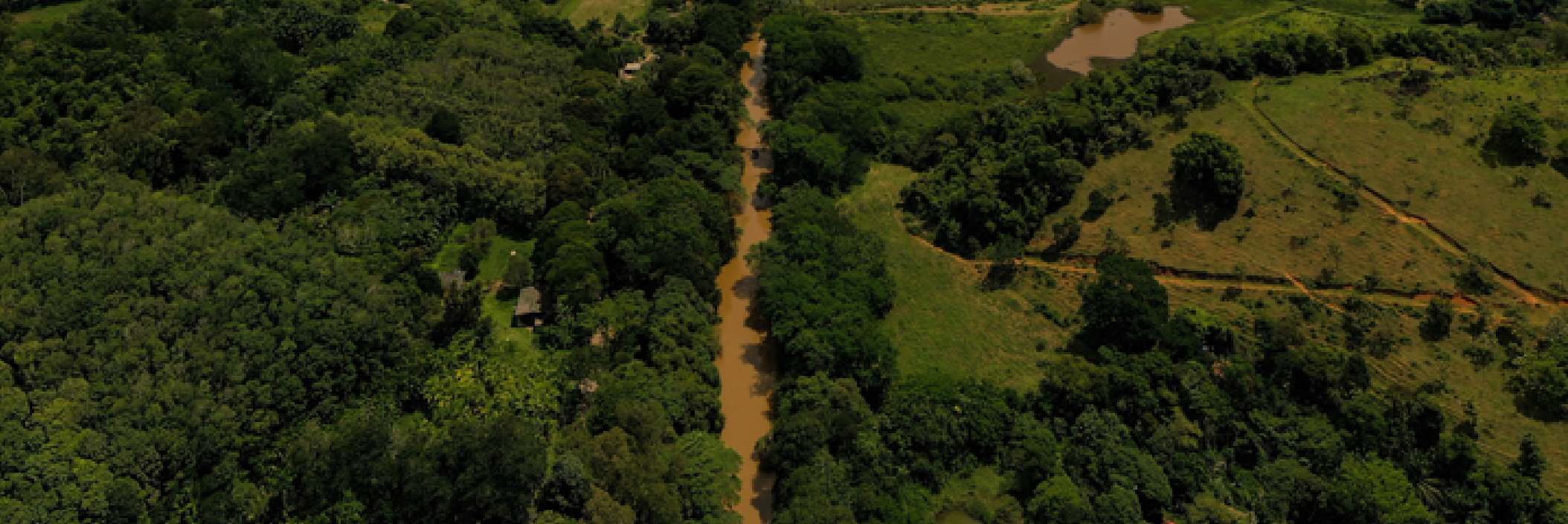

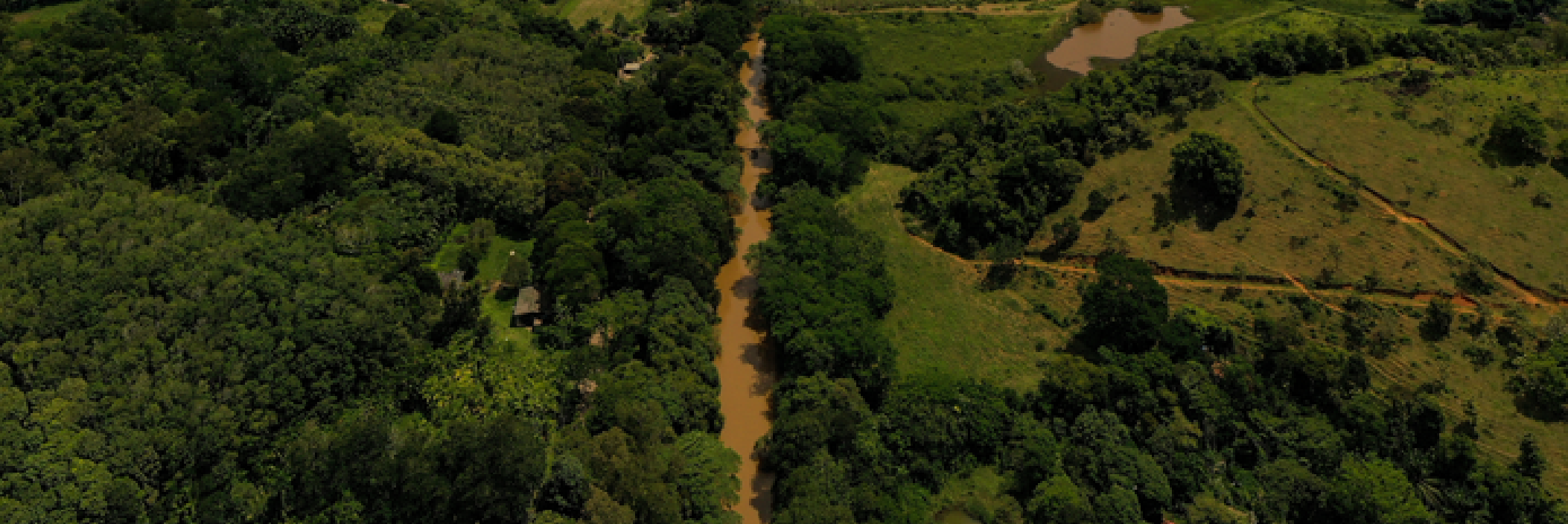

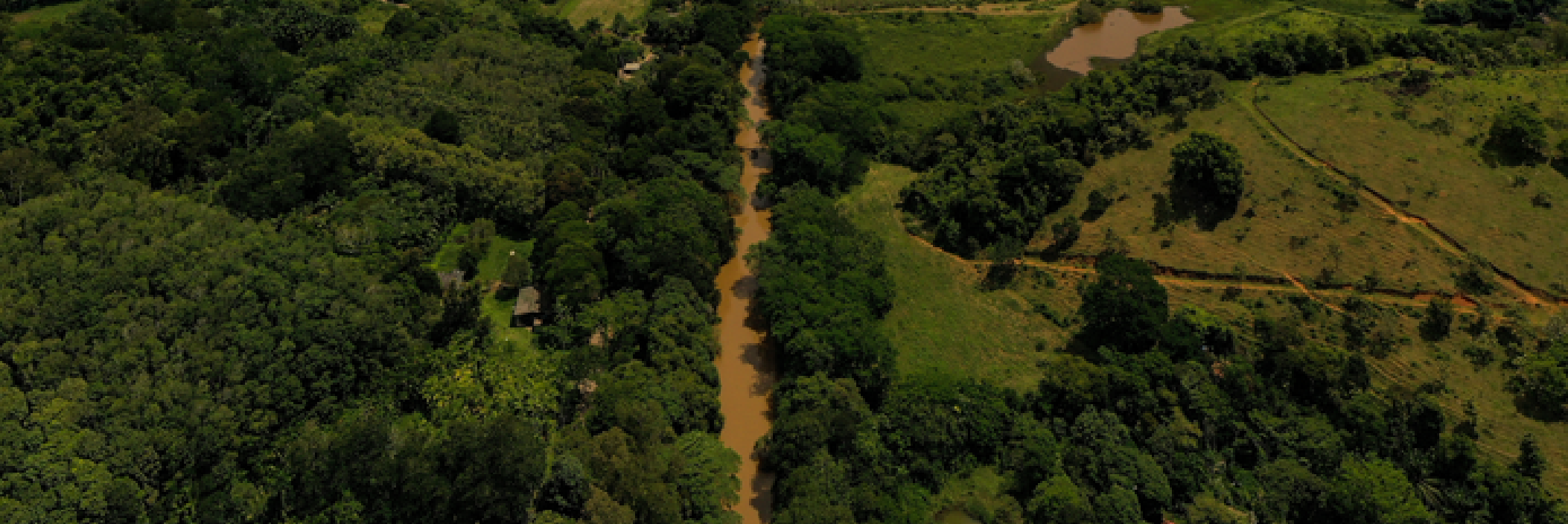

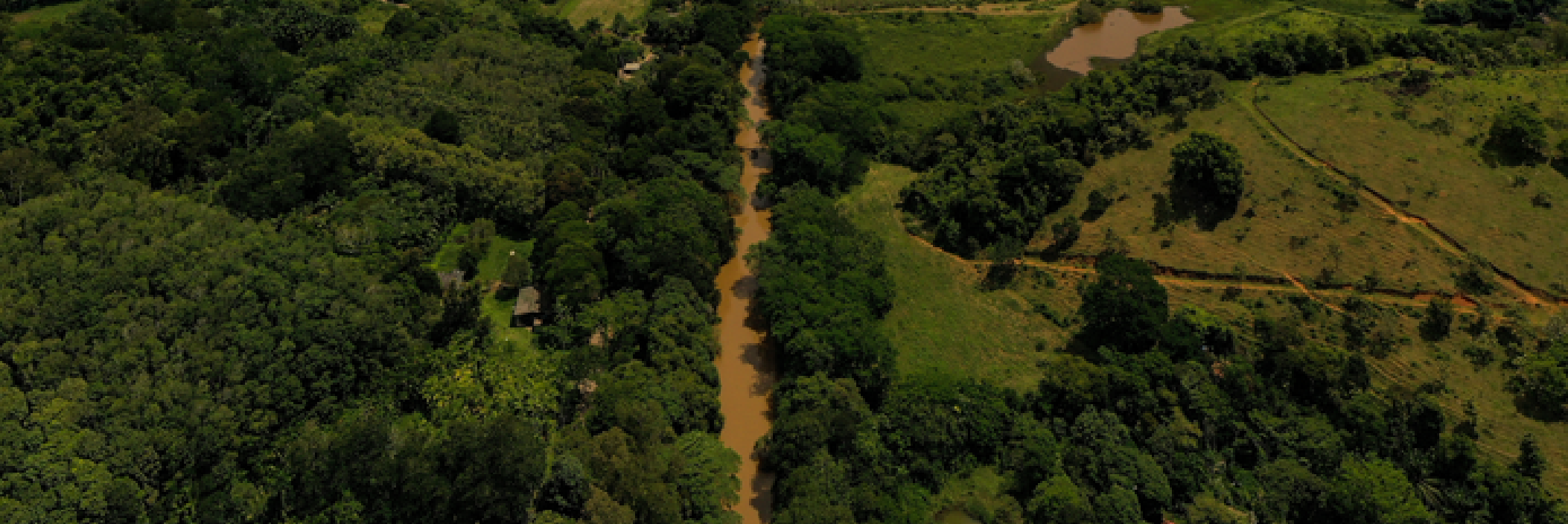

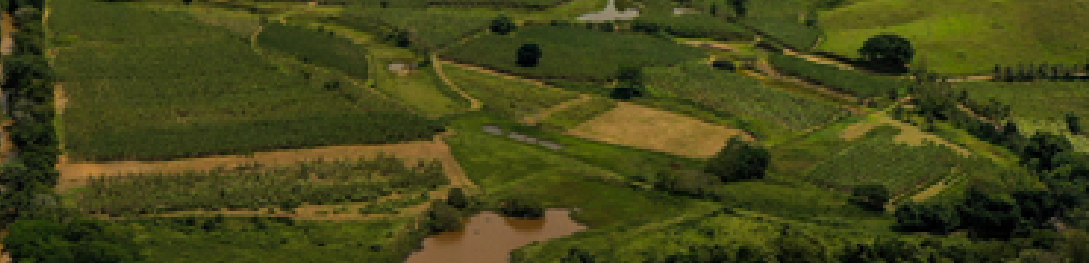

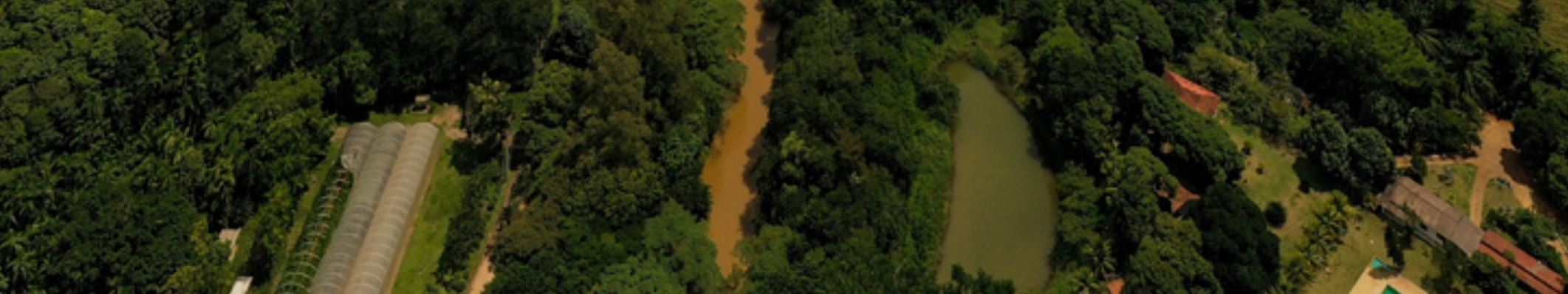




\section{CONCLUSÕES}

A infraestrutura natural - restauração florestal - melhora a qualidade da água nas Bacias do Jucu e Santa Maria da Vitória, e potencializa o desempenho da infraestrutura convencional, de forma economicamente viável. Fortalecer a governança das bacias e buscar convergências de objetivos de restauração florestal e gerenciamento de recursos hídricos são necessários para aumentar a captação de recursos e implantar a infraestrutura natural. 
água. Conforme os programas de infraestrutura natural amadurecem e buscam sustentabilidade financeira para garantir seus investimentos futuros, deve-se analisar como proceder: em que escala operar? Quais são os investidores-alvo? As conquistas serão individuais ou coletivas? Quais intervenções priorizar? O estudo fornece uma análise biofísica e financeira para melhorar a tomada de decisão sobre essas questões.

A pesquisa mostra que, caso as partes interessadas adotem uma abordagem focada nas duas bacias da UGRH Litoral Central, os investimentos em infraestrutura natural devem seguir parâmetros utilizados pelas próprias empresas de saneamento, no caso a Cesan, para que o plano de investimento seja mais realista - a começar pela taxa de desconto que reflita o custo de capital, ainda que se permita avaliar cenários alternativos na composição de diferentes perspectivas de aversão a risco.

Mas, primeiro, esse modelo de negócios deve ser relatado aos atores do setor hídrico e outros potenciais investidores de programas e, possivelmente, complementado com análises adicionais para atender às necessidades e aos interesses dos diferentes usuários e potenciais beneficiários, a começar pelos produtores rurais e consumidores urbanos de água. As estratégias de infraestrutura natural propostas e os 6 passos do GGA/WRI apresentados neste relatório ainda devem ser deliberados, reformulados e atualizados pelas partes interessadas. Como primeiro passo, esses segmentos foram convidados a revisar detalhadamente o relatório, criticar e discutir como aplicá-lo a decisões imediatas.

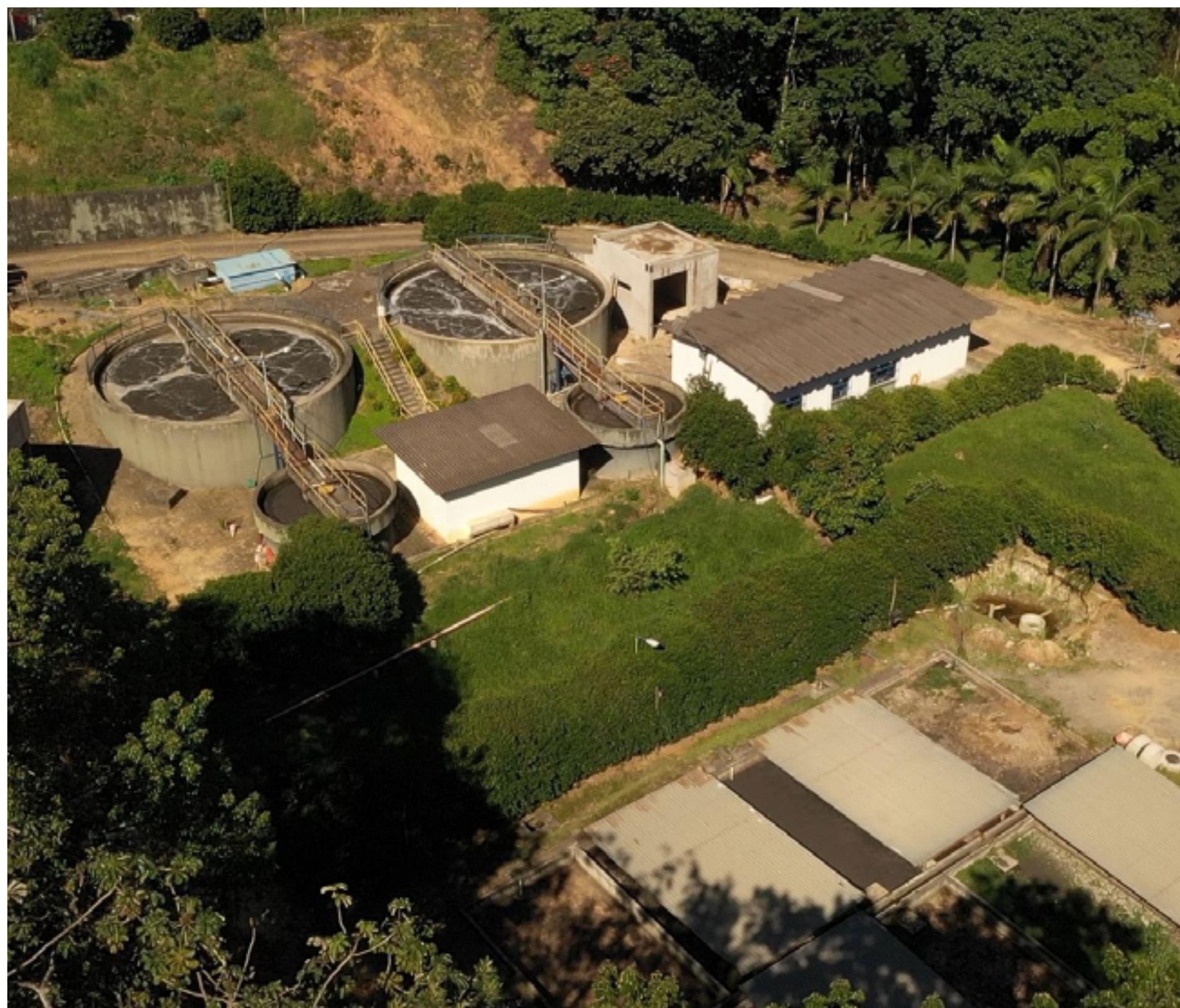


A população da RMGV pode ter suas necessidades de gestão hídrica atendidas por meio de parcerias com agricultores e gestores rurais. Ao mesmo tempo, os profissionais de desenvolvimento rural e ambiental, como os envolvidos no Programa Reflorestar, devem aprimorar suas estratégias para alcançar eficientemente os objetivos da infraestrutura natural em escala, abordando alguns dos elementos destacados neste relatório.

As agências reguladoras precisam reconhecer a relevância da infraestrutura natural como uma estratégia complementar às estruturas de engenharia convencionais, permitindo às próprias empresas de saneamento e comitês de bacias a lançarem seus gastos em restauração ambiental como investimentos - como devem ser - e não custos, como atualmente são.

\section{Expansão e replicação da análise}

As partes interessadas observaram que $o$ delineamento do investimento em infraestrutura analisado neste relatório é aderente à realidade local. Apesar disso, os custos e os benefícios pretendidos são bastante limitados, concentrando-se estritamente na restauração florestal, nos benefícios da qualidade da água em termos de turbidez. Estudos posteriores poderão examinar cenários e benefícios adicionais na combinação das infraestruturas natural e convencional para fortalecer ainda mais o modelo de negócios. Por exemplo:
1. Outras tipologias e modelos de infraestrutura natural. A infraestrutura natural pode assumir várias formas, como sistemas agroflorestais, silvicultura ou mesmo boas práticas agrícolas (BPA), como pastagem aprimorada, entre outras. Essas práticas expandidas devem ser selecionadas com base em sua relevância para produzir benefícios de infraestrutura natural, bem como em sua viabilidade e cumprimento das diretrizes para uso e ocupação do solo no território do projeto, previstas no Plano Estratégico de Desenvolvimento da Agricultura Capixaba (Governo ES, 2016). A análise de oportunidades para restauração (ROAM) no Espírito Santo deve ser um importante instrumento de suporte à expansão desses modelos de infraestrutura (Seama, 2017).

\section{Infraestrutura natural para aumentar} a disponibilidade de água na estação seca. Embora relatórios científicos não sejam ainda suficientes para determinar se a restauração na Mata Atlântica pode aumentar a disponibilidade hídrica já no curto prazo, novos estudos estão coletando dados sobre a capacidade das florestas costeiras de alta altitude de capturar a neblina como fonte de entrada adicional de água na paisagem. Além disso, a AGERH, agência que promove maior segurança hídrica através do mapeamento de áreas de recarga de água no estado, pode prover apoio técnico e legal a essas iniciativas. Esses novos estudos podem fornecer outros insumos de pesquisa para uma Avaliação
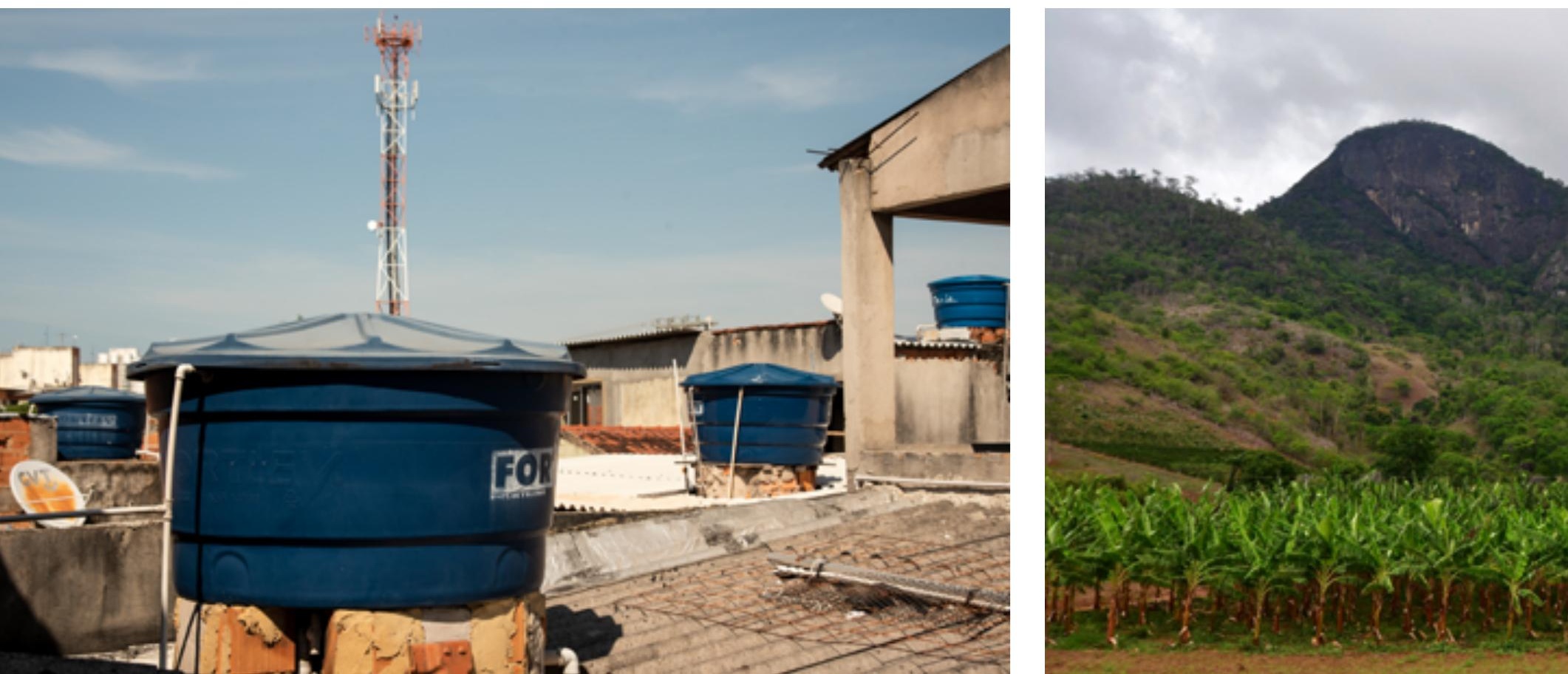


\section{APÊNDICES}

Este documento detalha os métodos utilizados no terceiro de uma série de três estudos de caso em Infraestrutura Natural para Água no Brasil, a saber:

도o 1: Sistema Cantareira - Região Metropolitana de São Paulo (SP)

- Caso 2: Bacia do Guandu - Região Metropolitana do Rio de Janeiro (RJ)

- Caso 3: Bacia do Jucu e do Santa Maria da Vitória - Região Metropolitana da Grande Vitória (ES)

Por se tratar de uma série de casos que compartilham boa parte da documentação e métodos, este apêndice apresenta informações especificamente utilizadas no Caso 3

Informações gerais sobre o escopo do projeto, a coleta de dados e os métodos utilizados nas análises biofísicas e financeiras comuns aos três casos podem ser encontradas no apêndice de referência do Caso 1: Sistema Cantareira, Região Metropolitana de São Paulo, que deu origem à série, disponível em https://www.wri.org/publication/naturalinfrastructure-sao-paulo.

\section{APÊNDICE A. MÉTODO DE CONSULTA ÀS PARTES INTERESSADAS EDESENVOLVIMENTO DAS PREMISSAS E PORTFÓLIOS DE INVESTIMENTO}

Este apêndice explica o método e as fontes de dados da análise contextual apresentados no Capítulo 1, Passos 1 e 2 do GGA/WRI

As partes envolvidas demonstraram interesse em desenvolver um plano de ação para avançar as estratégias de infraestrutura natural nas Bacias do Jucu e do SMV, de maneira mais ampla, no Espírito Santo. Para atender a esse interesse, foi elaborada uma linha de investigação adaptada da estrutura apresentada por Ozment et al. (2016), com 0 objetivo de identificar os principais fatores de sucesso e abordagens para estabelecer programas bem-sucedidos de investimentos em bacias hidrográficas. A fim de aplicar a estrutura analisada, as partes interessadas foram consultadas de três maneiras:

Workshop em Vitória, em 18 de novembro de 2016, para coletar informações relevantes, Quarenta pessoas participaram. As discussões referentes a essa pesquisa incluíram: (a) status das infraestruturas natural e convencional nas Bacias do Jucu e do SMV; (b) fontes de dados para avaliar a infraestrutura natural e (c) identificação de iniciativas relevantes de infraestrutura natural e oportunidades de colaboração.

Pesquisa oral e escrita realizada por e-mail, entre outubro e dezembro de 2017, para coletar dados e perspectivas sobre quais fatores de sucesso necessitam atenção mais imediata nas Bacias do Jucu e do SMV. As perguntas basearam-se diretamente no questionário utilizado por Ozment et al. (2018). A pesquisa foi enviada a 21 instituições, incluindo gestores de água e/ou agentes diretamente envolvidos na execução de programas de infraestrutura natural na região. Nove pessoas responderam a essa pesquisa, sendo três por meio de entrevistas pessoais e seis por escrito, incluindo representantes da Cesan, do Programa Reflorestar e da AGERH. Entre agosto e dezembro de 2020, foram realizadas chamadas on-line com representantes dos comitês das Bacias do Jucu e do SMV, funcionários da AGERH, Seama, lema e do Banco Mundial para atualizar os dados e informações relevantes.

Revisão dos documentos do programa. A revisão documental foi concentrada principalmente em estudos e arquivos que descrevem os esforços de infraestrutura natural nas Bacias do Jucu e do SMV. Essa literatura foi sintetizada a fim de entender melhor a respeito de fontes de financiamento mais importantes, principais líderes e partes interessadas envolvidas, investimentos atuais, principais riscos e preocupações e outros fatores relevantes.

Revisão do estudo. As instituições participantes representantes das partes interessadas foram convidadas a rever o conteúdo deste relatório. Seis deles aceitaram ser revisores formais (identificados na contracapa deste relatório) e outros seis preferiram rever o relatório

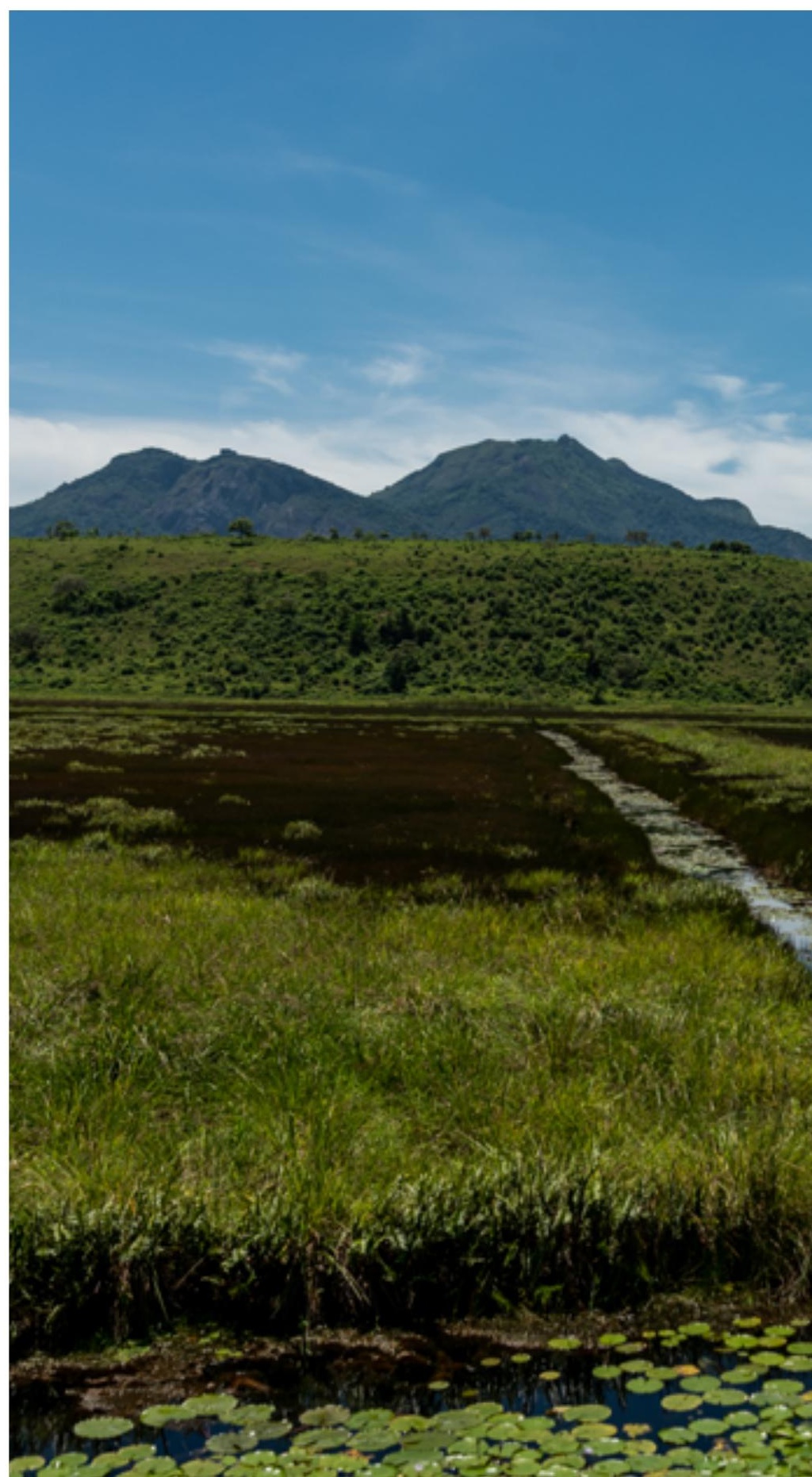


abrindo mão dos créditos de revisores. Todas as contribuições foram consideradas e, na medida de sua pertinência, incorporadas ao conteúdo final.

Os resultados dessa ampla investigação devem ser discutidos e testados entre os principais interessados, especialmente tomadores de decisão do setor hídrico. Dentre os participantes da pesquisa, 44\% representavam 0NGs, fundações ou sindicatos, $44 \%$ eram funcionários do governo estadual e $12 \%$ trabalhavam no setor hídrico. 0s participantes das pesquisas, entrevistas e workshop que contribuíram para este estudo estão listados na Tabela A1. Para garantir a utilidade e a relevância do plano de ação proposto, as recomendações preliminares foram compartilhadas com os parceiros do projeto e revisadas em duas ocasiões. A primeira em dezembro de 2018 e a segunda em dezembro de 2020.
Tabela A1 | Partes interessadas locais que participaram da pesquisa

\begin{tabular}{|l|l|}
\hline NOME & ORGANIZAÇÃo \\
\hline Aladim Cerqueira & Seama \\
\hline Robson Monteiro & Seama \\
\hline Marcos Sossai & Seama/Programa \\
\hline José de Aquino & Reflorestar \\
\hline Fabio Ahnert & Seama/Ufes \\
\hline Paulo Paim & AGERH \\
\hline Anselmo Tozi & AGERH \\
\hline Antônio de Oliveira Junior & AGERH \\
\hline Aline Serau & AGERH \\
\hline Fabricio Zanzarini & AGERH \\
\hline Ahnaiá Silva & Idaf \\
\hline Aline Nunes Garcia & Idaf \\
\hline Maria Aparecida dos Santos Chiesa & Fundágua \\
\hline Edmilson Teixeira & CERH \\
\hline Bruno Peterle Vaneli & Ufes \\
\hline Karla Libardi & Ufes \\
\hline Fernando Aquinoga de Mello & Ufes \\
\hline Robson Melo & Instituto Aplysia \\
\hline Tatiana Heid Furley & Instituto Aplysia \\
\hline Emerson Espíndula & Instituto Aplysia \\
\hline George Hilton Venturim & Vale \\
\hline Alisson Lopes & Prefeitura Municipal de \\
\hline Eduardo Figueiredo & Domingos Martins \\
\hline Edimar Binotti Jr & Ibio \\
\hline Murilo Pedroni & Ibio \\
\hline Vanessa Girão & Instituto Lorentzen \\
\hline Carlos Aurélio Linhalis & Faes \\
\hline Elza Abreu & TNC \\
\hline André Sefione & Cesan \\
\hline Andreia Neves & Cesan \\
\hline Stefano Pagiola & Cesan \\
\hline & Cesan \\
\hline Banco Mundial \\
\hline
\end{tabular}




\section{APÊNDICE B. MÉTODOS E PREMISSAS PARA MODELOS BIOFÍSICOS E COMPONENTES DO MAPEAMENTO}

Este apêndice fornece uma visão geral da modelagem biofísica, incluindo métodos, premissas e fontes de dados para execução do Passo 3 do GGA/WRI.

\section{Análise espacial do reservatório dos Imigrantes, Jucu}

Até a publicação deste relatório, o enchimento do reservatório dos Imigrantes não havia começado. Para mapear a localização e a área de inundação do reservatório, foram utilizadas imagens de satélite disponíveis em associação com os dados do Modelo de Elevação Digital (Digital Elevation Model - DEM) no ArcGIS. A simulação correspondeu a um reservatório com capacidade de armazenamento de 20 milhões de metros cúbicos e uma área alagada de 151 hectares, dos quais 65 hectares estão atualmente cobertos por vegetação nativa. Esse volume é consistente com as especificações propostas no projeto e foram divulgadas publicamente (Scalzer, 2016).

\section{Fluxograma geral para a execução de modelos biofísicos e cenários de restauração}

0 GGA/WRI considera várias etapas para estimar 0 impacto potencial na qualidade da água. 0 fluxograma geral na Figura B1 mostra as etapas necessárias para essa análise.

\section{Etapa 1 - Coleta de dados}

Coleta de dados de entrada necessários para executar o modelo biofísico. Os dados necessários são: Uso do Solo/Cobertura do Solo (Land Use/Land Cover - LULC), precipitação, mapa do solo e elevação (interpolação a partir das curvas de nível e ponto cotado).

\section{Etapa 2 - Preparação dos dados}

Ao preparar os dados de entrada, eles precisam ser ajustados ao mesmo tamanho de imagem e projetados para o mesmo sistema de coordenadas. Os atributos da camada vetorial e os parâmetros da tabela biofísica devem ser padronizados.

\section{Etapa 3 - Elaboração e execução do modelo biofísico}

Execução do modelo SDR (Sediment Delivery Ratio), em português, Taxa de Transferência de Sedimentos.

\section{Etapa 4 - Calibração do modelo}

A calibração do modelo é uma etapa necessária para ajustar o resultado gerado pelo modelo biofísico aos dados reais observados. Foram disponibilizados pela Cesan dados de sólidos em suspensão dos rios Jucu e SMV. Os dados contemplavam 24 observações, 12 para cada bacia, representando sólidos em suspensão média mensal para 0 ano de 2016.

\section{Etapa 5 - Definição dos cenários de restauração}

A definição da meta de restauração tem como base o gráfico de sedimentos exportados versus a área disponível a ser restaurada.

\section{Etapa 6 - Integração do modelo e dos cenários}

A camada LULC (uso e cobertura do solo) atual é substituída pelo cenário de restauração para estimar a possível redução de sedimentos, caso a região seja restaurada.

\section{Etapa 7 - Avaliação dos possíveis benefícios}

0 cenário de restauração é comparado ao LULC atual para estimar a possível redução na exportação de sedimentos.

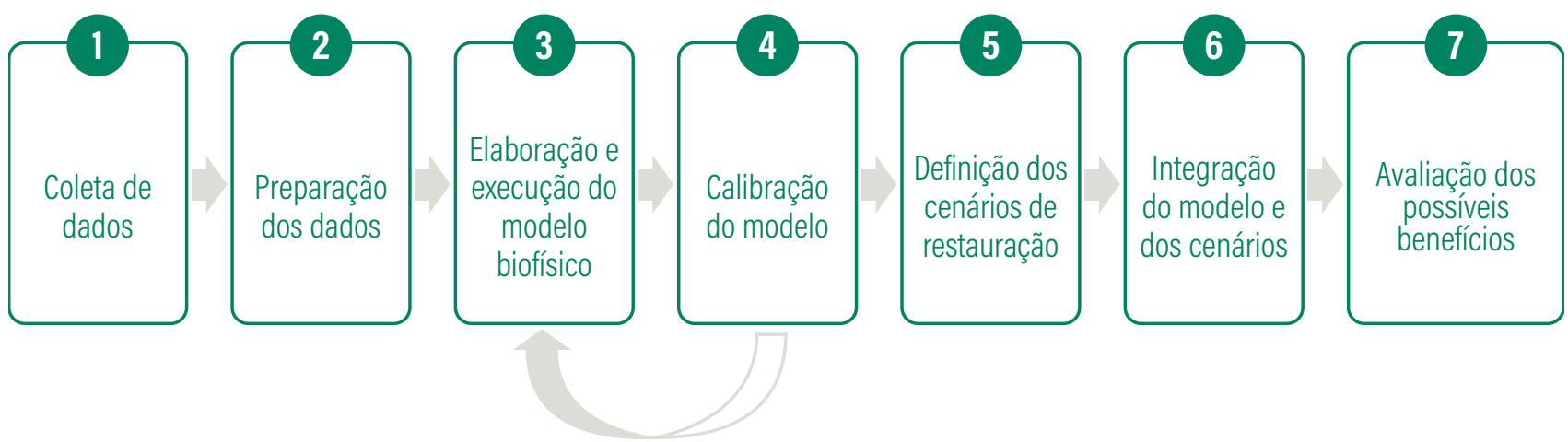




\section{Modelagem de sedimentos}

Para identificar os hectares a serem restaurados com maior potencial para redução de sedimentos e estimar os impactos gerais dessa redução com a infraestrutura natural, utilizou-se o SDR considerando o modelo 3.6.0 do Integrated Valuation of Ecosystem Services and Tradeoffs (InVEST), desenvolvido pelo Natural Capital Project (Sharp et al., 2016). 0 modelo SDR gera um resultado que mostra áreas com alto nível de exportação de sedimentos na região. A partir desse resultado, foram criados vários cenários espaciais de coberturas do solo atual e futuros (cenários de referência e de infraestrutura natural), bem como os impactos de sedimento exportado e retenção de sedimentos desses cenários. Os cenários futuros consideram a restauração de 1.600 hectares de área degradada na Bacia do Jucu e 900 hectares na Bacia do SMV, ceteris paribus.

Importante salientar que o modelo SDR estima a quantidade de sedimentos terrestres transferida aos cursos d'água (Figura B2). Existem várias fontes potenciais de geração de sedimentos, no entanto. a ferramenta SDR estima apenas a fonte terrestre.

0 modelo SDR é baseado na Equação Universal de Perda de Solo (Universal Soil Loss Equation - USLE), proposta inicialmente por Wischemeier e Mannering (1969). 0 modelo estima a perda de solo de acordo com atributos biofísicos da região avaliada, incluindo: padrão de precipitação, tipo de solo, topografia, sistema de cultivo e práticas de manejo da terra. A equação é dada pela seguinte fórmula (Stone e Hilborn, 2012):

\section{$A=R{ }^{*} K^{*} L S * C * P \quad$ (equação A1)}

Onde:

$A$ é a estimativa total da perda de solo por hectare por ano

$R$ é 0 índice de erosividade das chuvas, baseado nas chuvas mensais e no fator de escoamento; o potencial de erosão aumenta de acordo com a maior intensidade e a duração das chuvas

$K$ representa o índice de erodibilidade do solo, ou seja, o potencial das partículas do solo de se desprenderem e serem transportadas por enxurrada e escoamento; esse fator está diretamente associado à textura do solo, embora a estrutura, a matéria orgânica e a permeabilidade do solo também possam influenciar

$L S$ é o fator de comprimento e declividade da área; terrenos íngremes e longos tendem a aumentar o risco de erosão

$C$ é o fator de cobertura de culturas/vegetação; aponta a eficácia relativa dos sistemas de manejo do solo/culturas em evitar a erosão

$P$ representa o fator de práticas favoráveis ao manejo do solo, se houver algum tipo de prática que reduza a quantidade e a taxa de escoamento da água e, consequentemente, a erosão

Uma vez que a maioria dos fatores biofísicos são intrínsecos à região e não podem ser controlados, incluindo padrão de precipitação e tipo de solo e relevo, as classes de uso e cobertura do solo são os fatores que podem ser alterados a partir da substituição do tipo de cobertura do solo (fator $C$ ) ou da prática de manejo do solo (fator $P$ ). Assim, 0 cenário de mudança da cobertura terrestre de pastagens para floresta é avaliado em termos da estimativa de perda de solo com base na diferença entre o LULC atual e o seu cenário potencial de restauração, mantendo-se os fatores intrínsecos constantes. A Tabela B1 apresenta detalhes sobre a cobertura do solo nas Bacias do Jucu e do SMV.

Figura B2 | Esquema de entradas e saídas do modelo SDR

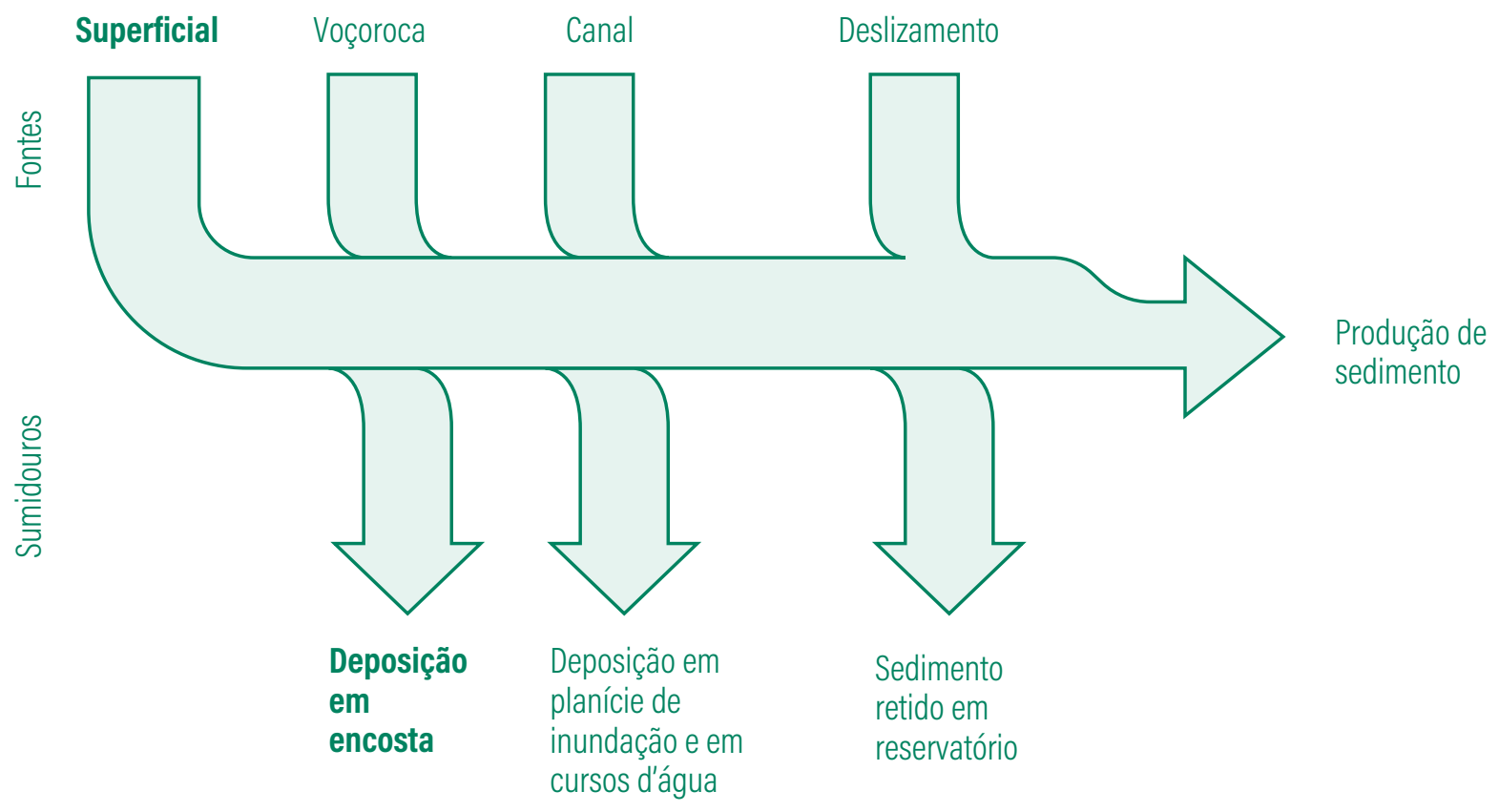

Fonte: Sharp et al. (2016). 
Tabela B1 | Padrão de uso e cobertura do solo em cada região das Bacias do Jucu e do SMV

\begin{tabular}{|c|c|c|c|c|c|c|c|c|}
\hline \multirow{3}{*}{ Tipo de cobertura do solo } & \multicolumn{6}{|c|}{ JUCU } & \multirow{2}{*}{\multicolumn{2}{|c|}{\begin{tabular}{|l}
\multicolumn{1}{c}{ SMV } \\
$\begin{array}{l}\text { Total da Bacia do } \\
\text { SMV }\end{array}$
\end{tabular}}} \\
\hline & \multicolumn{2}{|c|}{$\begin{array}{l}\text { Total } \\
\text { da Bacia do Jucu }\end{array}$} & \multicolumn{2}{|c|}{$\begin{array}{l}\text { A montante do } \\
\text { reservatório dos } \\
\text { Imigrantes }\end{array}$} & \multicolumn{2}{|c|}{$\begin{array}{l}\text { A jusante do reservatório } \\
\text { e a montante dos pontos } \\
\text { de captação }\end{array}$} & & \\
\hline & $\mathrm{Ha}$ & $\%$ & Ha & $\%$ & $\mathrm{Ha}$ & $\%$ & $\mathrm{Ha}$ & $\%$ \\
\hline Mata nativa & 70.496 & $36 \%$ & 57.861 & $38 \%$ & 12.635 & $30 \%$ & 55.197 & $39 \%$ \\
\hline Mata nativa em estágio inicial de regeneração & 15.091 & $8 \%$ & 11.444 & $7 \%$ & 3.647 & $10 \%$ & 11.189 & $8 \%$ \\
\hline Brejo & 1.027 & $1 \%$ & 364 & $0 \%$ & 662 & $2 \%$ & 420 & $0 \%$ \\
\hline Solo exposto & 2.062 & $1 \%$ & 1.906 & $1 \%$ & 156 & $0 \%$ & 2.064 & $1 \%$ \\
\hline Macega & 13.201 & $7 \%$ & 11.964 & $8 \%$ & 1.236 & $3 \%$ & 9.988 & $7 \%$ \\
\hline Campo rupestre/Altitude & 59 & $0 \%$ & 59 & $0 \%$ & 0 & $0 \%$ & 32 & $0 \%$ \\
\hline Extração de mineração & 64 & $0 \%$ & 49 & $0 \%$ & 15 & $0 \%$ & 22 & $0 \%$ \\
\hline Afloramento rochoso & 1.856 & $1 \%$ & 1.288 & $1 \%$ & 568 & $1 \%$ & 2.993 & $2 \%$ \\
\hline Reflorestamento - Eucalipto & 17.449 & $10 \%$ & 16.725 & $11 \%$ & 724 & $2 \%$ & 11.837 & $9 \%$ \\
\hline Reflorestamento - Seringueira & 499 & $0 \%$ & 7 & $0 \%$ & 492 & $1 \%$ & 34 & $0 \%$ \\
\hline Reflorestamento - Pinus & 293 & $0 \%$ & 293 & $0 \%$ & 0 & $0 \%$ & 0 & $0 \%$ \\
\hline Cultivo agrícola - Café & 12.631 & $6 \%$ & 12.040 & $8 \%$ & 591 & $1 \%$ & 8.283 & $6 \%$ \\
\hline Cultivo agrícola - Cana-de-açúcar & 129 & $0 \%$ & 0 & $0 \%$ & 129 & $0 \%$ & 6 & $0 \%$ \\
\hline Cultivo agrícola - Coco-da-baía & 127 & $0 \%$ & 35 & $0 \%$ & 93 & $0 \%$ & 83 & $0 \%$ \\
\hline Cultivo agrícola - Banana & 2.833 & $1 \%$ & 1.903 & $1 \%$ & 930 & $2 \%$ & 947 & $1 \%$ \\
\hline Cultivo agrícola - Outros cultivos permanentes & 2.534 & $1 \%$ & 2.204 & $1 \%$ & 330 & $1 \%$ & 1.335 & $1 \%$ \\
\hline Cultivo agrícola - Outros cultivos temporários & 7.846 & $4 \%$ & 7.286 & $5 \%$ & 560 & $1 \%$ & 11.199 & $8 \%$ \\
\hline Pastagem & 35.833 & $19 \%$ & 19.420 & $13 \%$ & 16.414 & $40 \%$ & 17.825 & $14 \%$ \\
\hline Massa d'água & 726 & $0 \%$ & 526 & $1 \%$ & 199 & $0 \%$ & 669 & $0 \%$ \\
\hline Área edificada & 754 & $0 \%$ & 353 & $0 \%$ & 401 & $1 \%$ & 352 & $0 \%$ \\
\hline Outros & 9.330 & $5 \%$ & 7.415 & $5 \%$ & 1.915 & $5 \%$ & 5.269 & $4 \%$ \\
\hline TOTAL & 194.840 & $100 \%$ & 153.142 & $100 \%$ & 41.697 & $100 \%$ & 139.744 & $100 \%$ \\
\hline
\end{tabular}

Fonte: Geobases-ES (2018).

\section{Entradas do modelo (dados e premissas)}

As fontes de dados para o modelo de sedimentos estão descritas na Tabela B2, enquanto a Tabela B3 apresenta o fator de manejo da cultura/vegetação da USLE para cada uma das classes de uso do solo/ cobertura do solo mapeadas na região. 0 s valores do fator $C$ foram atribuídos de acordo com Wischmeier e Mannering (1969). Assim, 0 processo de atribuição de diferentes classes de uso do solo/cobertura do solo combinou os seguintes critérios:

1. Tipo de vegetação predominante (campos, cerrados ou florestas);

2. Estimativa da porcentagem de cobertura do solo (25\%, $50 \%$ e $75 \%)$;

3. Tipo de planta dominante no sub-bosque (grama ou daninha); e

4. Quantidade de solo exposto (sem cobertura do sub-bosque) (20\% $40 \%-60 \%-80 \%-90 \%+)$.

\section{Calibração do modelo}

Como a USLE é uma equação geral aplicada globalmente, alguns fatores locais podem ser ajustados a partir de novas observações. Assim, o resultado será mais próximo dos dados reais observados. Em vários casos, o parâmetro monitorado é a turbidez da água, expressa em UNT (unidades nefelométricas de turbidez). UNT é basicamente a propriedade óptica da água referente à absorção e à reflexão da luz; um valor mais alto para a turbidez representa maior dispersão da luz devido à presença de sedimentos ou outros elementos. Como 0 resultado do modelo biofísico é expresso em toneladas de sedimentos por ano, é necessário converter a UNT em valores de sedimentos em suspensão (para mais detalhes sobre essa conversão, consulte 0 Apêndice C). Com os dados de sólidos em suspensão fornecidos pela Cesan, conforme descrito anteriormente, foram recalibrados os níveis de turbidez e sedimentos por equações reversas. 


\begin{tabular}{|c|c|c|}
\hline ENTRADA & DESCRIÇÃO & FONTE \\
\hline $\begin{array}{l}\text { Índice de erosividade } \\
\text { das chuvas }(R)\end{array}$ & $\begin{array}{l}\text { Conjunto de dados raster de SIG com um valor de índice de erosividade } \\
\text { para cada célula com resolução espacial de } 1 \text { km. Essa variável depende da } \\
\text { intensidade e da duração das chuvas na área de estudo. }\end{array}$ & Mello et al. (2012) \\
\hline $\begin{array}{l}\text { Índice de erodibilidade } \\
\text { do solo }(K)\end{array}$ & $\begin{array}{l}\text { Conjunto de dados raster de SIG com um valor de erodibilidade do solo para } \\
\text { cada célula. Essa medida corresponde à suscetibilidade das partículas do solo } \\
\text { ao desprendimento e subsequente transporte pela enxurrada ou escoamento } \\
\text { da água da chuva. Os dados originais estão em formato vetorial e foram } \\
\text { convertidos para o formato raster, ajustados para uma resolução espacial de } \\
30 \mathrm{~m} \text {. }\end{array}$ & Medeiros et al. (2016) \\
\hline $\begin{array}{l}\text { Modelo de Elevação } \\
\text { Digital (DEM) }\end{array}$ & $\begin{array}{l}\text { Conjunto de dados raster de SIG com um valor de elevação para cada célula } \\
\text { com resolução espacial de } 10 \text { m. A camada raster final foi gerada usando o } \\
\text { processo de interpolação da linha de contorno mapeada para o estado do } \\
\text { Espírito Santo. }\end{array}$ & Geobases-ES (2018) \\
\hline $\begin{array}{l}\text { Uso do Solo/Cobertura } \\
\text { do Solo (LULC) }\end{array}$ & $\begin{array}{l}\text { Conjunto de dados raster de SIG com um código LULC inteiro para cada } \\
\text { célula. } 0 \text { raster do LULC foi mapeado na escala 1:10.000 (adequada para uma } \\
\text { resolução espacial de aproximadamente } 5 \text { m). 0s dados originais estão em } \\
\text { formato vetorial e foram convertidos e reamostrados para uma resolução } \\
\text { espacial de } 30 \text { m. }\end{array}$ & $\begin{array}{l}\text { Baseado nas fotos aéreas de } 2012 \\
\text { (Geobases-ES, 2018) }\end{array}$ \\
\hline Tabela biofísica & $\begin{array}{l}\text { Tabela (.csv) contendo informações de modelo correspondentes a cada uma } \\
\text { das classes de uso do solo. Inclui um fator de gerenciamento de cobertura do } \\
\text { solo }(C) \text { e um fator de práticas favoráveis }(P) \text {. }\end{array}$ & $\begin{array}{l}\text { Adaptado de Wischmeier e } \\
\text { Mannering (1969); } \\
\text { ver Tabela B3 a seguir }\end{array}$ \\
\hline
\end{tabular}

Nota: Esses parâmetros foram avaliados para cada classe de LULC considerando suas características. 0 fator C foi atribuído a partir de uma combinação dos parâmetros.

A função SDR permite ao usuário calibrar quatro variáveis (Figura B3) (Sharp et al., 2016). Assim, as seguintes variáveis estão disponíveis para calibração no modelo SDR:

1. SDR máxima: proporção máxima de SDR que um pixel pode atingir; fração de partículas do solo superficial menores que a areia grossa $(<1 \mathrm{~mm})$.

2. Parâmetros $I C_{0}$ e $k_{b}$ : definem a relação entre o índice de conectividade e a taxa de transferência de sedimentos (SDR) (Figura B3).

3. Limiar de acumulação de fluxo (threshold flow accumulation TFA): cria a rede de fluxo potencial na região de estudo. 0 valor da configuração varia de acordo com a região; o resultado precisa ser comparado à rede de fluxo real. Valores maiores tendem a mapear uma rede de fluxo com menos afluentes, enquanto valores menores correspondem a uma rede com mais afluentes.

Existem poucos estudos locais para avaliar a quantidade de sedimentos transportados para os cursos d'água com base em modelagem espacial. Alguns estudos desenvolvidos sobre a região das Bacias do Jucu e do SMV são aqueles elaborados por Mendonça et al. (2014), Nunes (2013) e Sperandio et al. (2012); no entanto, a escassez de dados de campo é muito frequente. Os parâmetros de calibração do InVEST foram definidos para ajustar os resultados usando como referência o valor de 32 UNT para a Bacia do Jucu (Fioresi e Torres, 2019) e 38 UNT para a Bacia do SMV (Pagiola, Platais e Sossai, 2019).
Figura B3 | Variáveis passíveis de ajuste no modelo SDR

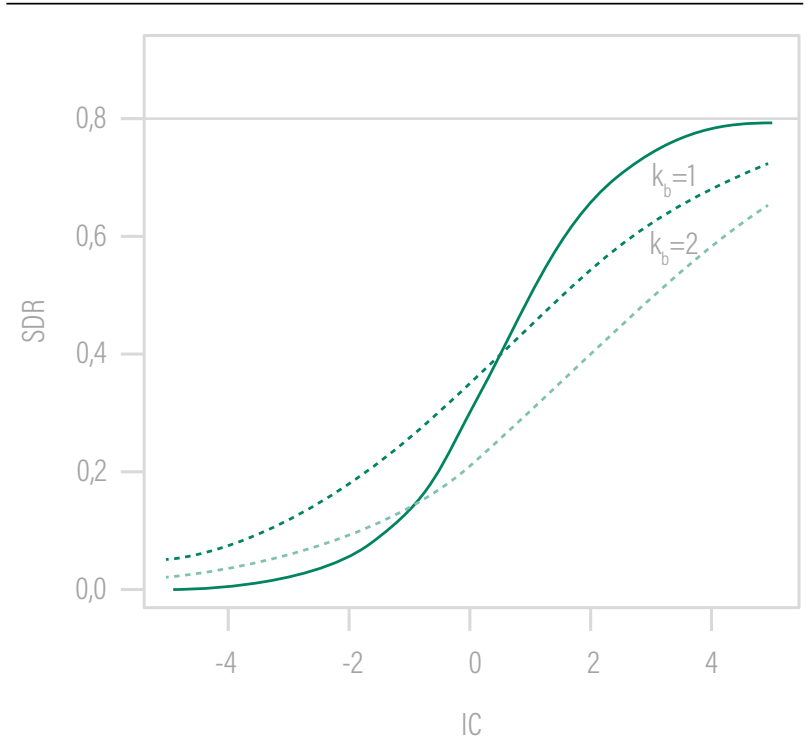

Fonte: Sharp et al. (2016).

Nota: 0 SDR é a taxa de transferência de sedimentos, enquanto o IC é o índice de conectividade. As curvas representam a relação entre o SDR e o IC quando diferentes valores são aplicados. 
Tabela B3 | Dados biofísicos de entrada para os fatores C e P exigidos pela USLE

\begin{tabular}{|c|c|c|c|}
\hline USO DO SOLO/COBERTURA DO SOLO & CÓDIGO & FATOR C & FATOR $P$ \\
\hline Mata nativa & 1 & 0,009 & 1 \\
\hline Mata nativa em estágio inicial de regeneração & 2 & 0,019 & 1 \\
\hline Brejo & 5 & 0,003 & 1 \\
\hline Solo exposto & 6 & 0,5 & 1 \\
\hline Macega & 7 & 0,019 & 1 \\
\hline Campo rupestre/Altitude & 8 & 0,0001 & 1 \\
\hline Extração de mineração & 9 & 0,0001 & 1 \\
\hline Afloramento rochoso & 10 & 0,0001 & 1 \\
\hline Reflorestamento - Eucalipto & 11 & 0,17 & 1 \\
\hline Reflorestamento - Seringueira & 12 & 0,17 & 1 \\
\hline Reflorestamento - Pinus & 13 & 0,17 & 1 \\
\hline Cultivo agrícola - Café & 14 & 0,19 & 1 \\
\hline Cultivo agrícola - Cana-de-açúcar & 15 & 0,1 & 1 \\
\hline Cultivo agrícola - Coco-da-baía & 18 & 0,19 & 1 \\
\hline Cultivo agrícola - Banana & 19 & 0,19 & 1 \\
\hline Cultivo agrícola - Outros cultivos permanentes & 20 & 0,2 & 1 \\
\hline Cultivo agrícola - Outros cultivos temporários & 21 & 0,2588 & 1 \\
\hline Pastagem & 22 & 0,1514 & 1 \\
\hline Massa d'água & 23 & 0,0001 & 1 \\
\hline Área edificada & 24 & 0,0001 & 1 \\
\hline Outros & 25 & 0,1384 & 1 \\
\hline
\end{tabular}

Fonte: Elaborada pelos autores, adaptada de Wischmeier e Mannering (1969).

Nota: 0 fator $C$ corresponde ao tipo de uso do solo/cobertura do solo e o fator $P$, ao tipo de manejo do solo para evitar a geração de sedimentos.

Os processos de calibração comparam o valor de UNT convertido em sedimentos exportados e os dados de saída do modelo biofísico, gerando as seguintes saídas (Sharp et al., 2016):

1. USLE: perda potencial de solo na região (toneladas/pixel);

2. Exportação de sedimentos: total de sedimentos exportados de cada pixel que atinge 0 curso d'água (toneladas/pixel); e

3. Índice de retenção de sedimentos: referência que verifica se todos os tipos de LULC são convertidos em solo exposto. A quantidade de sedimentos deve ser interpretada como um valor relativo (toneladas/pixel).

Com base nos valores de referência da UNT, foram utilizados os seguintes parâmetros ajustados para as Bacias do Jucu e do SMV: TFA: $1.000 ; I_{0}=0,65 ; k_{b}=0,38$.

\section{Modelagem espacial para aplicação do GGA/WRI}

A ferramenta chamada LegalGeo (0akleaf et al., 2017) foi utilizada para selecionar os pixels a serem restaurados em base na meta de área a ser restaurada. A ferramenta seleciona as áreas elegíveis (pixels) com valor mais alto de exportação de sedimentos até que a área que contempla o objetivo da restauração seja atingida.

Os resultados do InVEST foram traduzidos em valores anuais de sedimentos evitados, usando o método e as premissas detalhadas por Ozment et al. (2018). Como o cronograma de restauração ocorre em três anos e fornece custos e benefícios para um período de 20 anos, 0 controle da erosão total é uma função da área restaurada, da idade da restauração e da porcentagem do controle da erosão em cada ano. 


\section{APÊNDICE C. MÉTODOS E PREMISSAS DA ANÁLISE FINANCEIRA}

Este apêndice visa apresentar detalhes da estimativa de custos e benefícios, bem como a análise de sensibilidade, Passos 4, 5 e 6 do GGA/WRI.

\section{Regeneração natural e restauração ativa}

Para estimar a área com alto potencial de regeneração natural, utilizou-se um mapa de regeneração natural local seguindo o mesmo método apresentado por Ozment et al. (2018). 0 mapa assume que as regiões de pastagem degradada ao redor da floresta em pé serão mais capazes de se regenerar do que as regiões de pastagem mais distantes de remanescentes florestais, devido ao transporte de sementes, às condições hidrológicas e outros fatores ecológicos fornecidos pela floresta em pé. Para a regeneração natural, foram consideradas 33\% das áreas a serem restauradas. As demais exigiriam restauração ativa, por plantio completo.

\section{Sequenciamento de restauração (cronograma de implementação da restauração)}

A partir de um cronograma hipotético discutido entre participantes dos encontros presenciais e on-line, assumiu-se que o calendário de restauração ocorre durante um período de três anos, seguindo o que é apresentado na Tabela C1.

\section{Abastecimento e demanda de água}

Considerou-se que a demanda de água é dada pelo crescimento populacional dos sete municípios da RMGV projetado para os próximos 20 anos, multiplicado pela elasticidade-consumo de água da população. 0 crescimento populacional foi o mesmo utilizado pelo PERH-ES (AGERH e Seama, 2018). Calculou-se a elasticidadeconsumo de água da população em 1,41\%. A elasticidade foi calculada pelo modelo de Mínimos Quadrados Ordinários para os dados de população e consumo de água em Vitória, segundo dados do SNIS (2020). Considerou-se que a oferta para as respectivas demandas seria provida pelas próprias Bacias do Jucu e do SMV.

\section{Horizonte dos projetos}

0 prazo de 20 anos para projetos financeiros no setor hídrico reflete a vida útil média ponderada das estruturas e equipamentos mais importantes para o tratamento de água, tendo sido usado pelas empresas brasileiras de água na análise de infraestrutura (Ozment et al., 2018).

\section{Taxa de desconto}

Com base na estimativa do custo médio ponderado de capital (WACC) do BTG Pactual (8,6\%) para o setor de água e esgoto no Brasil (Junqueira, Pimentel e Castro, 2017), assumiu-se uma taxa de desconto referencial de 8,5\%. Na análise de sensibilidade (descrita no Capítulo 3), adotou-se a variação da taxa de desconto entre 5\% e 12\%. Esses valores foram determinados com base no prêmio de risco brasileiro em projetos financeiros (Assaf Neto, 2010). 0 Banco Interamericano de Desenvolvimento (BID) recomenda uma taxa de desconto de $12 \%$ para projetos públicos de infraestrutura hídrica na América Latina (Fontanele e Vasconcelos. 2012).

Tabela C1 | Cronograma de restauração

\begin{tabular}{|c|c|c|c|}
\hline ANO & $\begin{array}{c}\text { ÁREA RESTAURADA NA BACIA DO } \\
\text { JUCU (HA) }\end{array}$ & $\begin{array}{c}\text { ÁREA RESTAURADA NA BACIA DO } \\
\text { SMV (HA) }\end{array}$ & $\begin{array}{c}\text { ÁREA RESTAURADA UGRH LITORAL } \\
\text { CENTRAL (JUCU+SMV) (HA) }\end{array}$ \\
\hline 1 & 360 & 200 & 560 \\
\hline 2 & 720 & 400 & 1.120 \\
\hline 3 & 520 & 300 & 820 \\
\hline TOTAL & $\mathbf{1 . 6 0 0}$ & $\mathbf{9 0 0}$ & $\mathbf{2 . 5 0 0}$ \\
\hline
\end{tabular}

Fonte: Elaborada pelos autores, baseado em Sossai (2020)

Tabela C2 | Oferta e demanda de água tratada

\begin{tabular}{|c|c|c|c|}
\hline ANO & BACIA DO JUCU (M³/S) & BACIA DO SMV (M³/S) & $\begin{array}{l}\text { UGRH LITORAL CENTRAL } \\
\left.\text { (JUCU+SMV) ( } \mathrm{M}^{3} / \mathrm{S}\right)\end{array}$ \\
\hline 0 & 4,60 & 2,80 & 7,40 \\
\hline 4 & 4,87 & 2,96 & 7,83 \\
\hline 9 & 5,22 & 3,18 & 8,40 \\
\hline 14 & 5,60 & 3,41 & 9,01 \\
\hline 19 & 6,00 & 3,65 & 9,65 \\
\hline
\end{tabular}

Fonte: Elaborada pelos autores. 


\begin{tabular}{l|l|l}
\hline CENÁRIO FINANCEIRO & TAXA DE DESCONTO ESTIMADA (\%) & $\begin{array}{l}\text { TAXA DE DESCONTO APLICADA } \\
\text { (TAXA TOTAL) (\%) }\end{array}$ \\
\hline Baixo risco - Taxa social de desconto & 5,16 (Valor regular - MPRB - DP) $^{*}$ & 5 \\
\hline Referencial (benchmark) & 8,6 (Valor regular) $^{*}$ & 8,5 \\
Alto risco & 12,04 (Valor regular + MPRB + DP) $^{*}$ & 12 \\
\hline
\end{tabular}

* Valor regular corresponde à taxa de desconto aplicada pela Cesan. MPRB é a média do Risco Brasil nos últimos 5 anos (registrado diariamente). DP é o desvio padrão da média do Risco Brasil nos últimos 5 anos (registrado diariamente).

Fonte: Com base nas orientações de Assaf Neto (2010); Fontanele e Vasconcelos (2012).

\section{Estimativa de custos}

Custos de investimento: todos os investimentos necessários para implantar a restauração. Os custos de investimento são diferentes para a restauração ativa e regeneração natural. Na regeneração natural, o único investimento é o cercamento da área, enquanto a restauração ativa requer investimentos iniciais adicionais, incluindo mudas e insumos químicos. Com base nas práticas recomendadas pelo Programa Reflorestar (Sossai, 2020), os custos de mão de obra da implementação da restauração ativa não são incluídos no cenário de referência nesta análise por suporem a contrapartida do proprietário. No entanto, esses custos foram incluídos em um cenário de análise de sensibilidade como custo de oportunidade da mão de obra.

Custos de transação: despesas incorridas para envolver proprietários de terras nos projetos de restauração, projetar e monitorar o programa e administrar contratos e pagamentos. No contexto deste estudo, alguns programas operantes na região, como 0 Programa Reflorestar, cobrem os custos de administração do projeto. Assim, limitou-se a estimativa de custos de transação apenas aos custos para engajar e envolver proprietários de terras em projetos de infraestrutura natural. Assumiu-se que esses custos correspondem a $1 \%$ sobre os investimentos, vez que já são computados indiretamente nas outras iniciativas existentes, como o próprio Programa Reflorestar (Sossai, 2020).

Custos de oportunidade: neste estudo, considerou-se um custo de oportunidade equivalente ao do projeto de Pagamento por Serviços Ambientais do Programa Reflorestar, fixado em $\mathrm{R} \$ 281$ por hectare por ano para locais com restauração ativa e $\mathrm{R} \$ 267$ por hectare por ano para áreas de regeneração natural (Seama, 2020). Essa premissa é aplicada a Áreas de Preservação Permanente (APP) e a terras comercialmente viáveis, uma vez que o Programa Reflorestar paga proprietários de terra, independentemente do status de proteção de seus locais de restauração. Foram assumidos pagamentos anuais ao longo de 20 anos. Esses incentivos são pagos por cada ano de participação, à parte de um pagamento único ao longo de três anos para insumos de restauração, cobrindo os custos de implantação da restauração.

Também se pode presumir que os custos de oportunidade sejam equivalentes ao uso alternativo do solo mais comum na região, que nesse caso seria o preço do arrendamento de pastagem (FeltranBarbieri et al., 2018; Ozment et al., 2018). Os dados publicados sobre arrendamento de pastagens não estavam disponíveis para a região. No entanto, por meio de entrevistas com as partes interessadas locais, estimou-se que seja em torno de $\mathrm{R} \$ 420$ por hectare por ano. A análise de sensibilidade apresenta um cenário com essa entrada alternativa. Para motivar os proprietários de terras a implementar uma estratégia de infraestrutura natural, o investidor deve atender ou superar 0 custo de oportunidade desses proprietários em associação a um provável uso alternativo da terra. Um pagamento eficaz por serviços ecossistêmicos deve considerar esse custo de oportunidade.

\section{Estimativa de benefícios - Conversões de parâmetros}

Custos evitados no tratamento de água: através de consultas a funcionários de operação da Cesan, bem como na leitura de relatórios de sustentabilidade e financeiros da empresa, estimou-se que atualmente a Cesan gasta com energia elétrica em torno de $\mathrm{R} \$ 0,52$ por metro cúbico de água tratada e $\mathrm{R} \$ 0,22$ por metros cúbicos com produtos químicos, dos quais 33\% para tratar turbidez e o restante destinado a desinfecção e fluoração (Cesan, 2020; Pagiola, 2020). Considerou-se que 0 custo atual de energia apenas relacionado à turbidez é também de 33\% e que a economia de energia elétrica seria diretamente proporcional aos níveis de redução de concentração de sólidos suspensos ao longo do projeto.

Utilizou-se uma sequência de quatro passos com conversões de unidades para se estimar o custo evitado no tratamento de água em função dos diferentes níveis de turbidez média anual, seguindo recomendações de Sousa Júnior (2011). A Figura C1 ilustra o passo a passo. 


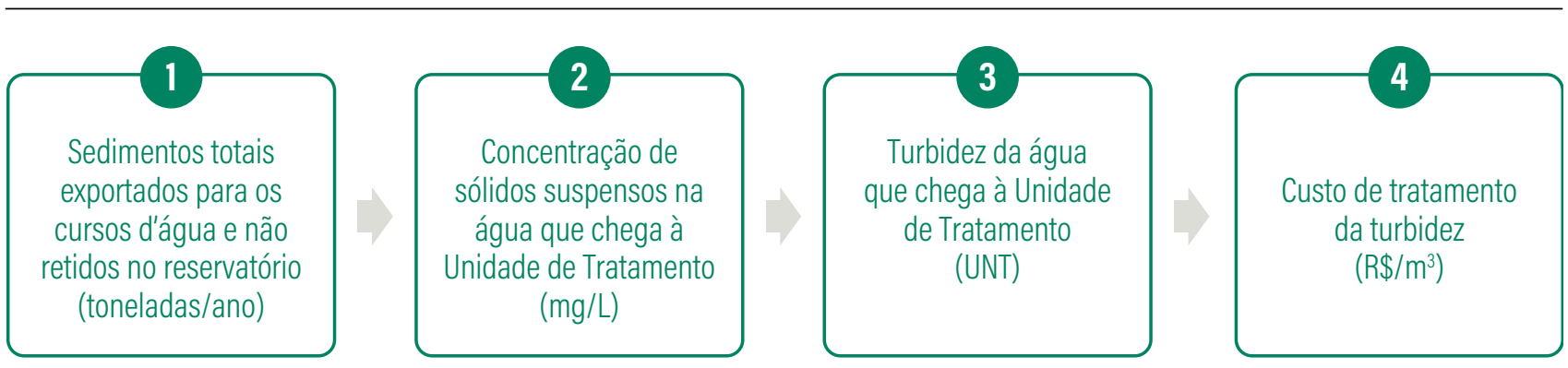

Fonte: Elaborada pelos autores.

\section{Etapa 1 - Estimativa do total de sedimentos na captação das estações de tratamento}

A quantidade anual de sedimentos que chega às estações de tratamento da Bacia do Jucu equivale à soma da exportação de sedimentos na região a montante e a jusante do reservatório. A primeira é uma função dos sedimentos produzidos, capacidade de retenção de sedimentos no reservatório, área restaurada e idade da restauração ano a ano. Para a região a jusante, é uma função dos sedimentos produzidos, área restaurada e idade da restauração ano a ano. Formalmente:

$$
\begin{aligned}
S_{\text {jucu }, a} & =\left\{\left[\begin{array}{ccc}
m_{1,1} & \ldots & m_{1, a} \\
\ldots & \ldots & \ldots \\
m_{a, 1} & \ldots & m_{a, a}
\end{array}\right]_{a, a} *\left[\begin{array}{c}
p_{1, a} \\
\ldots \\
p_{a, 1}
\end{array}\right]_{a, 1} * I_{m} *(1-k)\right\} \\
& +\left\{\left[\begin{array}{ccc}
j_{1,1} & \ldots & j_{1, a} \\
\ldots & \ldots & \ldots \\
j_{a, 1} & \ldots & j_{a, a}
\end{array}\right]_{a, a} *\left[\begin{array}{c}
p_{1, a} \\
\ldots \\
p_{a, 1}
\end{array}\right]_{a, 1} * I_{j}\right\}
\end{aligned}
$$

$S_{\text {jucu, } a}$ corresponde aos sedimentos que chegam aos pontos de captação das estações de tratamento (toneladas/ano), no ano a

$m_{a, i}$ refere-se à área restaurada a montante do reservatório no ano a (hectares), com idade $i$ (anos após o plantio)

$p_{1, a}$ é o percentual de retenção provido pela floresta restaurada com idade $i$ em relação à floresta madura (\%). Em que $p=0,2594$ * $\ln (i)+0,0373$ (estimado a partir de Pooter et alı, 2016)

$I_{m}$ é a quantidade de sedimentos retidos a montante do reservatório se toda a floresta restaurada tivesse $100 \%$ de seu potencial de retenção - output do InVEST (toneladas/ano)

$k$ é a capacidade de retenção de sedimentos do reservatório (\%), aplicado $k=32$ (Condé et al., 2019)

$j_{a, i}$ representa a área restaurada a jusante do reservatório no ano a (hectares), com idade $i$ (anos após o plantio)

$I_{j}$ é a quantidade de sedimentos retidos a jusante do reservatório se toda a floresta restaurada tivesse $100 \%$ de seu potencial de retenção output do InVEST (toneladas/ano)
Para a Bacia do SMV, a função é dada por:

$$
S_{S M V, a}=\left\{\left[\begin{array}{ccc}
v_{1,1} & \ldots & v \\
\ldots & \ldots & \ldots \\
v_{a, 1} & \ldots & v_{a, a}
\end{array}\right]_{a, a} *\left[\begin{array}{c}
p_{1, a} \\
\ldots \\
p_{a, 1}
\end{array}\right]_{a, 1} * I_{v}\right\}
$$

$S_{S M V, a}$ corresponde aos sedimentos que chegam aos pontos de captação das estações de tratamento (toneladas/ano), no ano a

$I_{v}$ é a quantidade de sedimentos retidos na bacia se toda a floresta restaurada tivesse $100 \%$ de seu potencial de retenção - output do InVEST (toneladas/ano)

\section{Etapa 2 - Conversão do total de sedimentos para concentração de sólidos suspensos na água}

Para as duas bacias, utilizou-se a equação estimada por Saad et al. (2018).

$$
s s_{B, a}=0,0317 * S_{B, a} * Q_{B}^{-1}
$$

Onde:

$s s_{B, a}$ corresponde à concentração de sólidos em suspensão na captação da bacia $B$ no ano a (mg/L)

$S_{B, a}$ refere-se aos sedimentos exportados para a bacia $B$ no ano a (t/ ano)

$Q_{B}$ é o fluxo médio de água para cada bacia $B\left(\mathrm{~m}^{3} / \mathrm{s}\right)$. Utilizado 20,91 para a Bacia do Jucu e 16,22 para a Bacia do SMV (AGERH e Seama, 2018)

$0,0317=$ constante de conversão 


\section{Etapa 3 - Conversão da concentração de sólidos suspensos em turbidez}

Para as duas bacias, adotou-se a equação estimada por Piccolo, Pinto e Teixeira (1999):

$$
T_{B, a}=0,29 * S s_{B, a}^{1,254}
$$

Onde:

$T_{B, a}$ é o nível de turbidez na captação na bacia $B$ no ano a (UNT)

$\boldsymbol{s} \boldsymbol{s}_{B, a}$ é a concentração de sólidos em suspensão na captação na bacia $B$ no ano a (mg/L)

\section{Etapa 4 - Custos de tratamento de água devido ao nível de turbidez}

Como existem estações de tratamento de água com capacidades de produção bastante diferentes, sendo três na Bacia do Jucu e duas na Bacia do SMV, antes de considerar os custos de tratamento, estimou-se um fator de economia de escala usando uma regressão em painel. Foi aplicada a estimativa em três bacias hidrográficas como proxy de escala (Jucu, Santa Maria da Vitória e Reis Magos), com dados de 2002 a 2017, disponibilizados pelo Sistema Nacional de Informações sobre Saneamento (SNIS, 2020). A regressão em painel é definida como:

$$
Y_{i t}=\beta X_{i t}+\alpha+u_{i t}+\xi_{i t} \quad \text { (equação A6) }
$$

Onde:

$Y$ = Iquímico, logaritmo natural dos custos com produtos químicos no tratamento de água (R\$) (SNIS, 2020), onde $i$ é o id da bacia hidrográfica e $t$ é 0 ano

$X$ = lágua, logaritmo natural da água tratada (milhares de m³) (SNIS, 2020)

Pibinp - logaritmo natural do PIB industrial per capita - lag (atraso) de 4 anos (IBGE, 2020)

$\alpha-$ intercepto

$u$ - erro entre bacias hidrográficas

$\xi$ - erro no interior da bacia hidrográfica

Os resultados da regressão em painel são apresentados na Tabela C4.
Tabela C4 | Resultados da regressão em painel para estimativa da elasticidade de demanda da água da população da RMGV

\begin{tabular}{ll}
\hline & $(1)$ \\
VARIÁVEL & lquímico \\
\hline lágua & $1,072^{*}$ \\
\hline Pibinp & $27,91^{* *}$ \\
Constante & 1,604 \\
\hline Observações & 46 \\
\hline Número de ottobacias & 3
\end{tabular}

Fonte: Elaborada pelos autores.

Nota: Coeficientes anotados com * significativo a 1\% e ** significativo a 5\%,

Ao contrário do esperado, identificou-se uma deseconomia de escala, como mostrado no coeficiente lágua (1,072). Isso significa que, para cada aumento de 1 ponto percentual na água tratada, 0 custo total aumenta em 1,072\%. Assumiu-se que a equação geral seria aplicada para a ETA Cobi, cuja capacidade de tratamento é 0,9 metros cúbicos por segundo, por ser a estação de capacidade intermediária. Aplicando o coeficiente de escala obtido na regressão em painel, estimou-se que para a ETA Vale Esperança, o custo total de tratamento deveria ser 3,92 vezes mais caro do que 0 de Cobi (enquanto a capacidade total de tratamento é 3,67 vezes maior). Para a ETA Caçaroca, assumiu-se um custo total que corresponde a $44 \%$ do total calculado em Cobi (enquanto a capacidade total de tratamento é $53 \%$ menor).

Tomando-se em conta o estudo de Pagiola, Platais e Sossai (2019) sobre os custos de tratamento na ETA Carapina, e atualizando os valores monetários para novembro de 2020, os custos médios de tratamento da água na ETA Vale Esperança seriam de aproximadamente $\mathrm{R} \$ 0,31$ por metro cúbico para turbidez de 10 UNT e R $\$ 0,59$ por metro cúbico para turbidez de 100 UNT, o que parece inconsistente. Assim, decidiu-se usar como base de cálculo para todas as três estações os valores obtidos por Pagiola, Platais e Sossai (2019) atualizados pelo IGP-DI, multiplicados pelo fator de correção de escala de 2,27 (inverso do coeficiente 0,44 estimado conforme parágrafo anterior).

0 estudo de Pagiola, Platais e Sossai (2019) não fornece a equação estimada, mas apresenta o gráfico com os pontos amostrados e linha tendencial. Utilizando o software CorelDraw, projetou-se o gráfico em zoom de 5 vezes, estimando as distâncias lineares entre o centro de cada ponto amostral e 0 eixo x (turbidez) e o eixo y (custos, em $R \$ / \mathrm{m}^{3}$ ). Mantendo a proporcionalidade das distâncias e da escala originalmente publicada, estimam-se os valores referentes de cada ponto em termos de turbidez e custo. Esses valores estimados foram corrigidos pelo índice IGP-DI e multiplicados pelo fator de escala. Para simplificar a análise financeira, utilizou-se a mesma função de custo para todas as estações e, portanto, todo o volume produzido. A função de custo derivada da função original de Pagiola, Platais e Sossai (2019) foi:

$$
C_{B, a}=\left(0,000756 * T_{B, a}\right)+0,069091
$$


Onde:

$C_{B, a}$ refere-se aos custos de insumos químicos para tratar a turbidez na captação na bacia $B$ no ano a ( $\mathrm{R} \$ / \mathrm{m}^{3}$ de água tratada)

$T_{B, a}$ é o nível de turbidez na captação na bacia $B$ no ano a (UNT)

Outros custos diretamente relacionados a níveis de turbidez, como substituição de areia, antracito e limpeza de lodo dos equipamentos, foram assumidos na relação dada por:

$$
O_{B, a}=O_{B} * \frac{T_{B, a}}{T_{B, a-1}}
$$

Onde:

$O_{B, a}$ corresponde a outros custos relacionados à turbidez na bacia $B$ no ano $a$

$O_{B}$ corresponde a outros custos referenciais para a bacia $B$ (conforme Tabela 3 do texto principal)

Para os custos com energia, foi aplicado o mesmo raciocínio, substituindo-se, entretanto, as variações no nível de turbidez pelas variações dos sólidos suspensos (trocando, na fórmula acima, $T$ por $s s$ ).

\section{Depreciação de ativos}

De acordo com entrevistas feitas com a equipe técnica da Cesan, a taxa de depreciação regular é, em média, 1,91\% ao ano e, para reservatório, espera-se 0,5\% ao ano. Assumiu-se que a redução de sedimentos resulta em uma economia de custos equivalente à depreciação evitada de equipamentos na estação de tratamento de água, supondo que quanto menor for a quantidade de sólidos em suspensão e lodo, menor será o desgaste do maquinário utilizado para tratar a turbidez. Calculou-se esse valor usando os mesmos quatro passos indicados anteriormente, substituindo-se, na última equação, os valores de outros custos pelo valor referencial de depreciação, obtidos nos relatórios financeiros da Cesan, cujo referencial está na Tabela 3 do texto principal.

\section{Custo de dragagem}

Refere-se ao custo de retirada de sedimentos depositados no reservatório e que precisam ser removidos periodicamente para manter a capacidade de reservação de água, recuperando ou minimizando os impactos de assoreamento. 0 custo unitário foi estimado em $R \$ 1,40$ por tonelada de sedimento retirado, baseado em entrevistas locais.

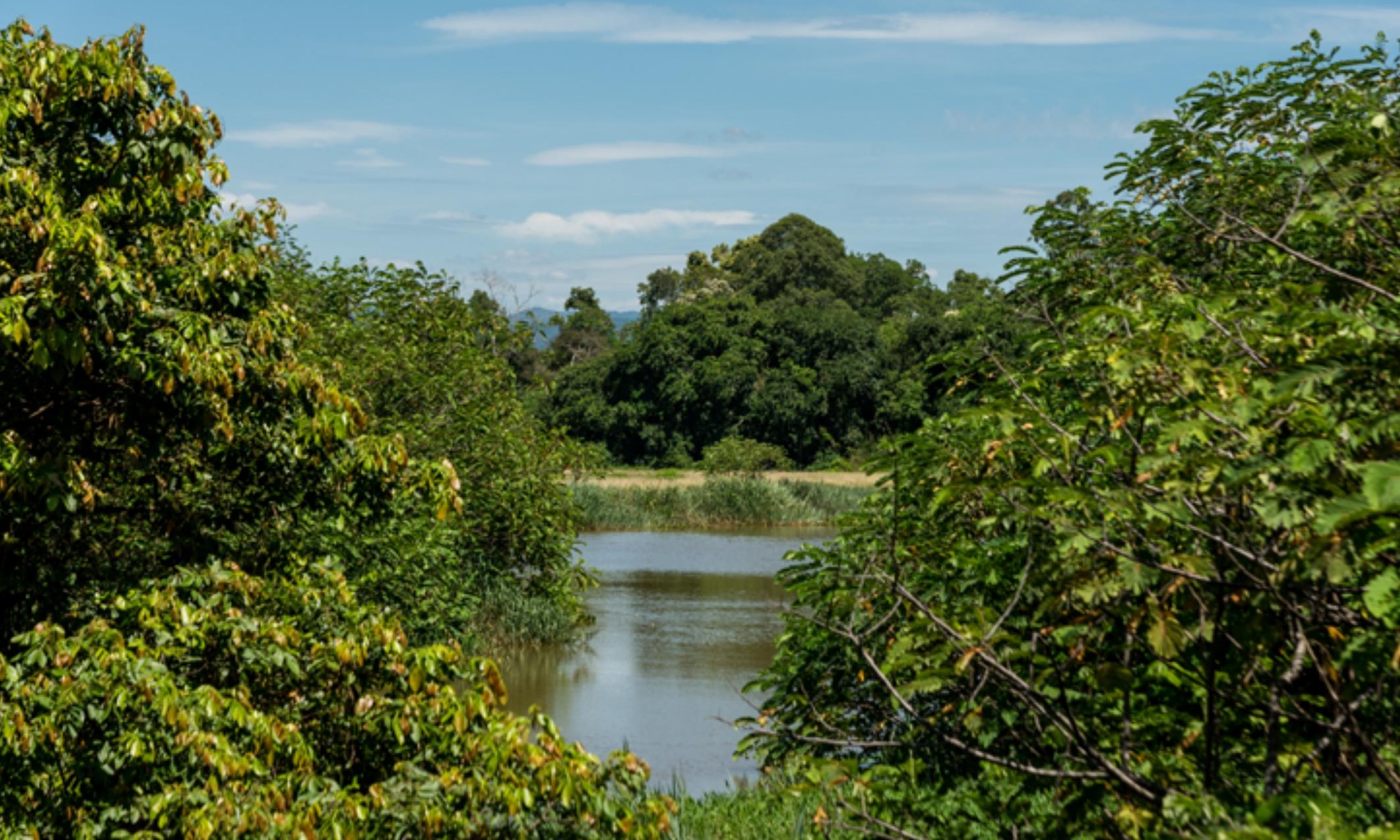


AGERH (Agência Estadual de Recursos Hídricos). Seama (Secretaria do Meio Ambiente e Recursos Hídricos). 2018. Plano Estadual de Recursos Hídricos do Espírito Santo. Macroproduto 5 - Versão Final. Vitoria: AGERH/SEAMA. Disponível em https://perh.es.gov.br/Media/ perh/Arquivos\%20Biblioteca/PERH-ES_DocumentoConsolidado.pdf Último acesso em 11 de Dezembro de 2020.

Ahnert. Fabio. 2020. Comunicação pessoal entre Rafael Feltran-Barbieri e Fabio Ahnert. Executive Director AGERH. Espírito Santo. Vídeo conferência. 20 de Novembro de 2020.

Assad. E.D. et al, 2019. Role of the ABC Plan and Planaveg in the adaptation of crop and cattle farming to climate change. Working Paper. São Paulo. Brazil: WRI Brasil. Disponível em: https://wribrasil. org.br/pt/publicacoes. Último acesso em 11 de Agosto de 2020.

Assaf Neto. A. 2010. Finanças corporativas e Valor. São Paulo: Atlas.

Benedict. M. A. McMahon. E. T. 2006. Green Infrastructure: Linking Landscapes and Communities. Washington: Island Press.

Benini. R. e Adeodato. S. 2017. Forest restoration economy. São Paulo: The Nature Conservancy. https://www.nature.org/media/brasil/ economia-da-restauracao-florestal-brasil.pdf. Último acesso em 11 de Outubro de 2020.

Browder. G. S. Ozment. I. Rehberger-Bescos. T. Gartner. and G-M. Lange. 2019. Integrating Green and Gray: Creating Next-Generation Infrastructure. Washington. DC: World Bank and World Resources Institute.

CBH Jucu e CBH SMV. 2017. Jucu RT-2 Diagnóstico Das Bacias. Volumes 1, 2 e 3. Vitória. Brasil: CBH Jucu/CBH SMV.

CBH SMV. CBH Jucu. IEMA 2016 Projeto de Restauração e Conservação da Biodiversidade e dos Recursos Hídricos no Estado do Espírito Santo. nas Bacias do Rio Jucu e Santa Maria da Vitória. Projeto Florestas para Vida. Vitoria: CBHSMV/JUCU/IEMA.

Cesarino. A. A.L.O. Lima. 2012. "Comparativo entre o Policloreto de Alumínio e o Sulfato de Alumínio na ETA V - Carapina."

Apresentação no VI Encontro de Inovação da CESAN. Vitória. Brazil. Disponível em https://www.cesan.com.br/encontroinovacao/ download.php?file =../wp-content/uploads/encontro/arquivos/ downloads/_20121108113525_thumb_24AlosioCeresino. pdf\&nome=24\%20-\%20Alo\%EDsio\%20Ceresino.pdf. Último acesso em 11 de Dezembro de 2020.

Cesan (Companhia Espírito Santense de Saneamento). 2010. Paralisação no abastecimento de água - ETA Carapina December 10. https://www.cesan.com.br/noticias/paralisacaono-abastecimento-de-agua-eta-carapina/. Último acesso em 3 de Agosto de 2019.

Cesan (Companhia Espírito Santense de Saneamento). 2019a. "Relatório da Administração: passado presente futuro". Vitoria: Cesan. Disponível em: https://www.cesan.com.br/wp-content/uploads/2019/01/ Relatorio_Administraca0_2015_2018_07_01_19.pdf. Último acesso em Dezembro de 2020.
Cesan (Companhia Espírito Santense de Saneamento). 2019b. "Relatório de Sustentabilidade 2017". Vitoria: Cesan. Disponível em: https:// relatorio17.sistemas.cesan.com.br/. Último acesso em 11 de Dezembro de 2020.

Cesan (Companhia Espírito Santense de Saneamento). 2020. "Balanços e relatórios".. Vitoria: Cesan. Disponível em: https://relatorio17.

sistemas.cesan.com.br/. Último acesso em 16 de Fevereiro de 2021.

Condé R.C. Martinez. JM. Pessotto. M... Villar. R. et al. 2019 "Indirect assessment of sedimentation in hydropower dams using Modis Remote sensing images. Remote Sensing 11(3). $314 \mathrm{https://doi.}$ org/10.3390/rs11030314.

CNM (Confederação Nacional de Municípios). 2018. Calamidades causadas por desastres afetam municípios brasileiros. Estudos Técnicos CNM. Edição Julho de 2018. Disponível em: https://www. cnm.org.br/cms/biblioteca/ET_Vol_10_01.Calamidades_causadas_ por_desastres_afetam_os_municipios_brasileiros.pdf.

Dargahi B. 2012. Reservoir Sedimentation. In: Bengtsson L.. Herschy R.W.. Fairbridge R.W. (eds) Encyclopedia of Lakes and Reservoirs. Encyclopedia of Earth Sciences Series. Springer. Dordrecht. https://doi. org/10.1007/978-1-4020-4410-6_215.

Elesbon. A. 2020. Segurança Hídrica no contexto do desenvolvimento regional sustentável. Vitória: Observatório do Desenvolvimento Capixaba. Seminário Temático Segurança Hídrica. 06 de novembro de 2020.

Feltran-Barbieri. R. S. Ozment. P. Hamel. E. Gray. H. Mansur. T. Piazetta Valente. J. Baladelli Ribeiro. M. Matsumoto. 2018. Infraestrutura Natural para água no Sistema Guandu. Rio de Janeiro. Sao Paulo: World Resources Institute-Brasil.

Fioresi. C. H. U. Torres. H. 2019. Analysis of soil use of areas of permanent preservation and water quality of rivers Itapemirim. Jucu. Benevente e Santa Maria da Vitória (ES). Brazilian Journal of Development 5(3):2030-2049.

Fontanele. R. and 0. Vasconcelos. 2012. Análise da viabilidade econômico-financeira de projetos de abastecimento d'água: 0 caso do sistema de abastecimento da cidade de Milhã. no estado do Ceará. Paper for Sociedade Brasileira de Economia. Administração e Sociologia Rural. http://www.sober.org.br/palestra/12/060320.pdf. Acessado em 19 de Dezembro de 2019.

Frame. D.J. Rosier. S.M. Noy. I. Harrington L.J. Carey-Smith. T. et al. 2020. Climate change attribution and the economic costs of extreme weather events: a study on damages from extreme rainfall and drought.

Climatic Change 162:781-797.

Geobases-ES (Sistema Integrado de bases geoespaciais do Estado do Espírito Santo). 2018. (Database) Retrieved from: https://geobases. es.gov.br/. Último acesso em 07 de Dezembro de 2020.

Gonzalez-Perez. A. Persson. K.M. Lipnizky. F. 2018 "Functional Channel Membranes for Drinking Water Production" Water 10. 859.w10070859. 
Governo ES. 2016. Pedag 3. Plano Estratégico de Desenvolvimento da Agricultura Capixaba 2015-2030. Vitoria: GES. Disponível em https:// seag.es.gov.br/Media/seag/Documentos/PEDEAG_Completo_ sem\%20ficha\%20t\%C3\%A9cnica\%20(1).pdf Último acesso em 17 de Maio de 2019.

Governo ES (Governo do Estado do Espírito Santo). 2017. Estado restabelece cenário de alerta e rodízio na Grande Vitória pode voltar. November 1. https://www.es.gov.br/Noticia/estado-restabelececenario-de-alerta-e-rodizio-na-grande-vitoria-pode-voltar. Último acesso em 11 de Novembro de 2019.

Governo ES. Banco Mundial. Cesan. 2013. Programa de Gestão Integrada das Águas e da Paisagem. Relatório de Avaliação Ambiental e Social-RAAS e arcabouço para o Gerenciamento Ambiental e Social do Programa. Sumário Executivo. Vitória: Governo ES. Disponivel em https://www.cesan.com.br/wp-content/ uploads/2013/10/16-Sumario-Executivo-Set-2013-AF-1.pdf. Último acesso em 11 de Setembro de 2020.

Gray. E. S. Ozment. J.C. Altamirano. R. Feltran-Barbieri. and G. Morales. 2019. Green-Gray Assessment: How to Assess the Costs and Benefits of Green Investments for Water Supply Systems. Washington DC: World Resources Institute.

IBGE (Instituto Brasileiro de Geografia e Estatísticas). 2020. Produto Interno Bruto dos Municípios - 2002-2018. Rio de Janeiro: IBGE Disponível em: https://sidra.ibge.gov.br/tabela/5938. Último acesso em 14 Dezembro de 2020.

Inmet (Instituto Nacional de Meteorologia). 2021. Banco de Dados Meteorológicos - Séries Históricas. Brasília: INMET/MAPA. Disponível em: https://bdmep.inmet.gov.br/.

Instituto Trata Brasil. 2020. Ranking do Saneamento 2020. SNIS 2018. relatório completo. São Paulo: Instituto Trata Brasil/GO Associados. Disponível em http://tratabrasil.com.br/estudos/estudositb/itb/ranking-do-saneamento-2020. Último acesso em 11 de Dezembro de 2020.

Junqueira. A. J. Pimentel. G. Castro. 2017. Brazilian Water and Sewage Sector: Is a Revolution Coming? New York: BTG Pactual. Equity Research. Disponível em: https://static.btgpactual.com/media/ brut170308-water-privatization.pdf. Último acesso em 04 de Maio de 2018.

Kissinger. G. 2014. Integrated Landscape Initiative Analysis: Financing Strategies for Integrated Landscape Investments: Case Study Atlantic Forest. Brazil. Washington. D.C.: EcoAgriculture Partners.

Kroeger. T. D. Shemie. T. Boucher. J.R.B. Fisher. E. Acosta and DennedyFrank. 2017. Assessing the Return on Investment in Watershed Conservation. Arlington. VA. USA: The Nature Conservancy.

Kummu. M. Varis. 0. 2007. Sediment-related impacts due to upstream reservoir trapping, the Lower Mekong River. Geomorphology 85:275-293.

Lapig Laboratório de Processamento de Imagens e Geoprocessamento. 2020. Atlas das pastagens brasileiras. Goiania: Lapig/UFG/IESA. Disponível em: https://www.lapig.iesa.ufg.br/lapig/index.php/ produtos/atlas-digital-das-pastagens-brasileiras. Último acesso em 05 de Dezembro de 2020.
Linhalis. C.A. 2019. Comunicação pessoal entre Rafael Feltran-Barbieri e Carlos Aurelio Linhalis. Executive Director. CESAN. Vitoria. Espírito Santo. Março de 2019.

Lopez, H. 2008. The social discount rate: estimates for nine Latin American countries. Washington: World Bank/Latin America and the Caribbean Region/Office of the Chief Economist Policy Research. Disponível em: http://documents.worldbank.org/curated/ pt/135541468266716605/pdf/wps4639.pdf.

Medeiros G.0.R. A. Giarolla. G. Sampaio. M.A. Marinho. 2016. Estimates of Annual Soil Loss Rates in the State of São Paulo. Brazil. Revista Brasileira de Ciência do Solo, 40. e0150497, http://dx.doi.org/10.1590 /18069657rbcs20150497.

Mello. C. R. M.R. Viola. N. Curi. A.M. Silva. 2012. Distribuição espacial da precipitação e da erosividade da chuva mensal e anual no Estado do Espírito Santo. Revista Brasileira de Ciência do Solo 36(6): 1878-1891.

Mendonça. H.F.P. E.M. Paterlini. F.S. Oliveira. R.P. Barbosa and A.R. Santos. 2014. Estimativa da perda de solo por erosão laminar para o município de Iconha. Estado do Espírito Santo. Enciclopédia Biosfera10(19):1027-1038.

Neary. D.G. G.G. Ice. and C.R. Jackson. 2009. Linkages between Forest Soils and Water Quality and Quantity. Forest Ecology and Management 258(10): 2269-2281. doi:10.1016/j. foreco.2009.05.027.

Nunes. A.R. 2013. Confronto do uso e ocupação da terra em APP's e estimativa de perda de solo na Bacia Hidrográfica do Rio Alegre. Dissertação de Mestrado. Programa de Pós Graduação em Ciências Florestais. Universidade Federal do Espírito Santo.

Oakleaf. J. R. M. Matsumoto. C.M. Kennedy. L. Baumgarten. D. Miteva. K. Sochi and J. Kiesecker. 2017. "LegalGEO: Conservation Tool to Guide the Siting of Legal Reserves under the Brazilian Forest Code." Applied Geography 86(1):53-65. https://doi.org/10.1016/j.apgeog.2017.06.025.

Oliveira. R.M.L. 2011. A criação dos Comitês de Bacias Hidrográficas dos rios Jucu e Santa Maria da Vitória: perspectivas e desafios da gestão. Vitoria. Universidade Federal do Espírito Santo. Centro de Ciências Humanas e Naturais. Dissertação de Mestrado.

Ozment. S. T. Gartner K. DiFrancesco. H. Huber-Stearns. N. Lichten. and S. Tognetti. 2016. Protecting Drinking Water at the Source: Lessons from United States Watershed Investment Programs. Washington. DC: World Resources Institute.

Ozment. S. R. Feltran-Barbieri P. Hamel. E. Gray. J. Baladelli Ribeiro. S. Barreto. and A. Padovezi. 2018. Natural Infrastructure in Sao Paulo's Cantareira System Washington. DC: World Resources Institute.

Pagiola. S. G. Platais and M. Sossai. 2019. "Protecting Natural Water Infrastructure in Espírito Santo. Brazil." Water Economics and Policy $e 1850027$.

Pagiola. S. (2020). Comunicação pessoal entre Rafael Feltran-Barbieri e Stefano Pagiola. Senior Environmental Economist. Latin America and Caribbean. World Bank. Vídeo conferência. Novembro. 2020. 
Pagioro. T.A. Thomaz. S.M. 2002. Longitudinal patterns of sedimentation in a deep. monomictic subtropical reservoir (Itaipu. Brazil-Paraguay). Archiv fur Hydrobiologie 154(3):515-528.

Piccolo. M.A.M. Pinto. C.A..Teixeira. E. 1999. Correlação entre sólidos em suspensão, cor e turbidez para água captada no Rio Jucu - ES. In XX Congresso Brasileiro de Engenharia Sanitária e Ambiental. Anais. II-053. Rio de Janeiro: Associação Brasileira de Engenharia Sanitária e Ambiental. Disponível em: http://www.bvsde.paho.org/bvsaidis/ brasil20/ii-053.pdf Último acesso em 19 de Novembro de 2019.

Poorter. L. F. Bongers. T.M. Aide. A.M. Almeyda Zambrano. P. Balvanera. J. Becknell. V. Boukiliet al. 2016. Biomass Resilience of Neotropical Secondary Forests. Nature 530 (7589): 211-14.

Ran. L.. Lu X.X. Xin. Z. Yang. X. 2013. Cumulative sediment trapping by reservoirs in large river basins: A case study of the Yellow River basin. Global and Planetary Change 100: 308-319.

Saad SI. Mota da Silva J. Silva MLN. Guimarães JLB. Sousa Júnior WC Figueiredo R0 et al. 2018. Analyzing ecological restoration strategies for water and soil conservation. PLoS One 13(2): e0192325.

Scalzer. P. 2016. Projeto de barragem do Rio Jucu fica pronto em oito meses. CBN Vitoria. 05 de Novembro. Disponível em: http://www. gazetaonline.com.br/cbn_vitoria/reportagens/2016/05/projeto-debarragem-do-rio-jucu-fica-pronto-em-oito-meses-1013942867.html. Último acesso em 17 de Fevereiro de 2018.

Seama (Secretaria de Estado do Meio Ambiente e Recursos Hídricos do Estado do Espírito Santo). 2017. Avaliação das oportunidades da restauração de paisagens e florestas para o Estado do Espírito Santo. Brasil. Vitoria/São Paulo: SEAMA/WRI Brasil/IUCN/TNC/Ibio/IIS

Seama (Secretaria de Estado do Meio Ambiente e Recursos Hídricos do Estado do Espírito Santo). 2020. "Programa Reflorestar. Disponível em https://seama.es.gov.br/como_funciona. Último acesso em 14 de Dezembro de 2020.

Seag. 2018. SEAG - Programa Estadual de Construção de Barragens. 2018. Disponível em: https://seag.es.gov.br/programa-estadual-deconstrucao-de-barragens. Último acesso em 17 de Junho de 2018.

Sharp. R. H.T. Tallis. T. Ricketts. A.D. Guerry. S.A. Wood. R. ChaplinKramer. E. Nelson, et al. 2016. InVEST +VERSION+ User's Guide. The Natural Capital Project. Stanford University. University of Minnesota. The Nature Conservancy, and World Wildlife Fund. Disponível em http://data.naturalcapitalproject.org/nightly-build/invest-usersguide/html/. Último acesso em 17 de Fevereiro de 2018.

SNIS (Sistema Nacional de Informações sobre Saneamento). 2020. Série Histórica. Brasília: Ministério do Desenvolvimento Regional. Disponível em: http://app4.mdr.gov.br/serieHistorica/. Último acesso em 09 de Dezembro de 2020.

Sossai. Marcos. 2020. Comunicação pessoal entre Rafael FeltranBarbieri e Marcos Sossai. Manager. Programa Reflorestar. SEAMA. Vídeo Conferência. Novembro de 2020.
Sossai. M.F., F.Z. Novelli. S.R.S. Aniceto. R. Boni. and R.J.S. Costa. 2013. "Projeto Florestas para Vida." In: S. Pagiola. and H. Carrascosa von Glehn. and D. Taffarello (Eds.). Experiências de pagamentos por serviços ambientais no Brasil. São Paulo: Secretaria do Meio Ambiente.

Sousa Junior. W.C. 2011. Análise econômica da relação entre 0 uso do solo e custos de tratamento de água no Estado de São Paulo São Paulo: SMA/GEF/WB. Projeto de Recuperação de Matas Ciliares. Produtos Técnicos 1. Junho de 2011.

Sperandio. H. V. R.A. Cecílio. W.A.Campanharo. C.F. CaroandM.P.de Hollanda. 2012. Avaliação da erosão hidrica pela alteração na superfície do solo em diferentes coberturas vegetais de uma sub-bacia hidrográfica no Município de Alegre. ES. Ciências Agrárias 33:1411-1418.

Stone R.P. Hilborn. D. 2012. Universal soil loss equation (USLE) factsheet. Ministry of Agriculture. Food and Rural Affairs. Ontario. Disponível em: http://www.omafra.gov.on.ca/english/engineer/facts/12-051.htm . Último acesso em 21 de Maio de 2019.

Taffarello. D. Mohor G.S. Calijuri M.C. Mendiondo E.M. 2016. Field investigations of the 2013-14 drought through quali-quantitative freshwater monitoring at the headwaters of the Cantareira System. Brazil. Water International 41(5):776-800.

Wischmeier. W. H. and Mannering. J. V. 1969. Relation of Soil Properties to its Erodibility. Soil and Water Management and Conservation. 15. 131-137. https://doi.org/10.2136/sssaj1969.03615995003300010035x. 


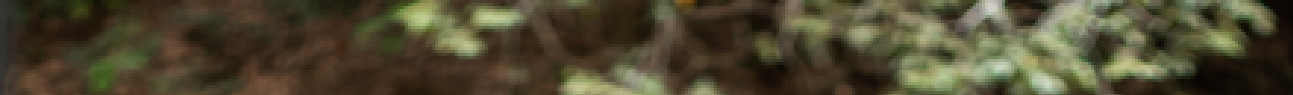

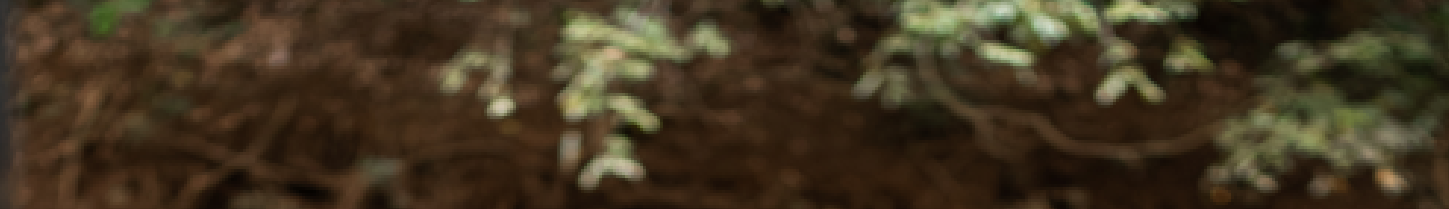

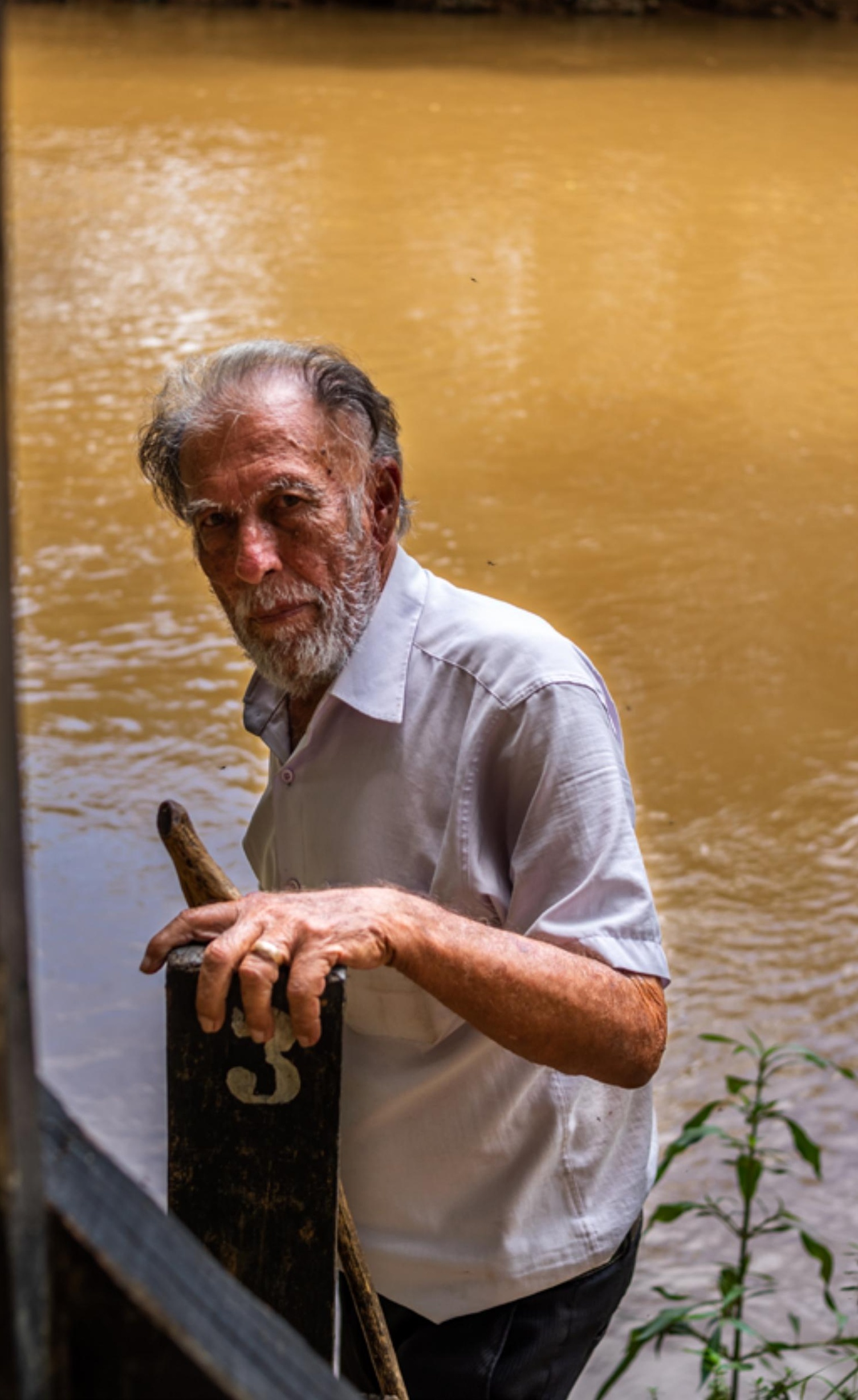




\section{SOBRE 0 WRI BRASIL}

0 WRI Brasil é um instituto de pesquisa que transforma grandes ideias em ações para promover a proteção do meio ambiente, oportunidades econômicas e bem-estar humano. Atua no desenvolvimento de estudos e implementação de soluções sustentáveis em clima, florestas e cidades. Alia excelência técnica à articulação política e trabalha em parceria com governos, empresas, academia e sociedade civil.

0 WRI Brasil faz parte do World Resources Institute (WRI), instituição global de pesquisa com atuação em mais de 60 países. 0 WRI conta com o conhecimento de aproximadamente 1.000 profissionais em escritórios no Brasil, China, Estados Unidos, Europa, México, Índia, Indonésia e África.

\section{CRÉDITOS}

Capa, Pag 2, 4, 7, 11, 22, 28, 37, 48, 50, 51, 65: Lucas Sandonatto/WRI Brasil; Pg 1, 10, 12, 14, 24, 43, 45, 46, 49: Ademir Ribeiro/WRI Brasil; Pg 38, 50: Marcelo Matsumoto/WRI Brasil. 
Cada relatório do World Resources Institute é o resultado de uma pesquisa acadêmica e oportuna sobre um assunto de interesse público. 0 WRI assume a responsabilidade pela escolha dos temas de estudo e garante liberdade de investigação aos autores e pesquisadores participantes. Também solicita e responde à orientação de painéis consultivos e revisões de especialistas. Exceto quando indicado, todas as interpretações e descobertas presentes nas publicações do WRI são as de seus autores.

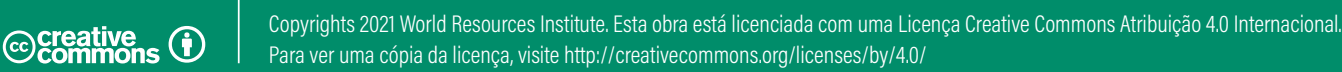




\title{
WRI BRASIL
}

\author{
SÃO PAULO \\ RUA CLÁUDIO SOARES, 72 CJ. 1510 \\ PINHEIROS, SÃO PAULO - SP \\ 05422-030, BRASIL \\ + 551130321120
}

PORTO ALEGRE

AV. INDEPENDÊNCIA, 1299 CJ. 401

PORTO ALEGRE - RS

90035-077, BRASIL

+ 555133126324
WRIBRASIL.ORG.BR

doi.org/10.46830/wrirpt.18.00155pt 